\section{All102 966 142}

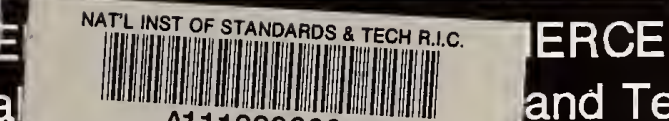

296664 inim Deckman A11102966642 QC100.U57 NO.754 1988 V 1988 C C 2 Nositlo and Technology andards)

NIST Special Publication 754

\title{
Vapor Phase Deposition Studies of Phosphate Esters on Metal and Ceramic Surfaces
}

Douglas E. Deckman, Stephen M. Hsu, and E. Erwin Klaus

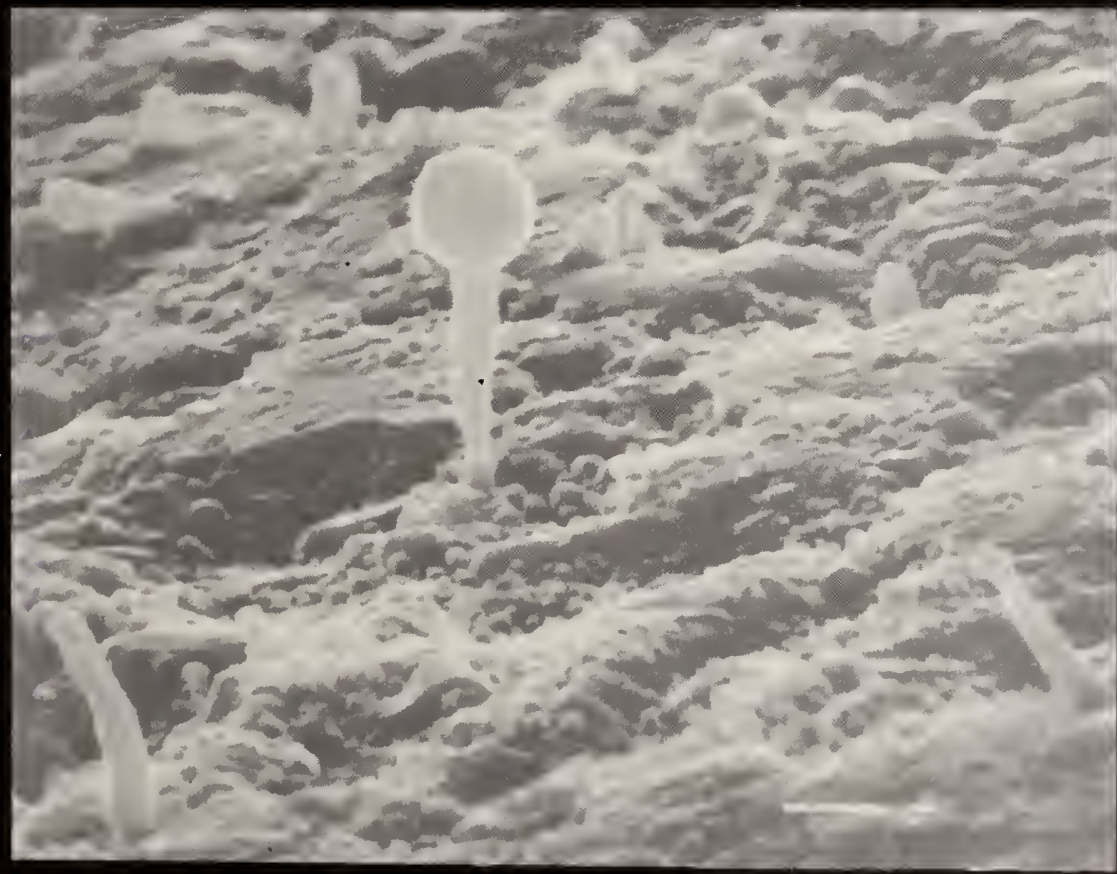




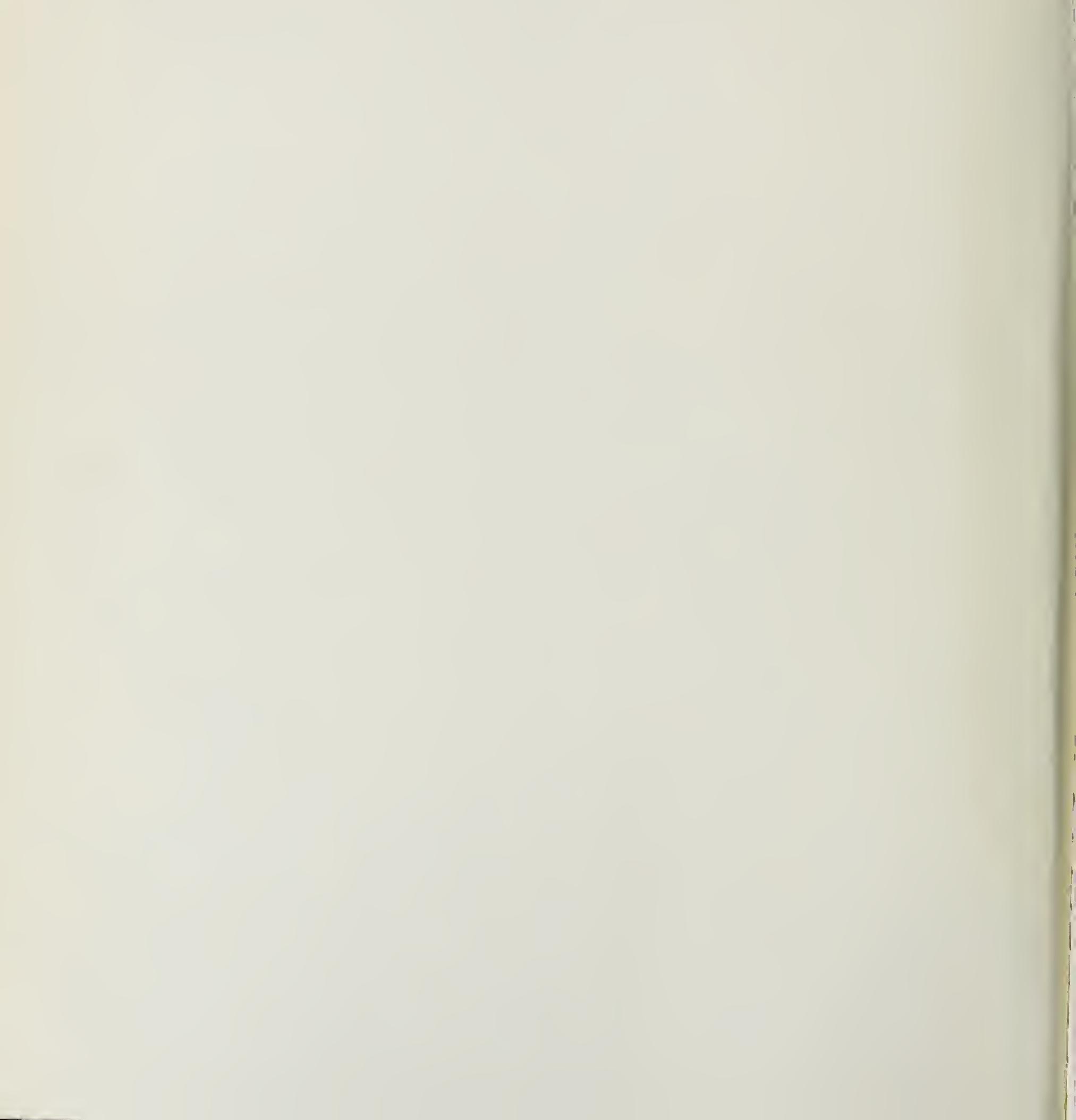




\section{Vapor Phase Deposition Studies of Phosphate Esters on Metal and Ceramic Surfaces}

\section{Douglas E. Deckman and Stephen M. Hsu}

\section{Ceramics Division}

Institute for Materials Science and Engineering National Institute of Standards and Technology (formerly National Bureau of Standards)

Gaithersburg, MD 20899

\section{E. Erwin Klaus}

Department of Chemical Engineering The Pennsylvania State University

University Park, PA 16802

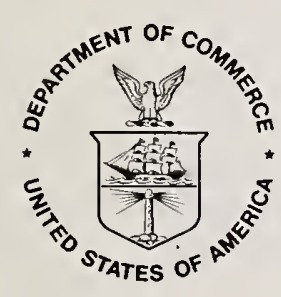

\section{September 1988}

U.S. Department of Commerce

C. William Verity, Secretary

National Institute of Standards and Technology (formerly National Bureau of Standards) Ernest Ambler, Director
NOTE: As of 23 August 1988, the National Bureau of Standards (NBS) became the National Institute of Standards and Technology (NIST) when President Reagan signed into law the Omnibus Trade and Competitiveness Act. 
Library of Congress

Catalog Card Number: 88-600578

National Institute of Standards

and Technology

Special Publication 754

154 pages (Sept. 1988)

CODEN: XNBSAV
U.S. Government Printing Office For sale by the Superintendent Washington: 1988 of Documents,

U.S. Government Printing Office, Washington, DC 20402 
This report is born out of a cooperative effort between the Chemical Engineering Department, at Pennsylvania State University (PSU), the Tribology Group of the National Bureau of Standards, and the partial support of the DOE ECUT Tribology Program. For years, the NBS has encouraged and sponsored graduate cooperative programs in which promising young scientists (some of them NBS staff members) come to NBS to conduct research, part of which often becomes the graduate's thesis. While it is not the objective of NBS to teach and train graduate students, such a program often furthers NBS programmatic goals by attracting high caliber scientists working on areas where NBS mission lies. Many excellent research papers have results and many students, upon graduation, have chosen to stay at NBS to continue their research careers. Such programs also draw many first rate university professors to NBS through the participation of these students in NBS research programs and projects, thus fostering NBSuniversity interactions and enhancing the scientific caliber of the work and reputation at NBS and the participating university. At the same time, through the frequent contacts that NBS has with industries, a natural university/government lab/industry relationship evolves, bringing a team focus on many research projects of significant economic and/technological impacts.

In 1984, primarily through the interactions of $\mathrm{Dr}$. Stephen $\mathrm{M}$. Hsu of NBS and Professors Elmer Klaus and Larry Duda of PSU, a cooperative program in Tribology was started. Three graduate students: $\mathrm{Mr}$. Richard Gates (a NBS staff member), Mr. Jeffrey Yellets and Mr. Douglas Deckman were enrolled at the Chemical Engineering Department at PSU. Three reports have been prepared to describe the fruit of their relentless efforts in the last three years. These studies were conducted at NBS under the guidance of Dr. Stephen Hsu with the close participation of Prof. Elmer Klaus who visited NBS frequently.

Dr. James Eberhardt, Mrs. Terry Levinson, and Mr. David Mello of the DOE ECUT Tribology Program have at the same time sponsored a major Tribology program at NBS. That program also benefited from the studies conducted by $\mathrm{Mr}$. Gates, Mr. Yellets, and $\mathrm{Mr}$. Deckman. These students, while not working on sponsored projects directly, enabled NBS to explore some high risk, high pay off projects parallel to ECUT projects. When appropriate, the students were supported by ECUT for some time. To this, we gratefully acknowledge the generous support of DOE ECUT, without whose support many ideas would not be explored.

Stephen M. Hsu

Chief, Ceramics Division 

This study focuses on a novel means of lubrication for ceramics and metals at high temperatures; called vapor phase lubrication. The deposition rate and mechanisms of tributyl phosphate ester and tricresyl phosphate ester have been explored. A Thermalgravimetric Analyzer (TGA) was modified to measure the rate of surface film formation of vapor phase deposition of lubricants on metal surfaces at elevated temperatures. Results from TGA studies showed that the vapor deposition process was a complex function of substrate, time, and temperature. Tricresyl phosphate ester (TCP) and tributyl phosphate ester (TBP) were observed to produce similar amounts of film on stainless steel substrates. The substrate had a substantial effect on the amount and rate of film formation. The observed order of metal activity was copper $>$ stainless steel $>$ nickel $>$ platinum. Film formation on nickel was found to be much more rapid at $600^{\circ} \mathrm{C}$ than $700^{\circ} \mathrm{C}$. Also, the concentration of oxygen present during deposition strongly influenced the amount of film formed. Scanning electron microscopy was conducted on TBP films formed on $\mathrm{Si}_{3} \mathrm{~N}_{4}, \mathrm{Al}_{2} \mathrm{O}_{3}$, and $\alpha$ SiC. The films produced contained globule and filamentous structures. The films on each ceramic were unique, demonstrating that vapor deposition is surface sensitive on ceramic substrates. High temperature friction testing was conducted on a TCP coated $\mathrm{Al}_{2} \mathrm{O}_{3}$ substrate. The coating reduced the friction level for alumina, thus demonstrating the potential of vapor lubrication for high temperature lubrication of ceramics. 

FOREWORD

ABSTRACT

LIST OF FIGURES

\section{Chapter}

1 INTRODUCTION . . . . . . . . . . . . . . . . 1

2 LITERATURE SURVEY . . . . . . . . . . . . . . . 9

2.1 High Temperature Lubricants . . . . . . . . . . . . 9

2.1.1 Synthetic Lubricants, Solid Lubricants, and Coatings . . . . . . . . . . . . . . . . . 9

2.1.2 Metal Working and Metal Forming Lubricants . . 13

2.2 Previous Vapor Deposition Studies . . . . . . . . . 16

2.3 Chemical Vapor Deposition Studies . . . . . . . . . . . 24

3 EXPERIMENTAL APPROACH AND RESULTS . . . . . . . . . . . . 30

3.1 Experimental Approach . . . . . . . . . . . . 30

3.2 Kinetic Data on Metal Surfaces . . . . . . . . . 31

3.2.1 TGA Vapor Deposition Apparatus . . . . . . . . . 31

3.2.2 TGA Vapor Deposition Procedures . . . . . . . . 37

3.2.3 TGA Vapor Deposition Results... . . . . . . . 39

3.3 Ceramic Vapor Lubrication Studies . . . . . . . . . . 55

3.3.1 Design of Vapor Deposition Apparatus . . . . . 55

3.3.2 Vapor Deposition Procedures . . . . . . . 66

3.3.3 SEM Results . . . . . . . . . . . . . . . 69

3.3.4 Performance Testing Equipment . . . . . . . . . 80

3.3.5 Ball Bearing Holder Design for the Intermediate 86

3.3.6 Sample Preparation Development . . . . . . . . . 89

3.3.7 Performance Testing Results . . . . . . . . 104 
TABLE OF CONTENTS (continued)

Page

4 CONCLUSIONS . . . . . . . . . . . . . . . . . . . . 111

5 FUTURE WORK . . . . . . . . . . . . . . . . . 114

REFERENCES . . . . . . . . . . . . . . . . . . 116

APPENDIX

A Physical Constants for TCP, TBP, and Argon

at Various Temperatures . . . . . . . . . . . . . 123

B Physical Constants for Mixtures of 18 Phosphate

Ester in Argon at Various Temperatures . . . . . . . . . . 126

C Estimation of Diffusion Coefficients for Phosphate

Ester in Argon at Various Temperatures . . . . . . . . . . 129

D Calculation of Back Diffusion in the TGA . . . . . . . . . 132

E Calculation of Mass Transfer Rates and Resistance

for the Vapor Deposition Process . . . . . . . . . . 138

F Calculation of Flow Regime During Vapor Deposition

Testing . . . . . . . . . . . . . 141 
Figure

1 Energy Balance Comparison Among Alternative

Diesel Engines . . . . . . . . . . . . . . . . . . . 4

2 Adiabatic Diesel Engine . . . . . . . . . . . 5

3 Vapor Lubricated Four Ball Wear Tester . . . . . . 22

$4 \quad$ Effect of Load on Wear Scar Diameter for Several

Vapor Lubricants at $370^{\circ} \mathrm{C}$ on M50 Steel . . . . . . 23

5 TGA . . . . . . . . . . . . . . . 32

6 TGA Vaporization Tube . . . . . . . . . . . . 33

7 Cutaway View of the TGA Furnace . . . . . . . . . . . 35

8 Effect of Substrate on Deposition at $700^{\circ} \mathrm{C}$ Using

1.068 TBP................... 40

9 Effect of Lubricant on the Deposition of Stainless

Steel at $700^{\circ} \mathrm{C}$. . . . . . . . . . . . . 45

10 Effect of Temperature on the Deposition of Nickel

Using 1.068 TBP.................. . . 46

11 Desorption of Deposit from Nickel Coated at $600^{\circ} \mathrm{C}$ with 1.068 TBP ................ . 50

12 Arrhenius Plot for the Desorption of a TBP Film on Nickel from 441 to $385^{\circ} \mathrm{C}$. . . . . . . . . . . 52

13 Arrhenius Plot for the Desorption of a TBP Film on Nickel from 814 to $727^{\circ} \mathrm{C}$. . . . . . . . . . . . 53

14 Vapor Deposition Equipment Designed by Lai . . . . . 56

15 Vapor Deposition Equipment Designed by Min . . . . . 57

16 Vapor Deposition Apparatus Designed by Gunsel . . . . 59 
LIST OF FIGURES (continued)

Page

Figure

Vapor Deposition Furnace and Quartz Tube Insert . . 61

Upper and Lower Baffles. . . . . . . . . . 62

Baffle Assembly . . . . . . . . . . . 63

Quartz Tube and Baffle Assembly . . . . . . . 65

21 Temperature Distribution in Deposition Portion of

Furnace . . . . . . . . . . . . . . . .

Wall Temperature and Center Line Temperature within

the Tubular Furnace. . . . . . . . . . . 68

SEM Photographs of $\mathrm{Si}_{3} \mathrm{~N}_{4}$ Coated with 0.738 TBP at $700^{\circ} \mathrm{C}$

EDAX Spectra of Filament Produced on $\mathrm{Si}_{3} \mathrm{~N}_{4}$ Coated

with $0.738 \mathrm{TBP}$ at $700^{\circ} \mathrm{C}$. . . . . . . . . 72

SEM Photographs of $\mathrm{Al}_{2} \mathrm{O}_{3}$ Coated with 0.738 TBP at $700^{\circ} \mathrm{C}$. . . . . . . . . . . . . . . 74

SEM Photographs of $\alpha$-SiC Coated with $0.73 \%$ TBP at $700^{\circ} \mathrm{C}$................... . . 75

Stages in the Growth of Filaments with a Catalyst Particle in the Growing End . . . . . . . . . 78

Ball on Three Flat Geometry . . . . . . . . . . 81

Side View of Ball on Three Flat Cup . . . . . . . 82

Top and Side View of Ball on Three Flat Cup . . . . 83

Four Ball Wear Tester... . . . . . . . . 84

33 Alumina Specimen Holder Used in the Intermediate Temperature Tribometer . . . . . . . . . . 87 
LIST OF FIGURES (continued)

Page

Figure

34

Ball Bearing Holder for the Intermediate

Temperature Tribometer . . . . . . . . . . . . .

$\alpha$-SiC Ball in a Stainless Steel Ball Bearing

Holder at $25^{\circ} \mathrm{C}$. . . . . . . . . . . . . . . . .

36

$\alpha$-SiC Ball in a Stainless Steel Ball Bearing

Holder at $1000^{\circ} \mathrm{C}$. . . . . . . . . . . . . . . 92

37

SEM Photographs of a Polished $\mathrm{Al}_{2} \mathrm{O}_{3}$ Specimen . . . . 94

38

Effect of Sputtering on Surface Contamination

Level. . . . . . . . . . . . . . . . .

39

Effect of Cleaning Procedure on Surface

Contamination Level . . . . . . . . . . . . . . 102

40

Effect of Cleaning Procedure on Friction Level

- Dry $\mathrm{Al}_{2} \mathrm{O}_{3}$ on $\mathrm{Al}_{2} \mathrm{O}_{3}, 150^{\circ} \mathrm{C}, 6 \mathrm{RPM}$. . . . . . . . 103

41

Effect of a TCP Vapor Coating on $\mathrm{Al}_{2} \mathrm{O}_{3}$ Tested

at $150^{\circ} \mathrm{C}, 6 \mathrm{RPM}$, and $10 \mathrm{~kg}$. . . . . . . . . . . . 106

42

Transmission Optical Photograph of TCP Coated

$\mathrm{Al}_{2} \mathrm{O}_{3}$ - Tested at $150^{\circ} \mathrm{C}$. . . . . . . . . . . 107

43

Effect of a TCP Vapor Coating on $\mathrm{Al}_{2} \mathrm{O}_{3}$ Tested

at $700^{\circ} \mathrm{C}, 1.5 \mathrm{~cm} / \mathrm{min}$, and $16 \mathrm{~N}$. . . . . . . . 109

44

Modelled and Actual Flow Regimes within the TGA . . . 133 

$\underline{\text { Table }}$

1 Comparison of Operating Temperatures for an Adiabatic Diesel Engine and a Conventional Diesel Engine

Operating Temperatures in the Automotive Gas Turbine

Thermal and Oxidative Stability of Various

Lubricants . . . . . . . . . . . . . . . .

Typical Interfacial Temperatures for Various

Metalworking Processes . . . . . . . . . . . .

Normalized Film Formation Amounts for Various

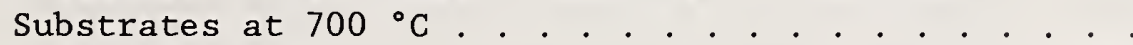

Normalized Initial Film Formation Rates for Various

Substrates at $700^{\circ} \mathrm{C}$

SEM Vapor Deposition Film Characteristics . . . . .

Gas Phase Reactions Involved in the Growth of Amorphous Hydrogenated Silicon Films by

Plasma CVD

Effect of Temperature and Pressure on the Microstructure of Fluoride CVD Tungsten Produced at $\mathrm{H}_{2} / \mathrm{WF}_{6}=6$

TGA Temperature Calibration Using Paramagnetic Standards

Initial Rate of Film Formation on Various Substrates at $700^{\circ} \mathrm{C}$. . . . . . . . . . . . .

Effect of Oxygen on the Initial Rate of Film Formation on Copper at $700^{\circ} \mathrm{C}$. . . . . . . . . . . . . .

Previous Studies Showing Decreasing Amounts of Film Formation with Increasing Temperature

Population of TPSR States for Carbon Deposited on an Alumina-Supported Nickel Catalyst (G-56H) Following Ethylene Exposure 
LIST OF TABLES (continued)

Page

$\underline{\text { Table }}$

Location of Catalyst Particle within Filaments . . . . 76

Activation Energies for Coke Formation on Various

Substrates................. . . . 79

Coefficient of Thermal Expansion for Three Advanced

Ceramics and Stainless Steel . . . . . . . . . 90

18 List of Possible Contaminants in the Sample

Preparation of $\mathrm{Al}_{2} \mathrm{O}_{3}$ Specimens . . . . . . . . . . . . 95

Solubility of Lapping Oil in Various Solvents . . . . 98

Solubility of cutting Fluid in Various Solvents . . . 99

21 ESCA and Auger Determination of Carbon Residue

on $\mathrm{Al}_{2} \mathrm{O}_{3}$ after Various Cleaning Procedures . . . . . . 100

22 Physical Constants of Argon at Various

Temperatures ................. 123

23 Physical Constants of Tributyl Phosphate Ester

at Various Temperatures . . . . . . . . . . 123

24 Physical Constants of Tricresyl Phosphate Ester

at Various Temperatures . . . . . . . . . . . 124

25 Physical Constants for a Mixture of 18 Tributyl

Phosphate Ester and 998 Argon . . . . . . . . . . . 126

26 Physical Constants for a Mixture of 18 Tricresyl

Phosphate Ester and 998 Argon . . . . . . . . . 126

27 Constants Needed to Calculate Diffusion

Coefficients................ 130

28 Diffusion Coefficients of Phosphate Esters in Argon

at Various Temperatures . . . . . . . . . . 131 


\section{Chapter 1}

INTRODUCTION

There is a great technological need in our society to develop better lubricants and more effective ways of applying lubricants. In particular, there is a real need for improved lubrication for high temperature applications. Low heat rejection engines (or so-called adiabatic engines) and metal working and metal forming processes are two examples where advanced lubrication technology is needed.

In any power plant, such as an engine, the overall cycle efficiency is increased as operating temperature is increased. Metals and alloys used in conventional engines have low strength and poor oxidation resistance when operated at temperatures above existing designs [1]. Ceramic materials have many desirable high temperature properties needed for heat engine applications. These include high strength at high temperature, excellent thermal shock resistance, low thermal conductivity, high oxidation resistance, and good corrosion resistance.

The potential of ceramics as engine components has led to the development of the adiabatic diesel and the automotive gas turbine. The energy saving potential of these propulsion systems arises from their high temperature operation. Secondary savings are realized because ceramics typically have $40 \%$ of the density of metals. This results in lower weight and inertia which translates into improved engine performance. The efficiency improvements in these designs 
could result in up to a $50 \%$ improvement over conventional diesel engines [2].

The economic implications of these improvements are enormous. It is estimated that the United States will ship 10 billion dollars worth of advanced ceramics in the year 2000 and the ceramics industry will create 250,000 new jobs. If the United States could become the dominant producer of advanced ceramics a cumulative real GNP gain of 278.9 billion dollars (1981 dollars) could be realized between 1985 and 2005. But if foreign countries are able to achieve this dominance a potential swing of 400 billion dollars could result.

For the case where the United States would dominate the advanced ceramics market the following yearly savings are projected in the year $2000[3]:$

- Automotive imports reduced and partial domestic replacement 8.3 billion

- Truck imports reduced and partial domestic replacement 2.5 billion

- Fuel Savings 1.5 billion

- Maintenance savings 0.3 billion

Also, reduced imports of engines and auto parts as well as increased exports of motor vehicles, engines, and engine parts would have a further impact on the trade balance. If foreign domination occurred, oil imports would still be reduced and motor vehicle imports would be unaffected if existing quotas remain. 
Thus ceramics offer the United States manufacturers an opportunity to regain the market share lost to fuel efficient imports and improving the United States international competitiveness. But to accomplish this the United States must win the international race to develop a commercial heat engine.

In a combustion engine, the energy produced by fuel ignition is divided between exhaust, the water cooling system, and useful work, see Figure 1 [4]. The adiabatic engine removes the cooling system thus reducing energy lost to this sink. This engine also combusts fuel in an insulated cylinder at higher than conventional operating temperatures thus enabling a more thermodynamically efficient combustion process. Energy from the exhaust is further extracted by turbocompounding. The resulting energy balance for an adiabatic diesel engine is shown in Figure 1. Figure 2 shows a schematic of this engine.

The elimination of the cooling system has numerous repercussions, since cooling systems account for 508 of commercial and military field engine failures. Improved reliability, simplified maintenance, and reduced maintenance costs would result. For military vehicles the loss of the cooling system means greater immunity to heat-seeking weapons .

Table 1 compares anticipated operating temperatures for the adiabatic diesel to a conventional diesel engine. Table 2 shows anticipated operating temperatures in an automotive gas turbine. Clearly the development of ceramics for high temperature applications such as adiabatic engines will have major economic 

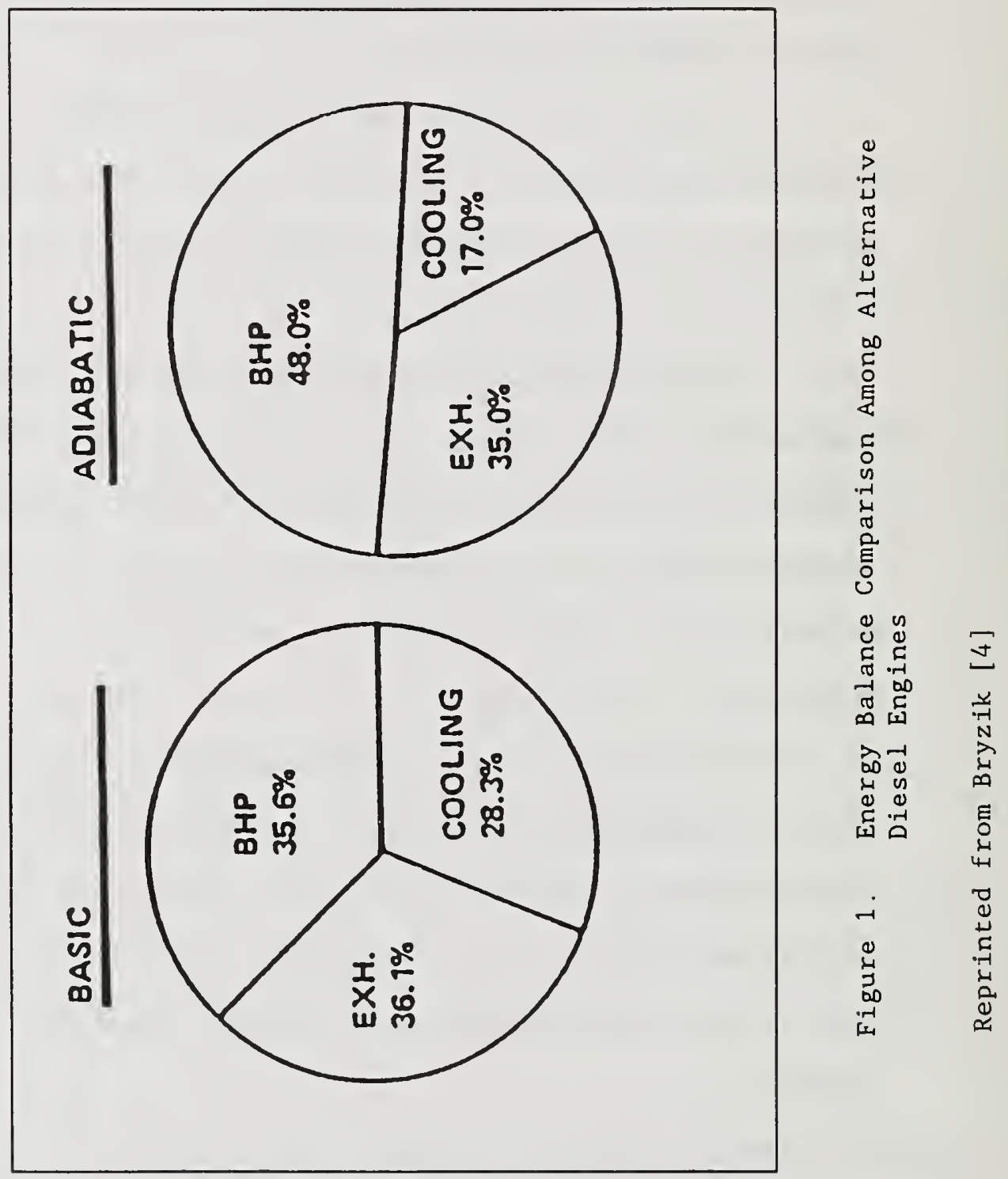


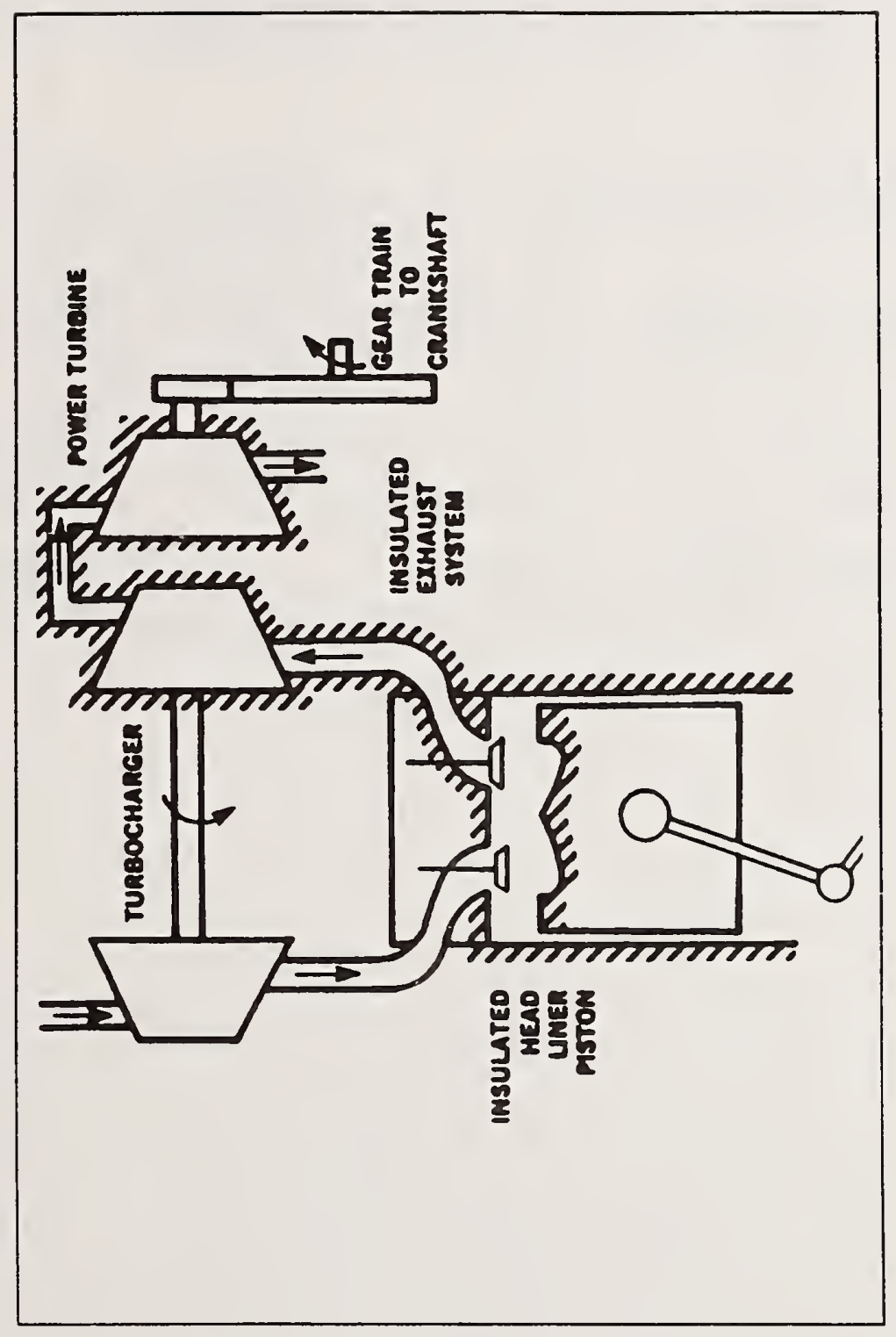

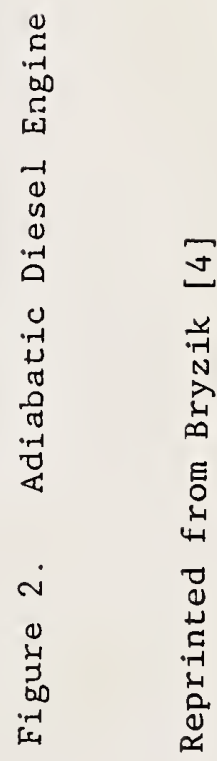


Table 1. Comparison of Operating Temperatures for an Adiabatic Diesel Engine and a Conventional Diesel Engine

\begin{tabular}{|l|l|l|}
\hline \multirow{2}{*}{ Engine Component } & \multicolumn{2}{|c|}{ Operating Temperature ${ }^{\circ} \mathrm{C}$} \\
\cline { 2 - 3 } & Conventional Engine & Adiabatic Engine \\
\hline Piston & 277 & $1000(5)$ \\
Liner & $400-600(6)$ & $600-1100(7)$ \\
Turbine Inlet & 600 & $1000(6)$ \\
\hline
\end{tabular}


Table 2. Operating Temperatures in the Automotive Gas Turbine

\begin{tabular}{|l|l|}
\hline Engine Component & Operating Temperature ${ }^{\circ} \mathrm{C}$ \\
\hline Gas Turbine Rotor & $1100(2)$ \\
Gas Turbine Stator & $1510(2)$ \\
Plenums, Flow Controls \\
and Support Structures \\
Regenerator \\
Foil Bearing (Main Shaft)
\end{tabular}


ramifications. A key barrier for high temperature operation of advanced ceramics is the development of effective lubrication methods for these temperatures. 
Chapter 2

LITERATURE SURVEY

\subsection{High Temperature Lubricants}

\subsubsection{Synthetic Lubricants, Solid Lubricants, and Coatings}

The technological demands of advanced high temperature systems poses two very fundamental questions. First, is lubrication needed for these systems? And what type of lubrication will prove effective in these operating regimes? The potential of unlubricated, air film lubricated, synthetic liquid lubricated, solid lubricated and coated systems are now examined.

The use of ceramics under dry conditions appears unfeasible for heat engine applications. Breznak et al. [8] examined four different advanced ceramics sliding with like and unlike pairs. In all cases the kinetic coefficient of friction was between 0.25 and 0.5 which is unacceptably high for engine applications. Also ceramics have been observed to seize at very low load when tested under dry conditions [9]. Thus, dry lubrication is unacceptable for heat engine and other high temperature applications.

The use of a gas lubricated piston and cylinder liner has the greatest potential for mechanical friction reduction in an adiabatic diesel. But a severe barrier which must be overcome to make this technology feasible is elimination of sidethrust transferred to the piston from the connecting rod [10]. It is not likely that this hurdle will be passed in the near future. 
The use of liquid lubricants to lubricate advanced heat engines requires withstanding high temperatures during continuous service in oxidizing environments. It is generally accepted that the oxidative stability of lubricants is less than the lubricant thermal stability and oxidation is the predominant mechanism for lubricant degradation [11]. Conventional mineral oils are being replaced by synthetic lubricants because of improved additive response and improved volatility characteristics. Improved additive response results in greater oxidation stability for these synthetic fluids. Table 3 displays the thermal and oxidative stability limits for a number of lubricants. The fluids with the highest thermal and oxidative stability, the polyphenyl ethers, have a very limited life under sustained high temperature operations. To circumvent these limitations current research focuses on continuous lubricant delivery methods to apply liquid lubricants.

One class of materials which have some potential for high temperature lubrication is solid lubricants. There are three requirements which must be met for solid lubricants to function [7]. First, they must have a high degree of plasticity for easy shear. Second, they must possess the ability to coalesce their individual particles under load and shear to form continuous coherent films. Finally, they must adhere to the lubricated surface. Two general categories of solid lubricants which will be discussed are coatings and composites.

A coating can be lubricious by itself or it can react to form a self-lubricating material. Sliney [21] has demonstrated that a $\mathrm{PbO}$ - 
Table 3. Thermal and Oxidative Stabilities of Various Lubricants

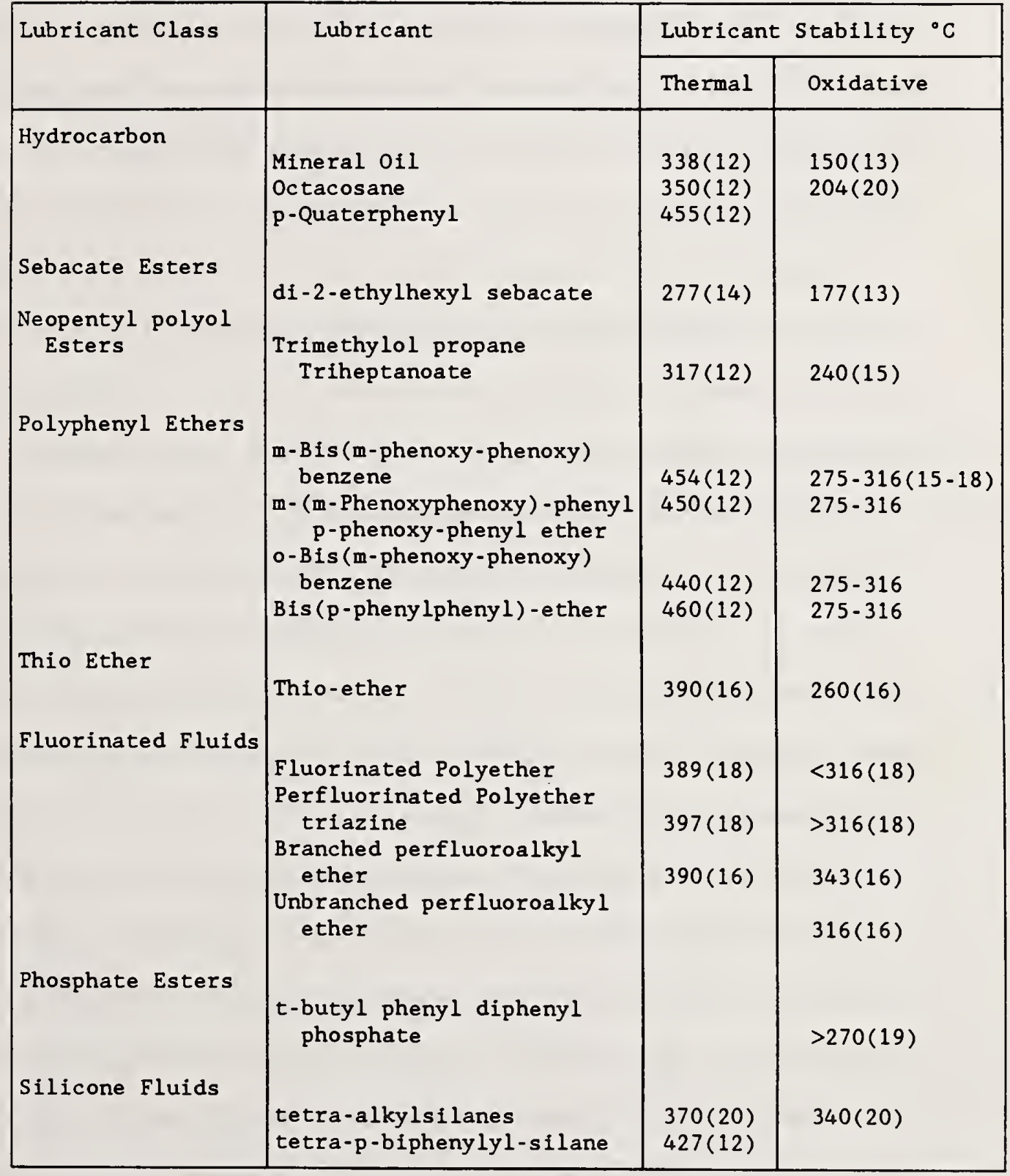


$\mathrm{SiO}_{2}$ coating can lubricate effectively up to $650^{\circ} \mathrm{C}$, but high sliding rates are needed for good frictional characteristics at low temperatures. Also, a $\mathrm{CaF}_{2}-\mathrm{BaF}_{2}$ coating can provide lubrication from 550 to $950^{\circ} \mathrm{C}$. TiN and TiC are examples of coatings which react to form lubricious films. TiC and $\mathrm{TiN}$ oxidize to form rutile $\left(\mathrm{TiO}_{2}\right)$ at $540^{\circ} \mathrm{C}$ [22]. Rutile has a lamellar structure thus providing a low shear film on top of a hard, high load carrying base. A similar phenomenon occurs with $\mathrm{Si}_{3} \mathrm{~N}_{4}$ which oxidizes to form $\mathrm{SiO}$ and $\mathrm{SiO}_{2}$ [22] . Another class of materials being examined for high temperature applications is composites. One class of composites which have been widely studied is polyimide composites [23-27]. In these composites an organic polymer, polyimide, is used as a matrix material. Solid lubricants such as graphite fluoride $\left(\mathrm{CF}_{1.1}\right)_{\mathrm{n}}$ and $\mathrm{MoS}_{2}$ are used as adjuvants to reduce friction at high temperatures. Graphite fibers are added to reinforce the matrix and enhance wear properties at elevated temperatures. Lubrication occurs during gradual wear through the composite. Wear in these composites increases exponentially with temperature. The maximum temperature of application for the polyimide composite is controlled by their glass transition temperature. Polyimide composites have been shown to be effective up to $370^{\circ} \mathrm{C}$. Sliney [28] demonstrated that a plasma sprayed coating containing $30 \%$ nichrome, $30 \% \mathrm{Ag}, 25 \% \mathrm{CaF}_{2}$, and $15 \%$ glass provided uniform wear and low friction (0.2) from 0 to $870^{\circ} \mathrm{C}$ in nitrogen and air environments. This composite has been used for an interstage seal in a small jet engine. The operating temperature of the seal is $650^{\circ} \mathrm{C}$. In general, composites have a longer endurance than coatings, but are difficult 
and time consuming to prepare. Also many composites lack required high temperature strength properties needed.

In summary, effective lubrication is required for advanced high temperature processes. Current high temperature lubricants (i.e., synthetic lubricants, solid lubricants, and coatings) are often inadequate for system demands. One alternative is to continuously supply lubricant in the vapor phase. This process is known as vapor phase lubrication.

\subsubsection{Metal Working and Metal Forming Lubricants}

Another area where there is a large need for high temperature lubrication is the area of metal working and metal forming processes. Table 4 shows typical interfacial temperature for various metal working and metal forming operations.

In these metal working processes the lubricant provides a number of functions. The ideal lubricant must reduce friction and wear between the tool and the work piece. Also the lubricant must act as a parting agent and prevent local welding, adhesion, pick-up, and subsequent damage to the tool and the work piece surface. Parting action can be achieved by lubricant vaporization. This produces a balanced gas pressure to assist in quick release of the forging from the die cavity. The lubricant must have low corrosion action and have a low accumulation rate on the interacting surfaces. Also, the lubricant should act as a cleaning agent preventing buildup of dirt or 
Table 4. Typical Interfacial Temperatures for Various Metal Working Processes

\begin{tabular}{|l|l|l|}
\hline Application & Temperature Regime, ${ }^{\circ} \mathrm{C}$ & Material Processed \\
\hline Hot Rolling & $900-1050(29)$ & Low Carbon Steel \\
Cold Die Forging & $482-704(30)$ & 1045 Steel \\
Isothermal Forging & $899-982(31)$ & Titanium Alloys \\
Metal Flow \& Die Filling & $900^{\circ} \mathrm{C}(32)$ & Steel \\
Drop Forging Die & $900^{\circ} \mathrm{C}($ dry $)(33)$ & 0.48 Carbon Steel \\
Extrusion & $500^{\circ} \mathrm{C}($ lubricated)(33) & \\
Metal Cutting & $816-1204(34)$ & 4340 Steel \\
\hline
\end{tabular}


scale. The lubricant must meet environmental, safety, and health requirements. Finally, it must minimize processing costs.

Traditional methods of applying these lubricants for metal working and metal forming operations include swabbing and spraying the lubricant onto the tool surface [34]. This results in lubricant vaporization, which can produce erosive wear, pitting of dies and thermal fatigue [33]. In close die forging, lubricant vaporization can produce a sufficiently high gas pressure to interfere with die filling.

Conventional lubricants used for metal working and metal forming processes include solvent based lubricants, water-based lubricants, glass coatings, and graphite films. Solvent-based lubricants are used because they require a very short coating time to apply a sufficient lubricant film, also these lubricants are self cleaning. The disadvantages of solvent-based lubricants include flammability and toxicity. Because of these factors, legislation is restricting the use of solvent-based lubricants [36]. Water-based lubricants use less lubricant, thus lessening disposal problems. Also the carrier, water, is nonhazardous. But there are numerous disadvantages associated with water-based lubricants. First, they are not self-cleaning. Also, longer times are required to put down a sufficient lubricant coating. Because of the high heat capacity of water, these lubricants cool the tool very quickly. This produces thermal shock which leads to heat checking. Finally, these lubricants are not as effective as other types and are more difficult and expensive to produce. 
Glass coatings provide a high degree of lubricity and maintain a continuous film for excellent protection. Drawbacks of the glass coatings include poor releasing ability. Also they accumulate and buildup in die cavities. Glass lubricants are corrosive toward some alloys and they produce a rough surface finish and leave glass stringers .

A final type of lubricant used for metal working processes is graphite films. These produce rough surface finishes. Also they have poor removability from specimens and poor release from dies. Their use also results in a less uniform metal flow. Clearly although there are many lubricants available for high temperature metal working processes there is much room for improvement.

The reason why these lubricants are effective at such high temperatures is that their needed effective lifetime is very short. Klaus and Lai [37] took advantage of this concept and demonstrated that lubricants applied in the vapor phase are effective for die casting operations. Consequently, because the lubricant can be continuously supplied during vapor phase lubrication this technique should be applicable to other continuous high temperature operations.

\subsection{Previous Vapor Deposition Studies}

One method of lubrication which has an enormous potential for high temperature applications is vapor lubrication. Because the lubricant is already vaporized, thermal fatigue of tool surfaces is avoided. This is because the tool surface does not supply the latent 
heat of vaporization to the contacting lubricant thus reducing thermal shock and fatigue. Erosive wear and pitting are also prevented.

Previous vapor deposition studies have measured the amount of vaporized film formation as a function of time using a Cahn electrobalance. Wire specimens of iron, copper, stainless steel, and nickel were used. Lubricants studied included polyol esters like TMPTH, and phosphate esters including diphenyl ditertiarybutyl phosphate (GT), tricresyl phosphate (TCP), and tributyl phosphate (TBP) .

A summary of film formation on various substrates at $700{ }^{\circ} \mathrm{C}$ is presented in Table $5[38-45]$. The amount of film formed is normalized per unit surface area and reported in $\mu \mathrm{g} / \mathrm{cm}^{2}$. It is clear that film formation is a function of substrate composition and lubricant type. These conclusions are also reinforced by the initial film formation rates displayed in Table 6 . If a deposition test is allowed to continue for long periods of time, similar rates are observed on all substrates. This implies that once the catalytic metal surface becomes deactivated, metal particles are no longer involved in the deposition process; thus, rates look similar on all surfaces.

Scanning electron microscopy (SEM) studies [40,42-47] have found that the nature of the film formed is a function of the substrate, the substrate temperature, and the vaporized lubrication. Table 7 presents a summary the SEM studies. Both globule and filamentous structures have been observed on metal surfaces, but no explanation for their formation has been offered. 


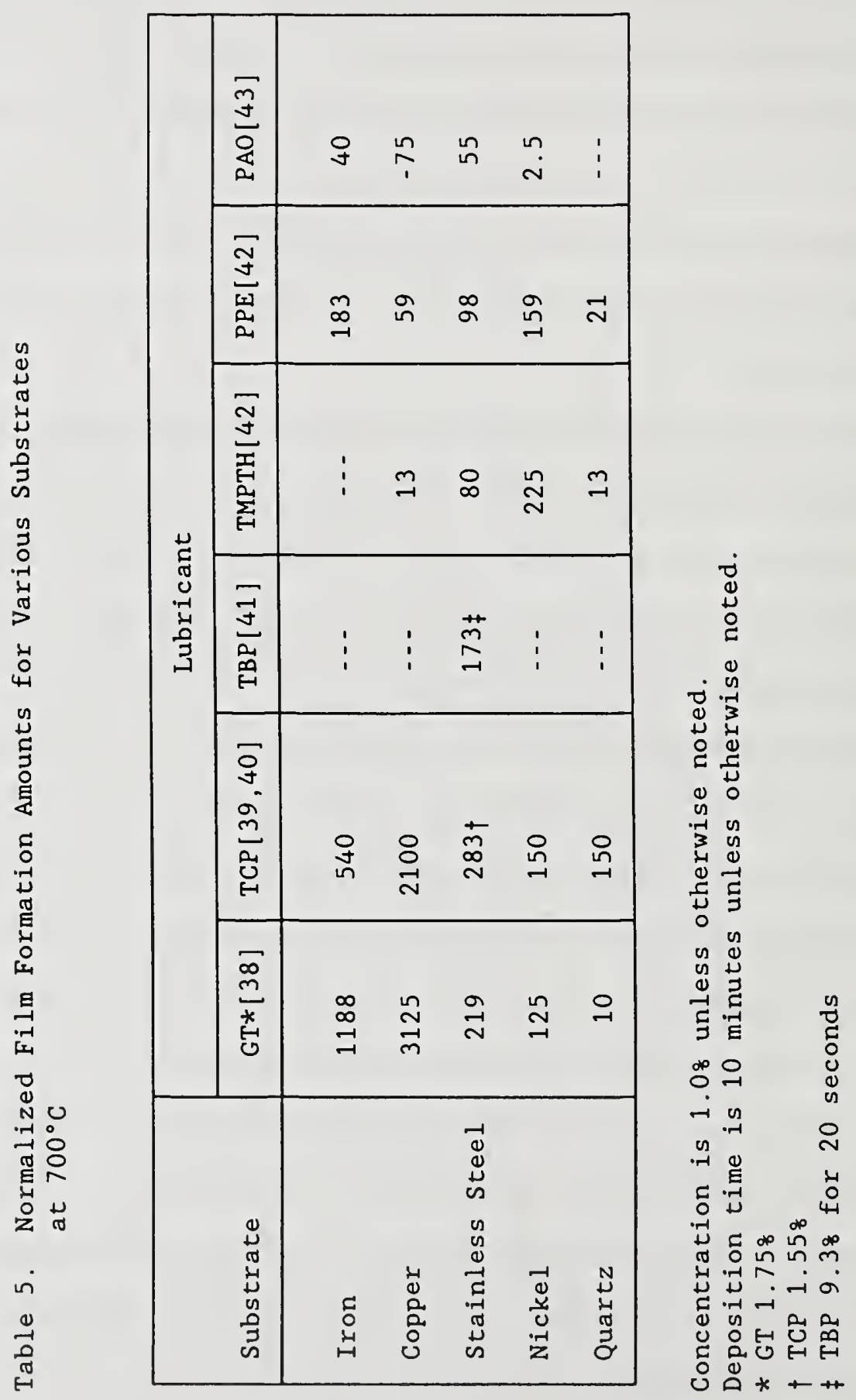




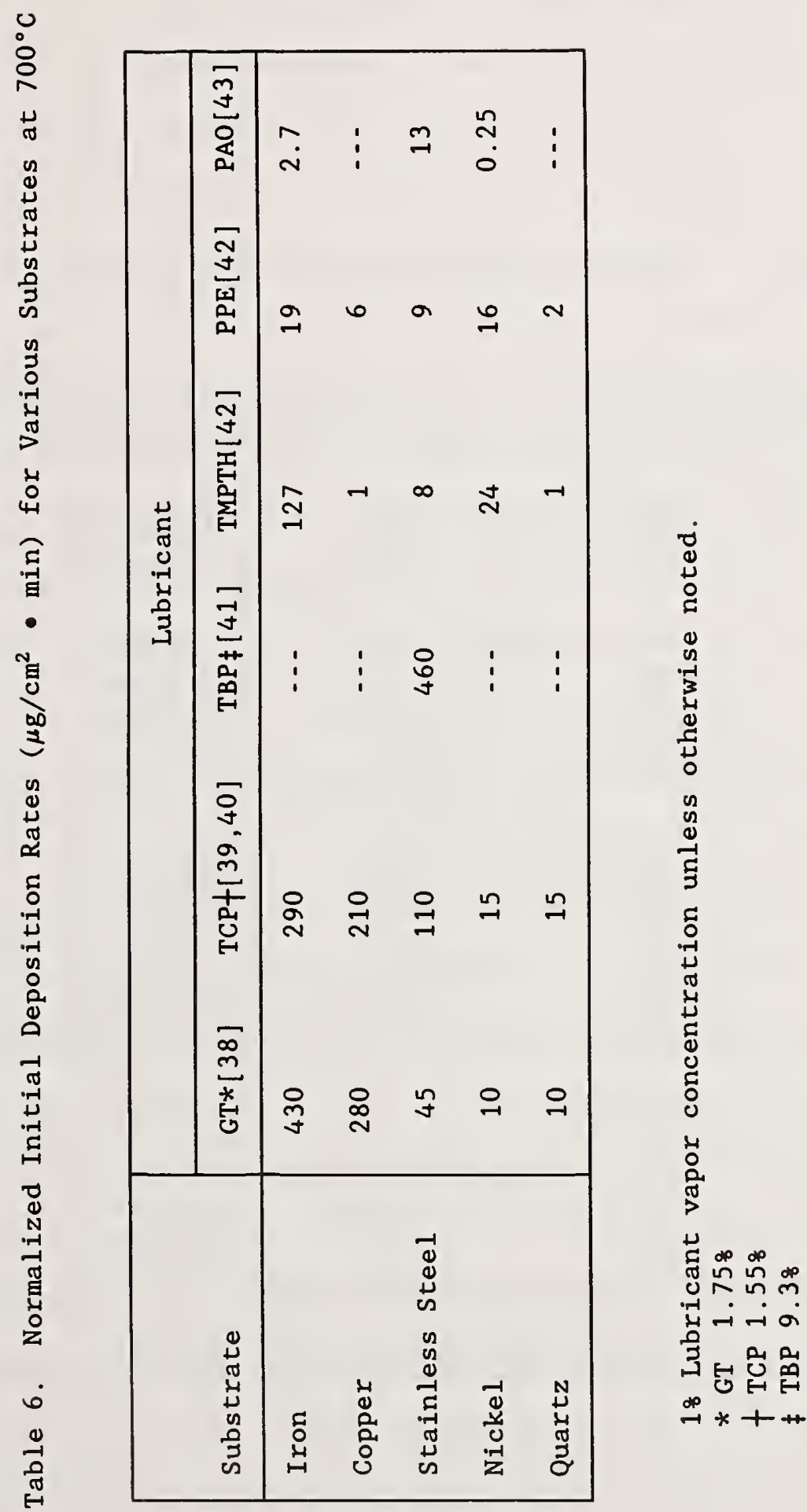


Table 7. SEM Vapor Deposition Film Characteristics

\begin{tabular}{|c|c|c|c|c|}
\hline Lubricant & Substrate & Temperature & Film Characteristics & Reference \\
\hline TMPTH & $\begin{array}{l}\text { Stainless Steel } \\
\text { Iron } \\
\text { Nickel }\end{array}$ & $\begin{array}{l}700^{\circ} \mathrm{C} \\
700^{\circ} \mathrm{C} \\
700^{\circ} \mathrm{C}\end{array}$ & $\begin{array}{l}\text { Filamentous } \\
\text { Filaments \& Globules } \\
\text { Filamentous }\end{array}$ & $\begin{array}{l}42 \\
42 \\
42\end{array}$ \\
\hline PPE & $\begin{array}{l}\text { Stainless Steel } \\
\text { Iron } \\
\text { Nickel } \\
\text { Copper } \\
\text { Quartz }\end{array}$ & $\begin{array}{l}700^{\circ} \mathrm{C} \\
700^{\circ} \mathrm{C} \\
700^{\circ} \mathrm{C} \\
700^{\circ} \mathrm{C} \\
700^{\circ} \mathrm{C}\end{array}$ & $\begin{array}{l}\text { Globules } \\
\text { Globules } \\
\text { Globules } \\
\text { Globules }\end{array}$ & $\begin{array}{l}42 \\
42 \\
42 \\
42\end{array}$ \\
\hline PAO & $\begin{array}{l}\text { Stainless Steel } \\
\text { Stainless Steel } \\
\text { Iron } \\
\text { Iron } \\
\text { Iron } \\
\text { Nickel } \\
\text { Copper }\end{array}$ & $\begin{array}{l}600^{\circ} \mathrm{C} \\
700^{\circ} \mathrm{C} \\
600^{\circ} \mathrm{C} \\
700^{\circ} \mathrm{C} \\
800^{\circ} \mathrm{C} \\
600-800^{\circ} \mathrm{C} \\
600-800^{\circ} \mathrm{C}\end{array}$ & $\begin{array}{l}\text { Globules } \\
\text { Filamentous } \\
\text { Globules } \\
\text { Filaments \& Globules } \\
\text { Filamentous } \\
\text { Filamentous } \\
\text { Pitted Surface }\end{array}$ & $\begin{array}{l}43 \\
43 \\
43 \\
43 \\
43 \\
43 \\
43\end{array}$ \\
\hline GT & Stainless Steel & $600^{\circ} \mathrm{C}$ & Globules & 44 \\
\hline $\mathrm{TCP}$ & $\begin{array}{l}\text { Stainless Steel } \\
\text { Iron } \\
\text { Copper }\end{array}$ & $\begin{array}{l}500-700^{\circ} \mathrm{C} \\
700^{\circ} \mathrm{C} \\
700^{\circ} \mathrm{C}\end{array}$ & $\begin{array}{l}\text { Globules } \\
\text { Globules } \\
\text { Globules }\end{array}$ & $\begin{array}{c}45,46 \\
40 \\
47\end{array}$ \\
\hline TBP & Stainless Steel & $600^{\circ} \mathrm{C}$ & Globules & 44 \\
\hline
\end{tabular}


Performance testing of vapor delivered lubricants on M50 steel surfaces was accomplished by using a modified four ball wear tester. This tester is shown in Figure 3. In this system lubricant vapors were introduced into the ball pot which was heated to $370{ }^{\circ} \mathrm{C}$. Tests were run for 30 minutes at a speed of 100 rpms under loads varying from 6 to $60 \mathrm{kgs}$. TBP, TCP, GT, TMPTH, and PPE were studied.

A summary of wear results is presented in Figure $4[42,45,47]$. The data representing each lubricant were those which provided superior performance. Upon a detailed examination of these data one finds that several general trends can be observed. The wear scar diameter versus load plot parallels the Hertzian contact line for TCP, TBP, GT, and TMPTH. This trend is commonly seen in literature $[48,49,50]$. And three of these fluids are phosphate esters. The polyphenyl ether and GT experienced seizure which is one measure of load capacity for a lubricant. The polyphenyl ether had significantly higher wear scars than the other lubricants particularly at low loads. Also, the TCP showed enhanced performance at high loads. Thus an overall rating of decreasing wear resistance would give $\mathrm{TCP}>\mathrm{TBP}=$ TMPTH $>$ GT $>$ Polyphenyl ether. It is noteworthy that the TCP, TBP, and GT tests were performed in nitrogen while TMPTH and polyphenyl ether were tested in air. Also, vapor concentrations varied from 0.118 to 18 . This implies there are optimum concentrations and environments for specific lubricants which give optimum performance. The concentration levels used indicate that the vapor lubrication delivers effective high temperature lubrication with minimal quantities of lubricants. 


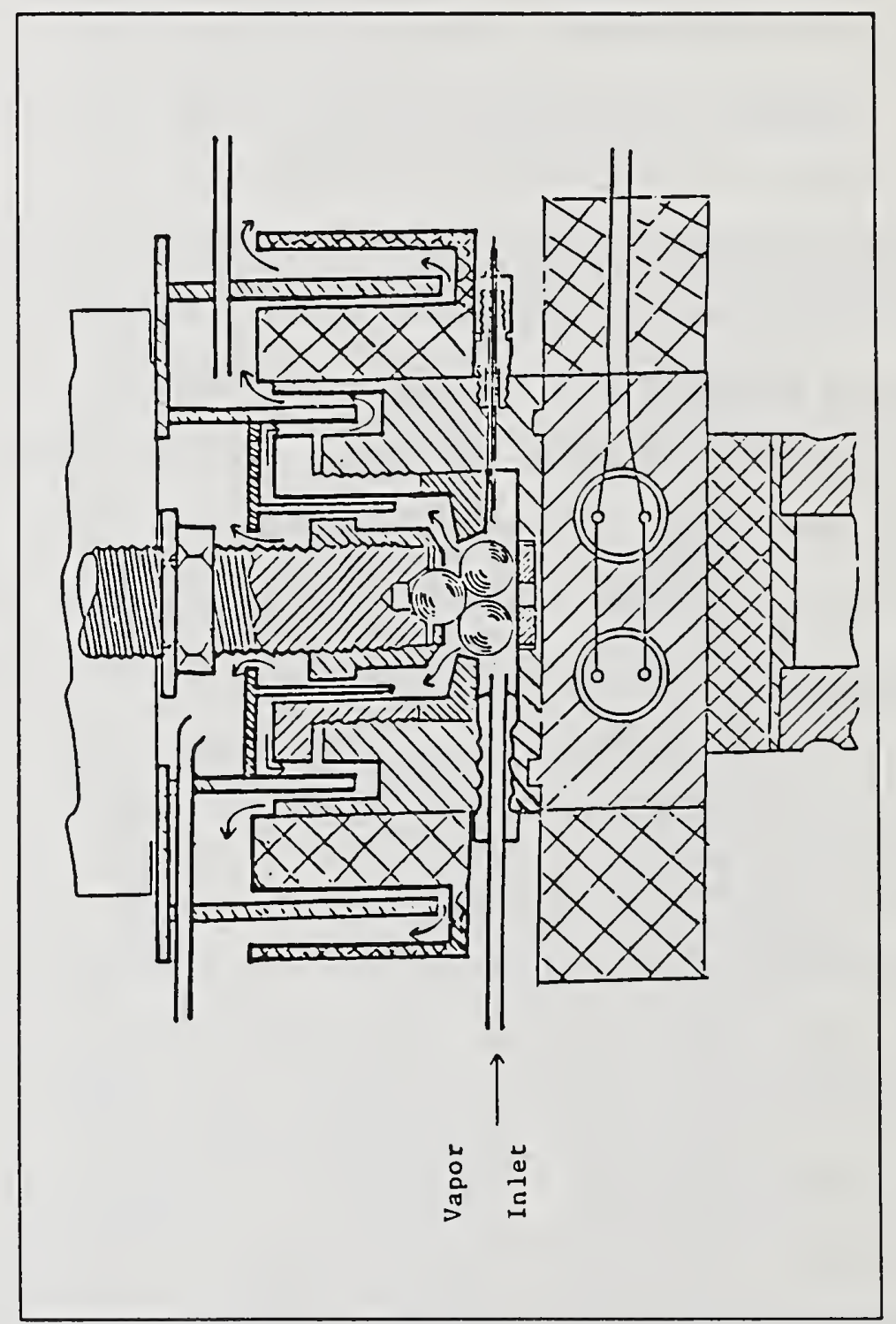

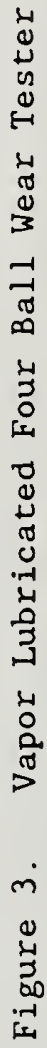




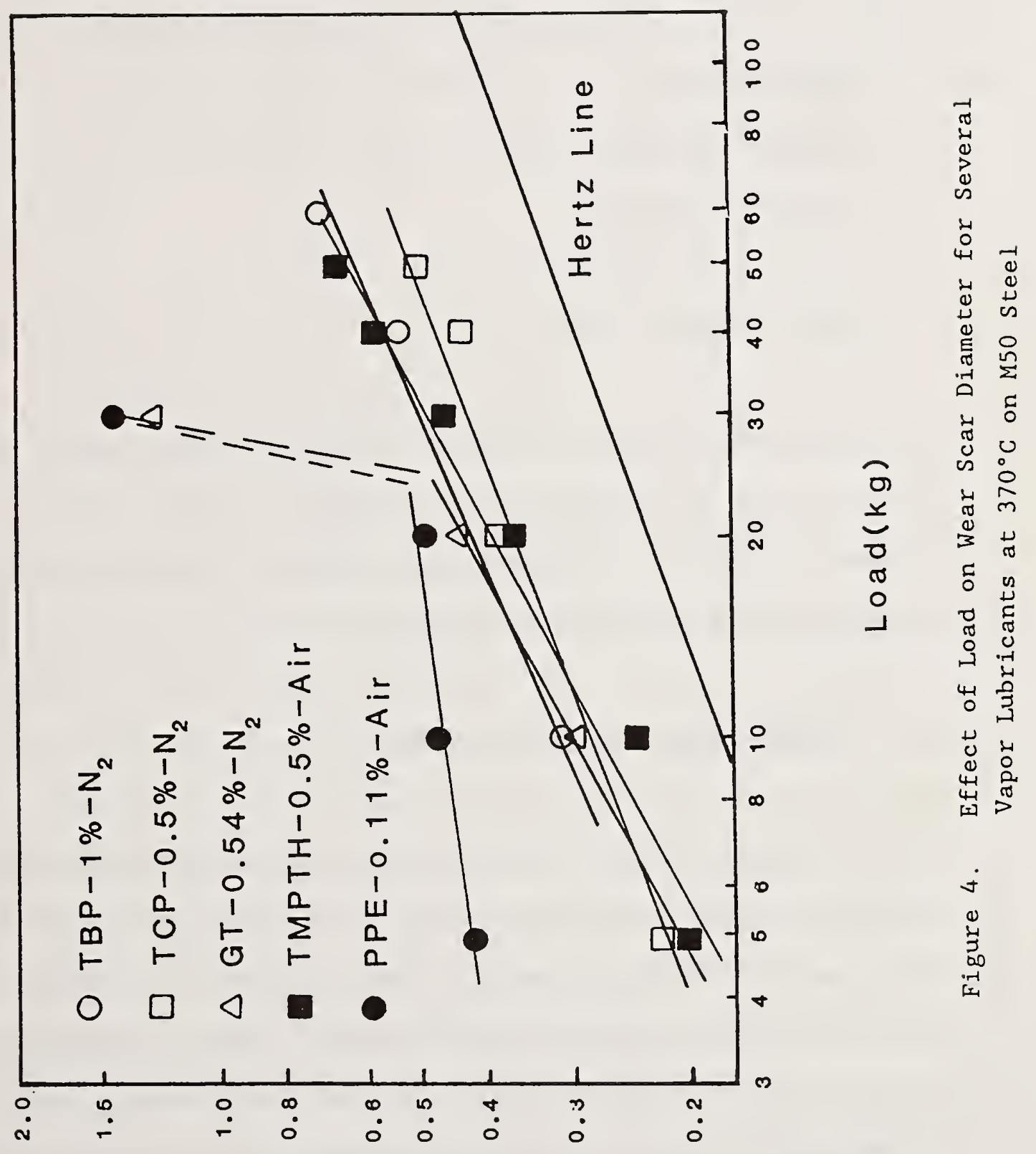

( 
In summary, previous work has found that vapor-deposited films provide lubricity in inert-to-air atmospheres. The formation of these films depends on numerous variables, including:

\author{
Lubricant Type \\ Substrate Composition \\ Vapor Concentration \\ Carrier Gas Composition \\ Vapor Exposure Time
}

SEM studies have shown the presence of globular and filament-like deposits, but no explanations were offered for their formation. Another key issue is whether ceramic surfaces will behave like metal surfaces in their film forming behavior.

\title{
2.3 Chemical Vapor Deposition Studies
}

A process closely related to vapor deposition is chemical vapor deposition (CVD). Many important materials are being prepared by CVD for electronic and optic devices. They include films of silicon, germanium, silicon nitride, silicon oxide, gallium arsenide, cadmium sulfide, and zinc selenide [51]. In the CVD process a gaseous phase chemically reacts at or near the specimen surface to produce one or more condensed phases (deposit) plus gaseous product species. Various types of CVD include thermal energy input CVD, plasma CVD, photochemical CVD, laser CVD, and acoustic CVD [52]. These techniques 
differ in the manner which they produce gaseous reactant species. The CVD process is influenced by numerous effects including surface charges and gas phase reactions.

Hitchman et al. found that electrostatic forces play a large role in the deposition of films by CVD [52]. An example of this was found in the growth of silicon films by thermal CVD. Key reactions are shown below:

$$
\begin{aligned}
\mathrm{SiH}_{4}(\mathrm{~g}) & \ddagger \mathrm{SiH}_{4}(\mathrm{a}) \\
\mathrm{SiH}_{4}(\mathrm{a}) & \ddagger \mathrm{Si}(\mathrm{s})+2 \mathrm{H}_{2}(\mathrm{a}) \\
\mathrm{H}_{2}(\mathrm{a}) & \doteqdot \mathrm{H}_{2}(\mathrm{~g})
\end{aligned}
$$

The use of dopants as reactants greatly altered the growth rate and the activation energy for deposition by influencing the electrostatic properties of the surface. p-Dopants such as $\mathrm{PH}_{3}$ and $\mathrm{AsH}_{3}$ gave the silicon substrate a partial positive charge, while n-dopants like $B_{2} H_{6}$ give the surface a partial negative charge. The silane molecule, $\mathrm{SiH}_{4}$, contained a silicon atom which has a partial positive charge while the hydrogen atoms had partial negative charges. Thus, as this molecule approached the silicon surface adsorption was enhanced in the presence of $\mathrm{p}$-dopants while it was retarded in the presence of $\mathrm{n}$ dopants. Thus as the ratio of $\mathrm{n}$-dopant to silane gas increased the rate of deposition decreased and the activation energy for deposition increased. The converse was true for p-dopants.

Gas phase reactions typically control deposition rate. An example of this was reported by scott et al. for the growth of 
amorphous hydrogenated silicon films by plasma CVD [53]. Gas phase reactions for this reaction are shown in Table $8 . \mathrm{SiH}_{2}$ diradicals are intermediates for the process and lead to the formation of all primary and secondary products of $\mathrm{SiH}_{4}$ pyrolysis. The rate determining step for this process was homogeneous although film growth was heterogeneous. The substrate temperature determined the film composition, but the growth rate was determined by gas phase reactions. Other authors [54] have observed that homogeneous deposition was controlled by a combination of hot zone length, gas flow rate, gas thermal diffusivity, and gas temperature.

The growth and formation mechanism for a CVD film was detailed by Bryant [55]. Following adsorption, atoms diffused along the surface of the substrate. Stable nuclei, consisting of a few atoms, formed at preferred sites on the substrate surface. Growth proceeded by the addition of individual atoms from the reactant gas stream and from surface diffusion across the uncovered portion of the substrate. Atom additions during the growth process occurred at positions of lowest free energy like steps or kinks and proceeded to form crystallites. The crystallites resembled islands in appearance and formed a thin single crystal upon coalescence.

A number of factors have been shown to influence film deposition rate, amount, structure, and uniformity. The nature of the substrate surface can have a profound effect on the structure of deposits formed. Also deposit microstructure is controlled by substrate temperature [56], gas phase mass transport, and concentration of the reactants. Table 9 shows the effect of temperature and pressure on 
Table 8. Gas Phase Reactions Involved in Growth of Amorphous Hydrogenated Silicon Films by Plasma CVD

\begin{tabular}{|c|}
\hline $\begin{aligned} \mathrm{SiH}_{4} & =\mathrm{SiH}_{2}+\mathrm{H}_{2} \\
\mathrm{Si}_{2} \mathrm{H}_{6} & =\mathrm{SiH}_{2}+\mathrm{SiH}_{4} \\
\mathrm{Si}_{3} \mathrm{H}_{8} & =\mathrm{SiH}_{2}+\mathrm{Si}_{2} \mathrm{H}_{6} \\
\mathrm{Si}_{4} \mathrm{H}_{10} & =\mathrm{SiH}_{2}+\mathrm{Si}_{3} \mathrm{H}_{8} \\
& \text { etc. } \\
\mathrm{Si}_{2} \mathrm{H}_{6} & =\mathrm{SiH}_{3} \mathrm{SiH}+\mathrm{H}_{2} \\
\mathrm{Si}_{3} \mathrm{H}_{8} & =\mathrm{Si}_{2} \mathrm{H}_{5} \mathrm{SiH}+\mathrm{H}_{2} \\
\mathrm{Si}_{3} \mathrm{H}_{8} & =\mathrm{SiH}_{3} \mathrm{SiH}+\mathrm{SiH}_{4} \\
\mathrm{Si}_{4} \mathrm{H}_{10} & =\mathrm{Si}_{3} \mathrm{H}_{7} \mathrm{SiH}+\mathrm{H}_{2} \\
\mathrm{Si}_{4} \mathrm{H}_{10} & =\mathrm{Si}_{2} \mathrm{H}_{5} \mathrm{SiH}+\mathrm{SiH}_{4} \\
\mathrm{Si}_{4} \mathrm{H}_{10} & =\mathrm{SiH}_{3} \mathrm{SiH}+\mathrm{Si}_{2} \mathrm{H}_{6} \\
& \text { etc. }\end{aligned}$ \\
\hline
\end{tabular}

Reprinted from Scott [53]. 
Table 9. Effect of Temperature and Pressure on the Microstructure of Fluoride CVD Tungsten Produced at $\mathrm{H}_{2} / \mathrm{WF}_{6} \approx 6$

\begin{tabular}{|c|l|l|}
\hline $\begin{array}{c}\text { Temperature } \\
\left({ }^{\circ} \mathrm{C}\right)\end{array}$ & 760 torr & 0.1 torr \\
\cline { 2 - 3 } & Microstructure & Microstructure \\
\hline & & fine grained $(<1 \mu \mathrm{m})$ \\
350 & No deposition & \\
500 & Less coarse grained & \\
600 & Coarse grained & \\
650 & Coarse grained & \\
700 & Coarse grained & \\
800 & Coarse grained & \\
900 & Botryoidal & \\
1000 & Dendritic, powder & \\
1350 & Dendritic & Whiskers, fine grained $(<1 \mu \mathrm{m})$ \\
& & Epitaxial \\
\hline
\end{tabular}

Reprinted from Bryant [58] 
deposit morphology as reported by Bryant [55]. Deposit morphology and rate can be influenced by preferred adsorption of impurity gases. While the minimum temperature for deposition depends upon substrate material. Choice of substrate material influences the nucleation rate and hence the growth rate. Film thickness uniformity is controlled by the axial temperature profile, the pressure conditions, and the reactant gas flow [57].

In many cases, the test parameters for CVD processes are similar to those used in vapor deposition. But the reactant mix, the number of intermediates, the number of adsorbed species, the number of reactants, and consequently the products produced are much more complex for vapor deposition studies. Still, this implies that fundamental knowledge gained from CVD studies may advance research efforts of vapor deposition studies. 
Chapter 3

EXPERIMENTAL APPROACH AND RESULTS

\subsection{Experimental Approach}

The previous section has outlined the need for high temperature lubricants for metal and ceramic systems. Vapor phase lubrication has shown great promise for high temperature lubrication, but a number of questions remain unanswered. Kinetic data collected during earlier vapor deposition studies have been obtained by weighing samples after a finite coating period. A more useful approach would be to generate continuous kinetic data. This would provide true kinetic rate data and save experimental time. Another key issue is whether advanced ceramics will behave as metals have during vapor deposition.

Ceramics, often considered inert, may not react with vaporized lubricants to form continuous films. If this is true, vapor lubrication would not be a useful technology for the high temperature lubrication of ceramics. The presence of sintering aids and dopant may affect vapor deposition film formation behavior. And if films do form on ceramics, what is their appearance and do they have lubricous qualities? This thesis will address many of these questions. A TGA apparatus is adapted to allow the collection of continuous kinetic data on metal surfaces. The film forming behavior of TBP on $\mathrm{Si}_{3} \mathrm{~N}_{4}$, $\mathrm{SiC}$, and $\mathrm{Al}_{2} \mathrm{O}_{3}$ is investigated. Finally the lubricating qualities of vaporized lubricants on ceramics are investigated. 


\subsection{Kinetic Data on Metal Surfaces}

\subsubsection{TGA Vapor Deposition Apparatus}

Vapor deposition studies were conducted to obtain continuous kinetic data on metal specimens. The system used incorporated a Thermalgravimetric Analyzer (TGA) into its design. A conventional TGA is shown in Figure 5. Key features include a microbalance which measures weight changes of a sample positioned with a furnace. A purge flows through the microbalance to prevent reacted material from contacting the delicate microbalance works. The furnace has a heating capability of up to $1000^{\circ} \mathrm{C}$. The furnace temperature was monitored by

a thermocouple located within the furnace just under the sample pan. Also, the TGA has a side arm to introduce various atmospheres to the furnace zone.

A vaporization tube was constructed such that its nozzle would fit in the side arm and would be positioned at the furnace mouth. The TGA vaporization tube is shown in Figure 6 . The quartz tube had separate carrier gas and air inlets. The air inlet was downstream from the lubricant introduction point. This eliminated the possibility of liquid phase oxidation of the lubricant. The lubricant was injected through a drawn capillary tube into a plug of glass wool. The glass wool provided a large surface area for the liquid lubricant to interface with heated carrier gas, resulting in complete vaporization. The drawn capillary tube minimized the amount of 


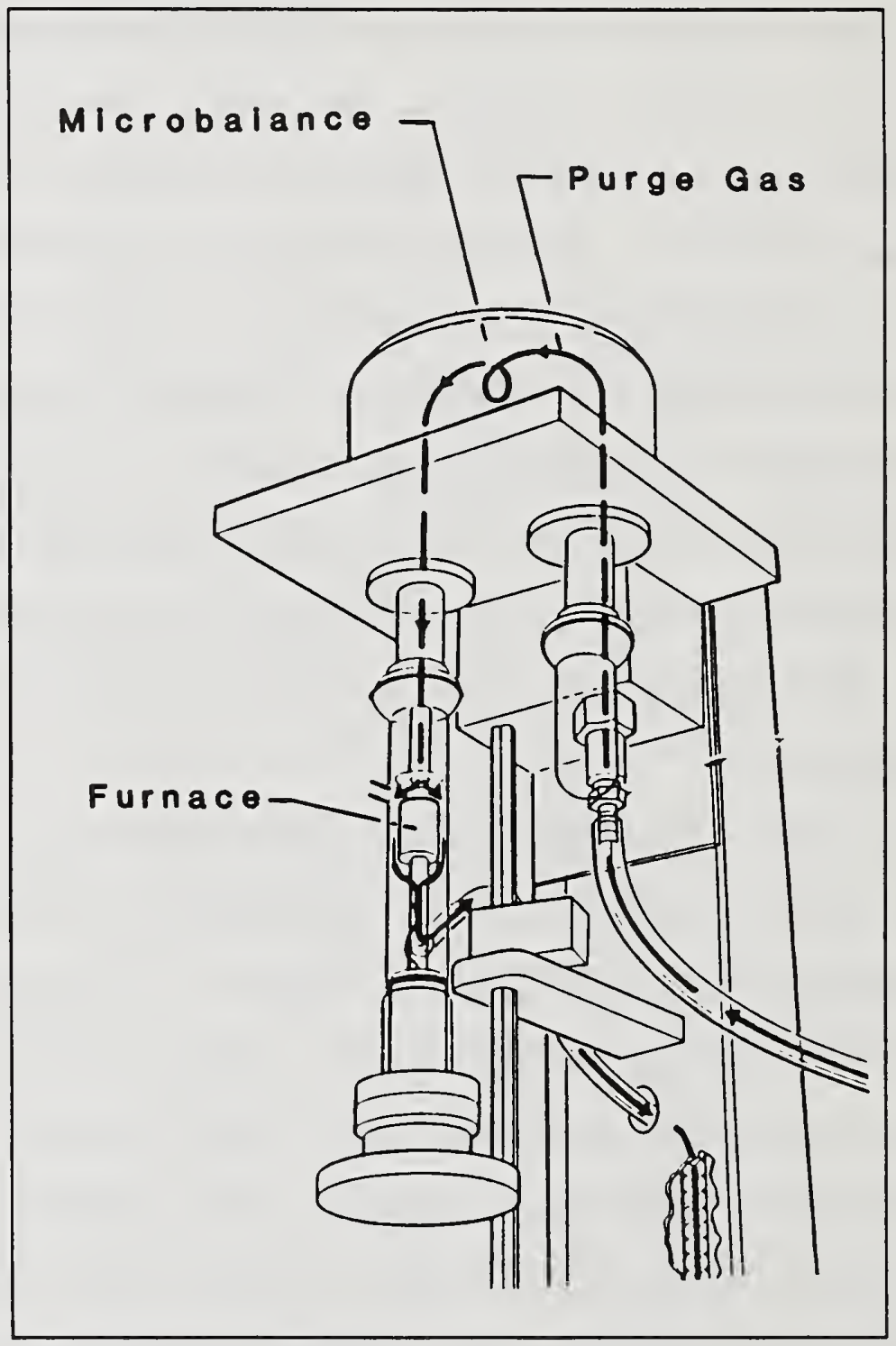

Figure 5 TGA 


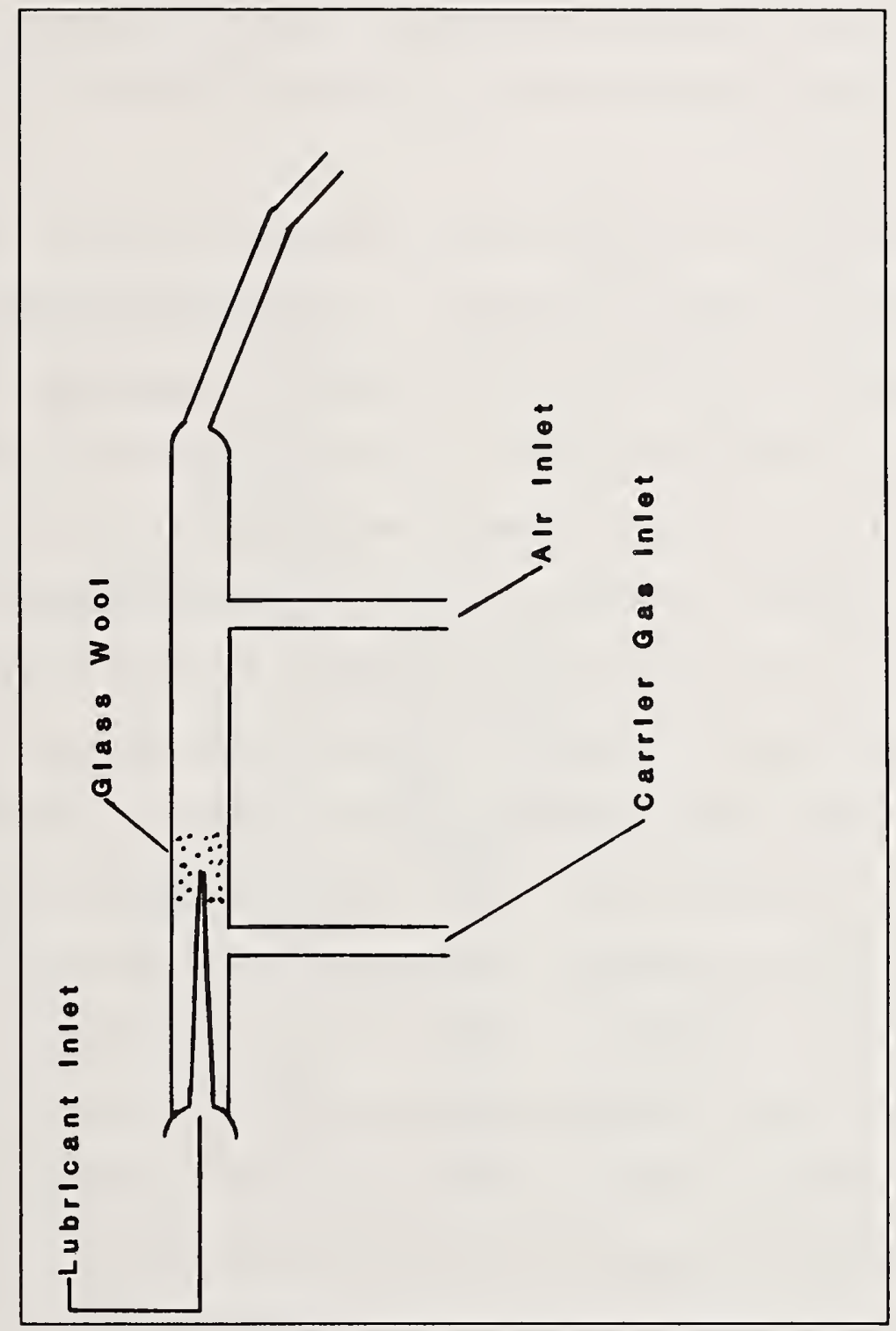

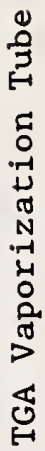

0

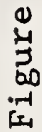


lubricant present within the system at any time. The end of the vaporization tube was fitted with a $12 / 1$ female ball joint. A syringe pump with a syringe epoxied within a $12 / 1$ male ball joint was clamped to the female ball joint of the TGA adapter using a pinch clamp.

The syringe pump provided a very controlled flow of lubricant through the system.

Before any testing could be performed, the TGA furnace had to be calibrated. Figure 7 displays a cutaway view of the furnace. During calibration, a series of four paramagnetic standards were placed in a gold pan within the furnace. A weight of zero was then entered into the TGA data station. A magnet was placed outside the TGA tube such that a maximum positive deflection occurred in the recorded sample weight. The temperature of the furnace was then ramped at a rate of $10^{\circ} \mathrm{C} / \mathrm{min}$ with the weight continuously monitored. Each paramagnetic sample has a well defined Curie Point. This was the temperature where, at and above, the sample loses its magnetic characteristics. Thus, the weight measured was constant until the Curie Point was reached and exceeded. At this point, a large decrease in weight was observed. The indicated temperature of transition was compared to known reference values and the controls were adjusted accordingly. The process was repeated until the indicated Curie Point and actual Curie Point were in accord for all standards. Table 10 compares the actual values to the reference values. Clearly the TGA provides controlled temperature over a very large temperature range.

The ideal specimen for TGA vapor deposition studies was one with a large surface area to volume ratio. This maximizes the ratio of 


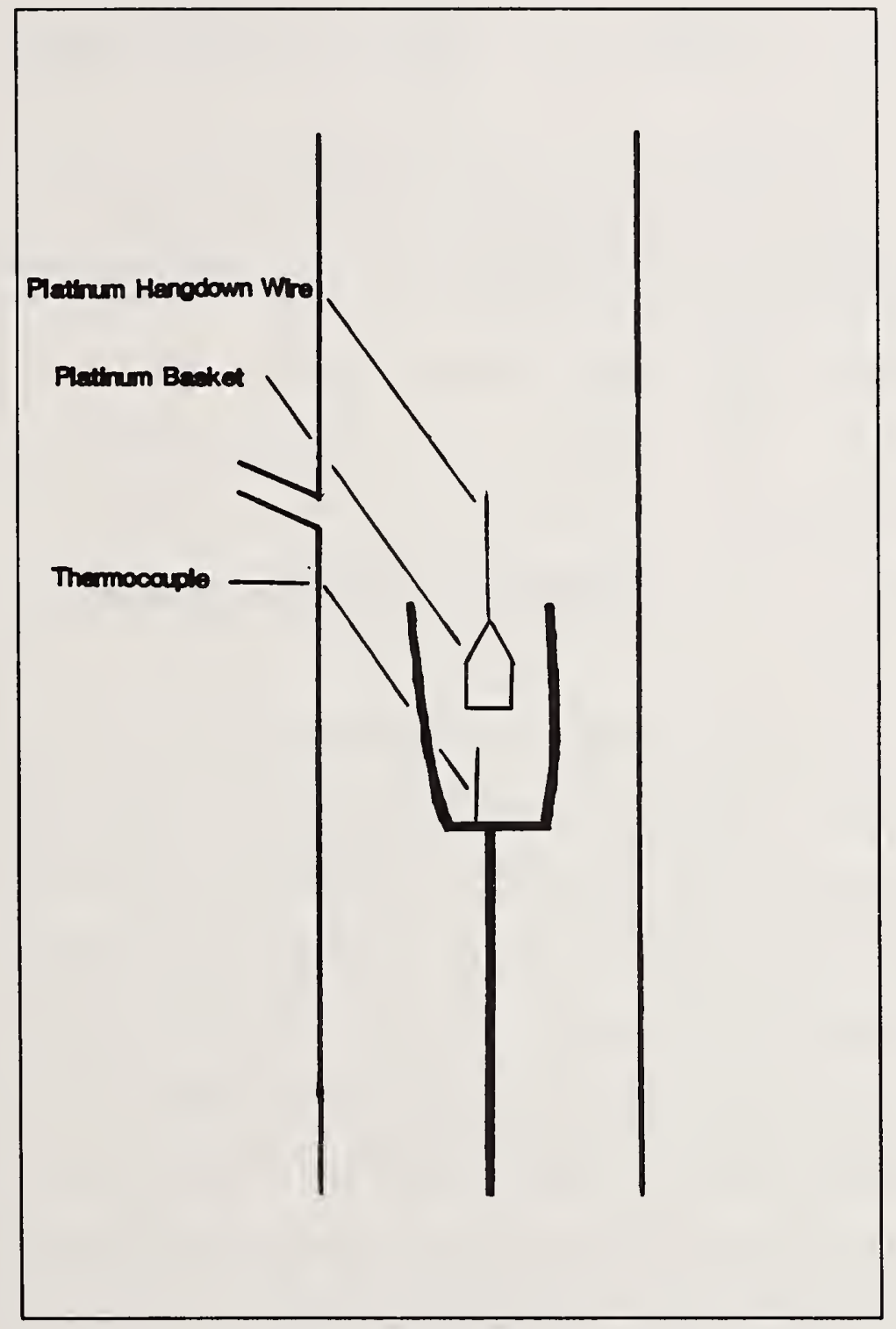

Figure 7. Cutaway View of the TGA Furnace 
Table 10. TGA Temperature Calibration Using Paramagnetic Standards

\begin{tabular}{|l|c|c|r|}
\hline Standard & $\begin{array}{r}\text { Point, }{ }^{\circ} \mathrm{C} \\
\text { Reference Curie }\end{array}$ & $\begin{array}{r}\text { Point, }{ }^{\circ} \mathrm{C} \\
\text { Measured Curie }\end{array}$ & $\Delta \mathrm{T}$ \\
\hline Alumel & 163 & 163.9 & -0.9 \\
Nickel & 354 & 352.9 & 1.1 \\
Perkalloy & 596 & 596.0 & 0 \\
Iron & 780 & 776.2 & 3.8 \\
\hline
\end{tabular}


deposited lubricant film to substrate weight thus providing maximum sensitivity. Wires, $0.005^{\prime \prime}$ in diameter, were selected for the metals studied in this work.

The wire samples were cut into 10" lengths. Then the specimens were abraded with a 600 grit sand paper followed by steel wool. The abraded samples were balled into spheres approximately $1 / 4^{\prime \prime}$ in diameter. These spheres fit within the platinum basket in the TGA furnace. The balls were then ultrasonically cleaned for 30 minutes in acetone, hexane, and finally toluene. The specimens were then stored in toluene until testing.

\subsubsection{TGA Vapor Deposition Procedures}

The test procedure consisted of removing a balled metal specimen from the toluene and rinsing it off with ethanol. The sample was then placed on the platinum basket in the TGA and the TGA was closed. The purge through the microbalance was set at $40 \mathrm{cc} / \mathrm{min}$. The vaporization tube was positioned with its nozzle through the TGA side arm and pointed at the balled sample in the TGA furnace. The syringe pump, supported on a stand, was then clamped to the TGA vaporization tube. A tube containing preheated carrier gas was then connected to the carrier gas inlet. If argon studies were being performed, a plastic cap was placed over the air inlet of the TGA vaporization tube. The TGA vaporization tube was then wrapped with heating tape with a thermocouple placed between the tape and the vaporization tube at the point of lubricant introduction. A second heating tape was wrapped 
around the TGA tube surrounding the furnace. The temperature of this interface was also monitored by a thermocouple. The carrier gas flow rate was set at $80 \mathrm{cc} / \mathrm{min}$ to flush out any residual gases from within the furnace. Both heating tapes were turned on. The heating tape wrapping the vaporization tube was set at $30^{\circ} \mathrm{C}$ above the saturation temperature for the selected lubricant injection rate. This insured complete vaporization. When both heating tapes had reached their temperature set points, the purge rate was reduced to $25 \mathrm{cc} / \mathrm{min}$, the carrier gas flow rate was reduced to $40 \mathrm{cc} / \mathrm{min}$, and the furnace was ramped to the desired test temperature. The sample weight was initially set at zero, then a weight suppression dial was adjusted so that a sample weight of $0.15 \mathrm{mg}$ was entered into the TGA data station. This weight represented full scale (1008) on the TGA printout of weight gain versus time. The weight suppression was further adjusted to indicate only 108 sample $(0.015 \mathrm{mg})$ was initially present. The syringe pump was turned on and a weight gain versus time was continuously recorded as vaporized lubricant deposited on the specimens .

The ability to continuously collect kinetic data is a major advantage over previous systems. Data collected from earlier vapor delivery system were obtained by measuring the weight gain at the end of a given deposition time. Thus, many individual tests had to be conducted to characterize a given substrate, lubricant, and deposition temperature. This new technique allows a more complete characterization by conducting only one test. 
The possibility of back diffusion of vaporized lubricant reaching the microbalance working is detailed in Appendix D. These calculations demonstrate that no vaporized lubricant reaches the microbalance.

\subsubsection{TGA Vapor Deposition Results}

The TGA vapor deposition system was used to collect continuous film formation data on copper, nickel, stainless steel, and platinum substrates. Also, the effects of temperature and lubricant were studied. Initial studies were conducted using purge rates of 25 $\mathrm{cm}^{3} / \mathrm{min}$ through the balance and $40 \mathrm{~cm}^{3} / \mathrm{min}$ through the vaporizing tube .

The effect of substrate on vapor deposition at $700^{\circ} \mathrm{C}$ using $1.06 \%$ TBP is shown in Figure 8. Several observations are apparent from this data. First, the vapor deposition of TBP is surface sensitive with copper being more active than stainless steel, followed by nickel and platinum. The same pattern of metal activity was observed for two other phosphate esters, TCP and GT [47]. Also the rates are more rapid during the first few minutes. This implies that the metal surface is catalyzing the deposition process. As more deposit is formed, the metal becomes encapsulated in deposit; thus, the rate is reduced and approaches a steady state value for long test times. The deposition rate on copper was still very rapid for long test times. This indicates that copper remains active. This deposit forming rate behavior has also been observed in coke formation studies. The rate 


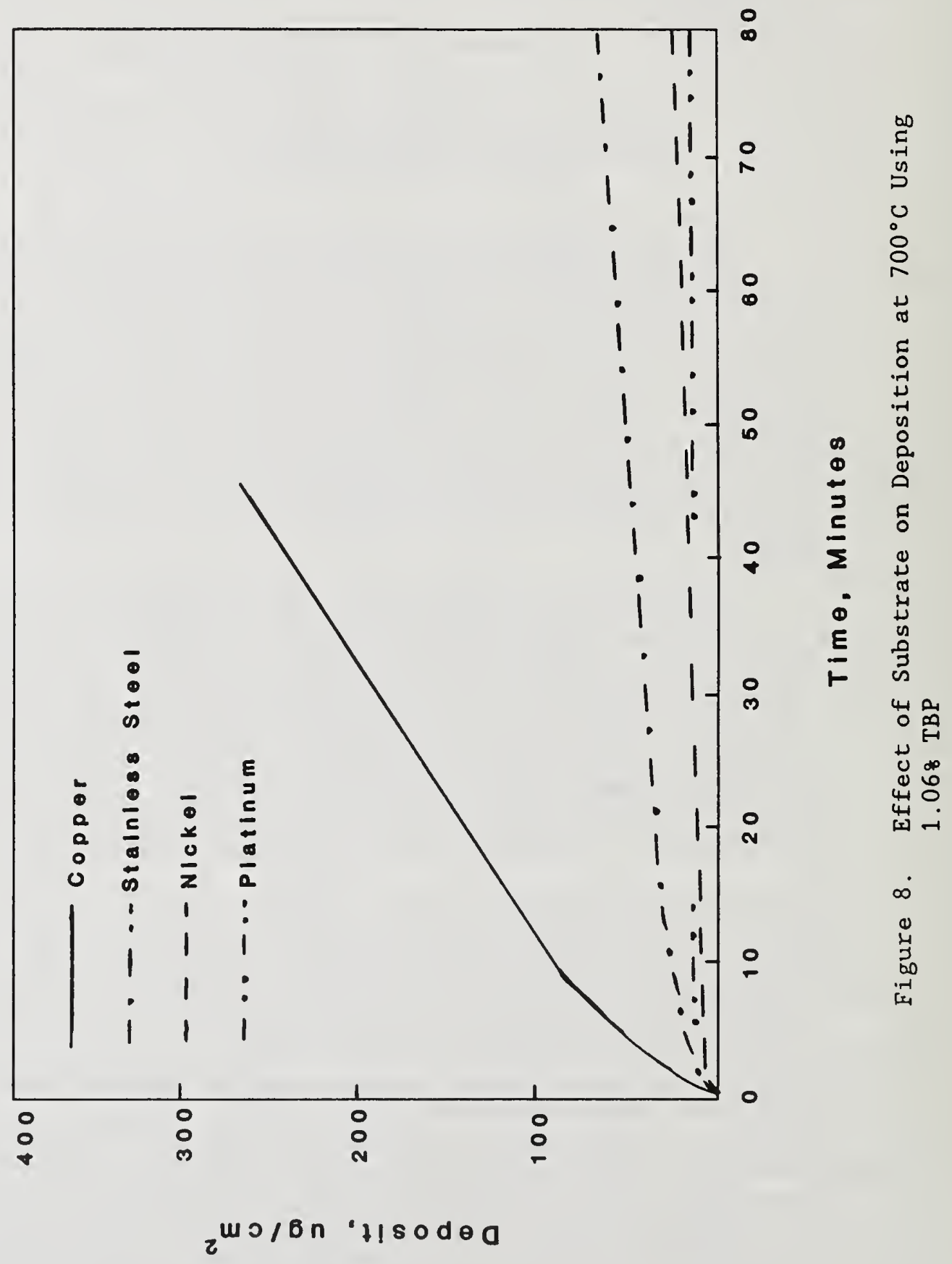


of coke formation is very rapid initially and decreases as time progresses [58-60]. This is consistent with the scenario where catalyst particles become deactivated and coke continues to form on existing coke. This also agrees with previous vapor deposition findings .

Coke studies have also shown that the type of metal surface a gas contacts at elevated temperatures has a major impact on the quantity of coke deposit formed. The amount of coke produced on iron surfaces decreases in the following order $\mathrm{FeO}>\mathrm{Fe} \approx \mathrm{Fe}_{2} \mathrm{O}_{3}>\mathrm{Fe}_{3} \mathrm{C}$ [61]. While iron produced substantial quantities of coke, LaCava et al. [62] determined nickel forms even more. And a $\mathrm{Ni}-\mathrm{Fe}$ surface produces more coke than either of the parent materials [63] suggesting a synergetic interaction between the two metals. In general, metals form more deposit than nonmetallic materials. Holmen et al. [58] observed deposits decrease in the following order: Co $>$ steel $>\mathrm{Cu}>\mathrm{Mo}$ quartz. This inertness of silica based materials has been observed by other authors $[63,64]$. Brown [64] found that silica coated HK 40 steel formed much less deposit than uncoated steel. While vycor formed smaller amounts of deposit than an aluminized incoloy sample which produced less deposit than unadulterated incoloy [59]. Nonmetallic oxide additives have been found to reduce coke formation on a $\mathrm{Ni}-\mathrm{Fe}$ surface by several methods according to Baker et al. [63]. Alumina and titania provide a physical barrier against hydrocarbon adsorption and decomposition which results in coke formation. $\mathrm{WO}_{3}$, $\mathrm{MoO}_{3}$, and $\mathrm{Ta}_{2} \mathrm{O}_{3}$ reduce the solubility of carbon in the metal while silica reduces both solubility and diffusion of carbon through a 
catalyst particle. Thus, the surface composition has a pronounced effect on the coke formation which occurs.

Table 11 compares the initial rate of film formation on various substrates at $700^{\circ} \mathrm{C}$ from previous studies [65] and this work. The measured formation rates of this study are less than those of previous studies. These differences can be explained by examining the effect of using argon as a carrier gas. The argon carrier gas passed through an oxygen scavenger which removed oxygen to a level of 1 PPM. Commercial nitrogen used in previous studies contained substantially more oxygen. Table 12 displays the effect oxygen on the initial film formation rate on copper at $700^{\circ} \mathrm{C}$. Clearly, the presence of oxygen greatly enhances the rate of film formation. Thus, the lack of oxygen may substantially reduce the amount of film formed on various substrates.

The effect of the lubricant on the deposition on stainless steel at $700^{\circ} \mathrm{C}$ is shown in Figure 9. An alkyl phosphate ester, TBP, is compared to an aryl phosphate ester, TCP. Both fluids appear very similar, showing an initially rapid deposition rate which is followed by a slower rate at long test times. The similarity between the two phosphate esters differs from the results observed by Lai [41], but this is most likely related to the lack of oxygen within the TGA.

Figure 10 displays the effect of temperature on the deposition of nickel using 1.068 TBP. The data shows that a much greater deposition occurs on nickel at $600^{\circ} \mathrm{C}$ compared to $700^{\circ} \mathrm{C}$. This inverse relationship between temperature and amount of deposit has been observed previously. Table 13 shows a compilation of other 
Table 11. Initial Rate of Film Formation on Various Substrates at $700^{\circ} \mathrm{C}$

\begin{tabular}{|l|c|c|c|}
\hline \multirow{2}{*}{ Substrate } & \multicolumn{3}{|c|}{ Initial Rate, $\mu \mathrm{g} / \mathrm{cm}^{2} \bullet \mathrm{min}$} \\
\cline { 2 - 4 } & TBP 1.068 & TCP 1.55\% [77] & GT 1.75\% [77] \\
Copper & 19.6 & 210 & 280 \\
$\begin{array}{l}\text { Stainless } \\
\text { Steel }\end{array}$ & 6.8 & 110 & 45 \\
Nickel & 3.8 & 15 & 10 \\
Platinum & 0.8 & $\ldots$ & $\cdots$ \\
\hline
\end{tabular}


Table 12. Effect of Oxygen on the Initial Rate of Film Formation on Copper at $700^{\circ} \mathrm{C}$

\begin{tabular}{|l|c|c|}
\hline \multirow{2}{*}{ Lubricant } & \multicolumn{2}{|c|}{ Atmosphere } \\
\cline { 2 - 3 } & $\mathrm{N}_{2}, \mu \mathrm{g} / \mathrm{cm}^{2} \cdot \min$ & Air, $\mu \mathrm{g} / \mathrm{cm}^{2} \bullet \mathrm{min}$ \\
\hline 0.1268 TCP [77] & 29 & 651 \\
0.1068 GT [77] & 89 & 1630 \\
\hline
\end{tabular}




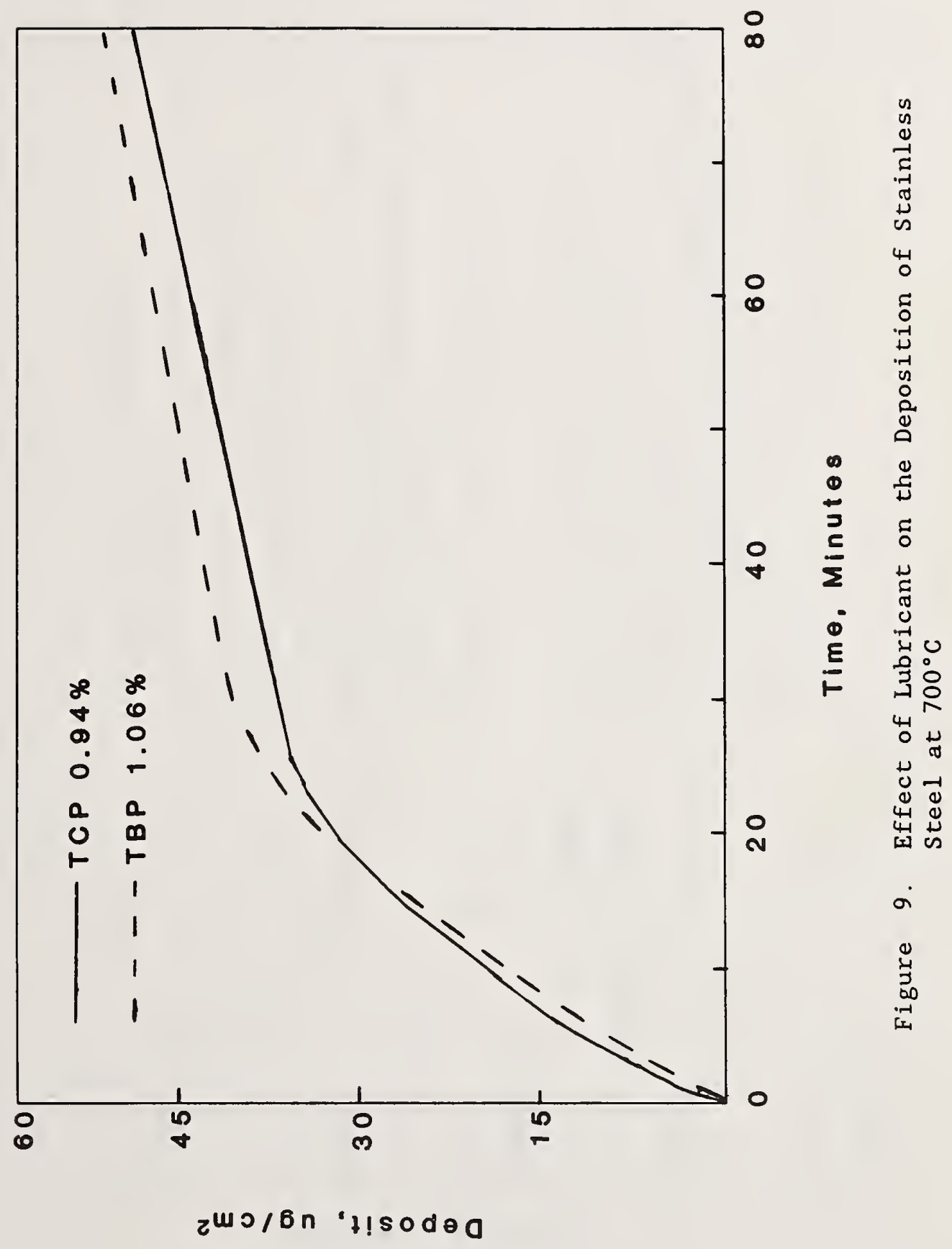




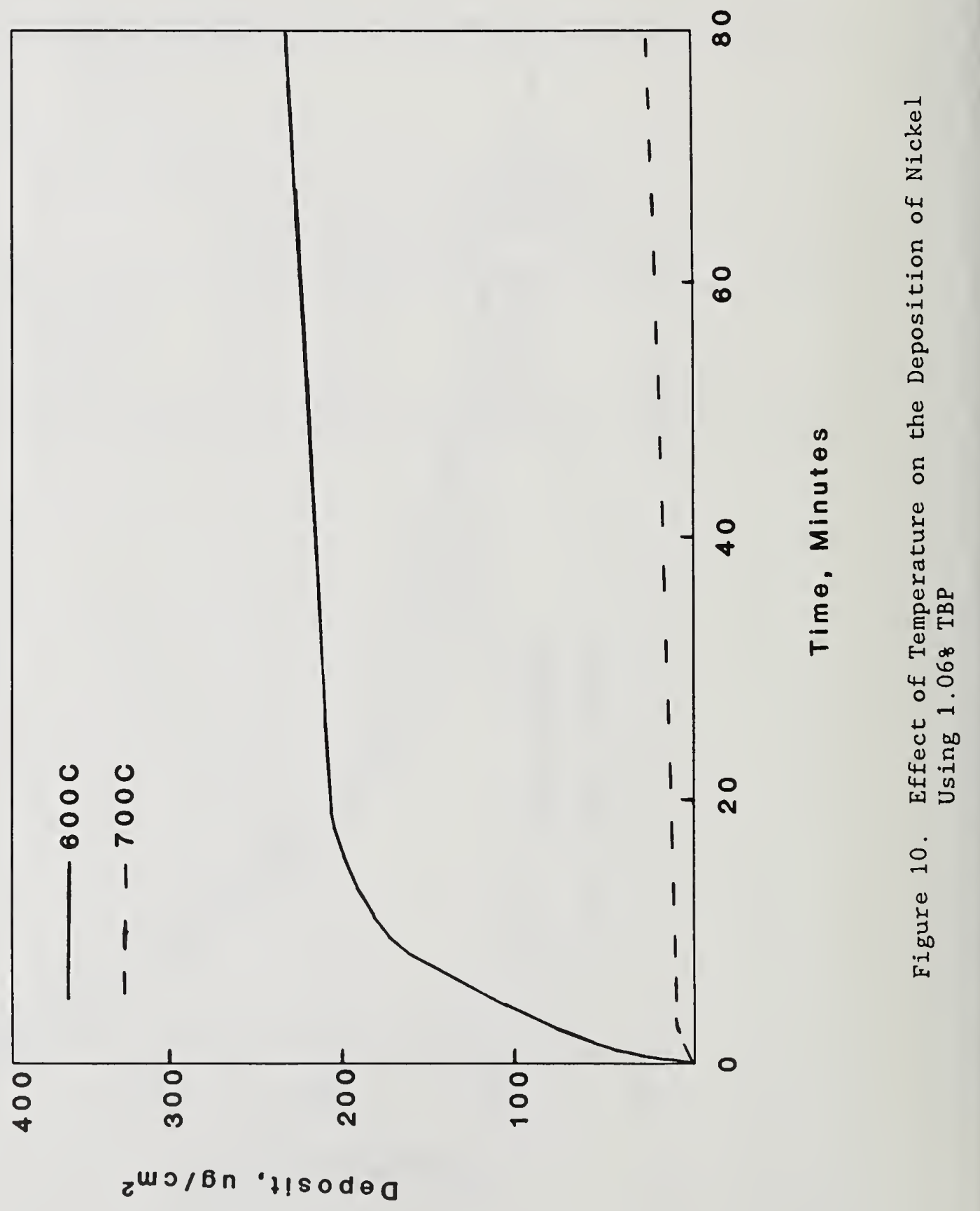


researchers studying high temperature film formation who witnessed decreasing amounts of film formation with increasing temperature. Lai observed similar results for stainless steel coated with TBP [41]. This has also been observed for coke formation results on nickel [58,59,62-64,66-77]. Also the film formation of GaAs has been shown to decrease with increasing temperature starting as low as $600^{\circ} \mathrm{C}$ by various authors [78-82]. Petzke et al. [78] and Leys et al. [79] attributed this phenomena to homogeneous nucleation in the vapor phase. Zaouk et al. [80] determined that dissociation of molecules in the gas phase caused a reduction in deposition rates at elevated temperatures. They also suggested increased rates of desorption as a possible explanation [78]. Finally, Stringfellow et al. [81] and Shaw [82] concluded that the rate of film growth at elevated temperatures is limited by thermodynamic equilibrium. The occurrence of homogeneous nucleation is not likely in this work. This is because the low vapor concentrations used, 1.068 maximum, result in a very low collision frequency thus, homogeneous nucleation is minimized. The most likely explanation would be either thermodynamic equilibrium limitation or desorption becoming dominant at elevated temperatures. Because adsorption is exothermic and desorption is endothermic if equilibrium of an adsorption-desorption reaction is achieved the proportion of desorbed species would increase as the temperature is raised, thus decreasing the film formation rate.

To gain a deeper understanding regarding the adsorptiondesorption characteristics of vapor deposited films, the following experiment was conducted. A nickel sample that was coated at $600^{\circ} \mathrm{C}$ in 
$1.06 \%$ TBP for 80 minutes was placed in the platinum basket within the TGA furnace. The furnace was then ramped at $10^{\circ} \mathrm{C} / \mathrm{min}$ from $300^{\circ} \mathrm{C}$ to $900^{\circ} \mathrm{C}$ in flowing argon. Figure 11 shows weight loss versus temperature for the desorption of the surface film. At $900^{\circ} \mathrm{C}$ all of the film had been desorbed.

The data in Figure 11 shows that the desorption of the vapor deposited film is a staged process. A portion of the film is desorbed between 350 and $550^{\circ} \mathrm{C}$. A second part of the film is desorbed between 750 and $900^{\circ} \mathrm{C}$. This implies the presence of different types of film having different thermal stabilities. A similar phenomena has been observed by researchers studying coke formation. Up to five different types of coke have been observed to exist simultaneously. Table 14 provides a description of coke formed by reacting ethane with nickel at various temperatures as reported by McCarty et al. [72] .

Figure 12 shows an Arrhenius plot for the desorption of the low temperature form of decomposed species from 441 to $385^{\circ} \mathrm{C}$. A best line fit is superimposed on the data. The regressed line had a correlation coefficient of 0.98. The slope of the line is -15695.9 . Thus the activation energy for the desorption of the low temperature species is $31.2 \mathrm{kcal} / \mathrm{mole}$. Figure 13 shows an enlarged view of the Arrhenius plot for the desorption of the high temperature form of decomposed species from 814 to $727^{\circ} \mathrm{C}$. A regressed line is superimposed on the data. The regressed line had a correlation coefficient of 0.998 . The slope of the line was - 20822.4. Thus, the activation energy for the desorption of the high temperature form of the desorbed species is 


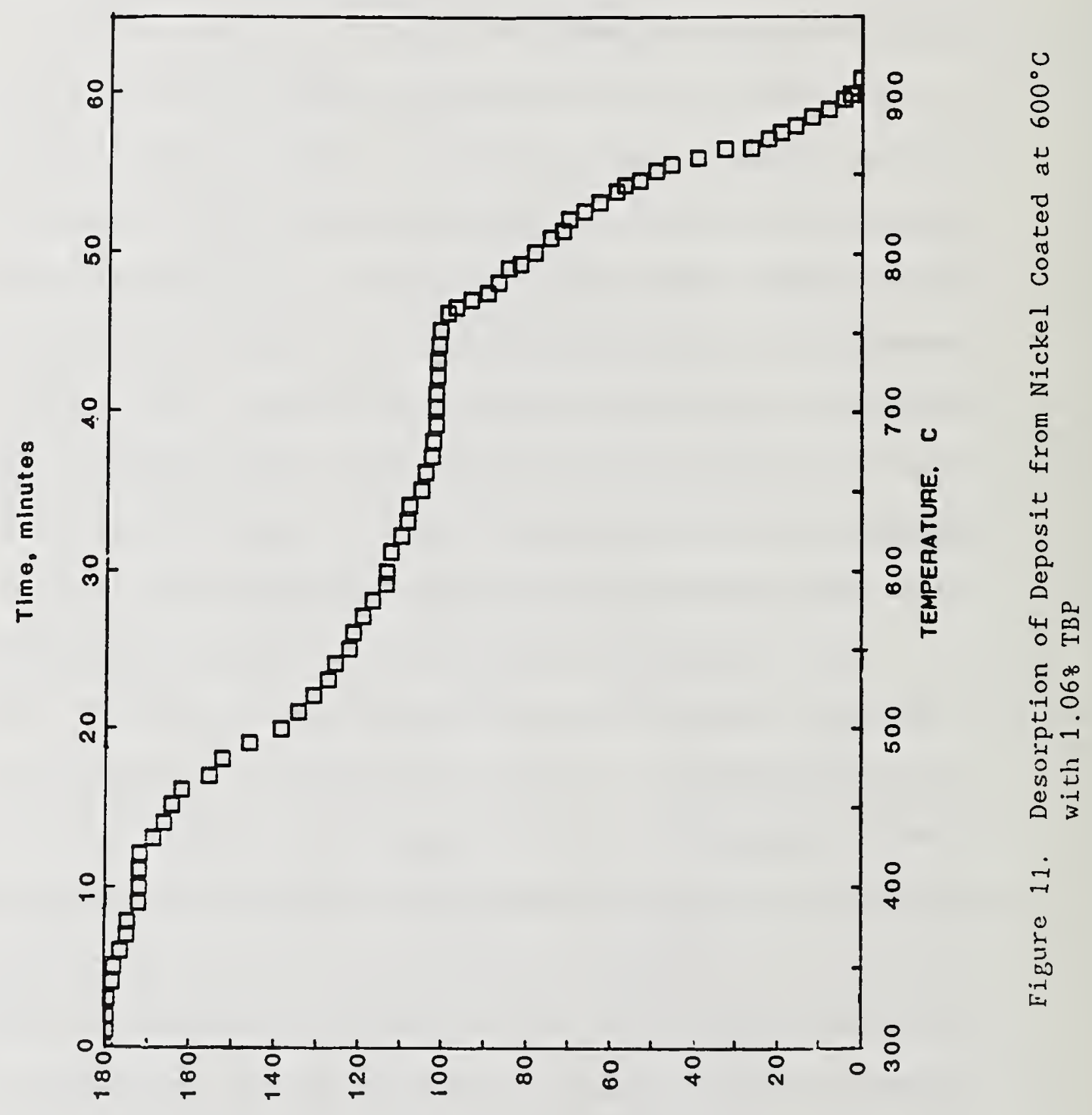

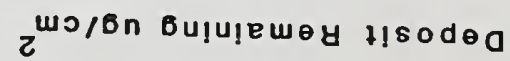




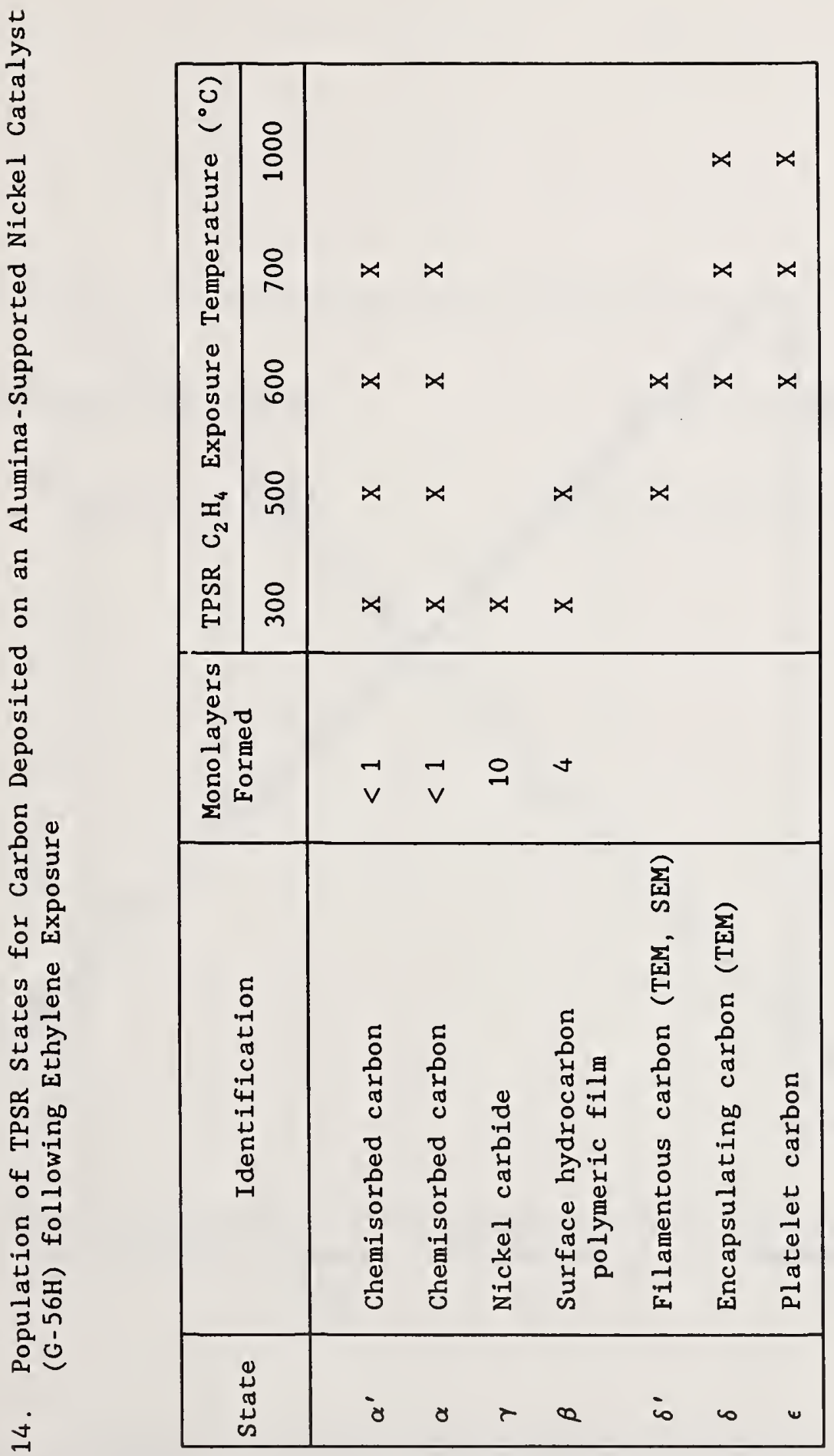

$\underset{\substack{0 \\-1}}{\stackrel{0}{0}}$ 


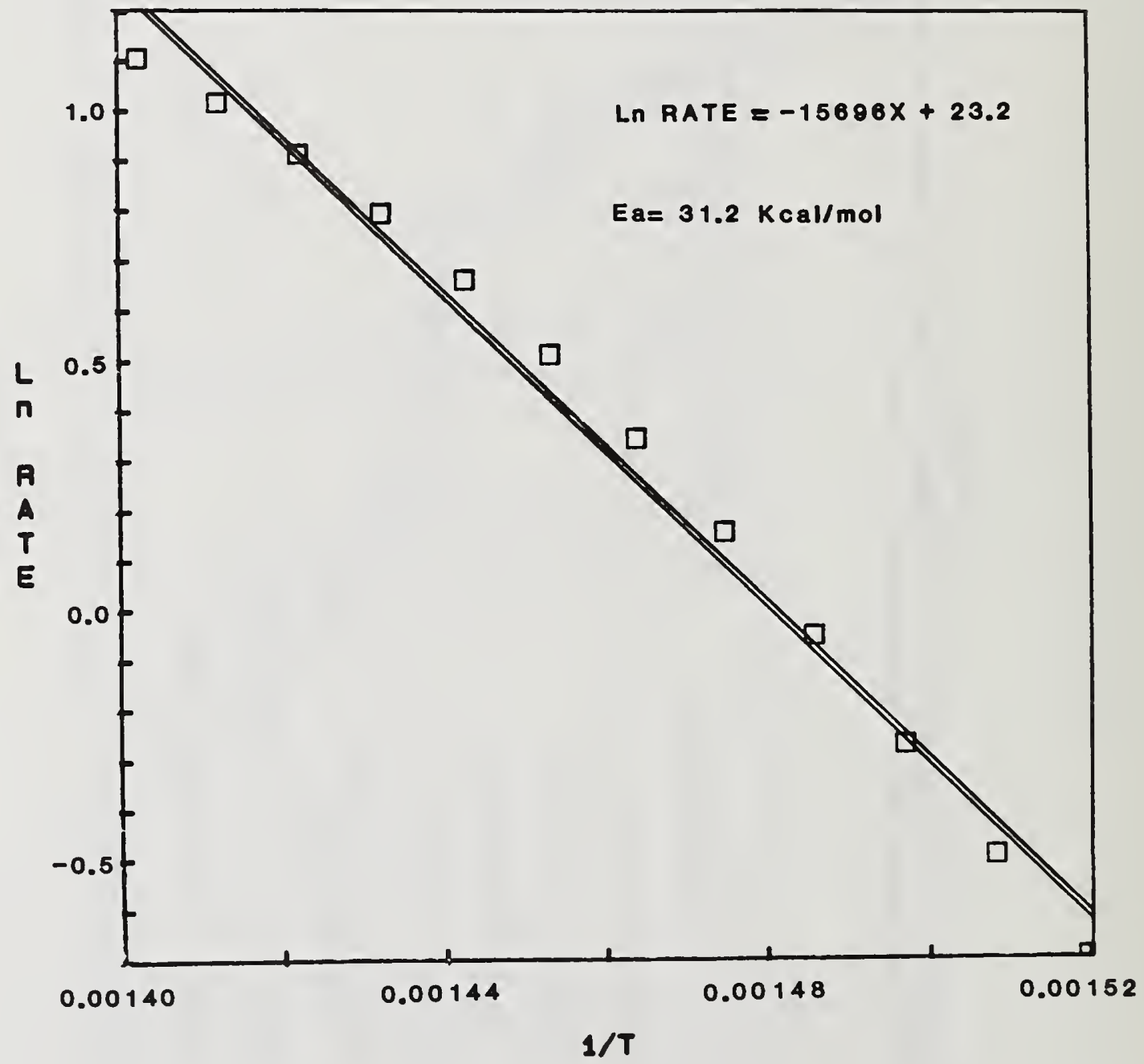

Figure 12. Arrhenius Plot for the Desorption of a TBP Film from Nickel from 441 to $385^{\circ} \mathrm{C}$ 


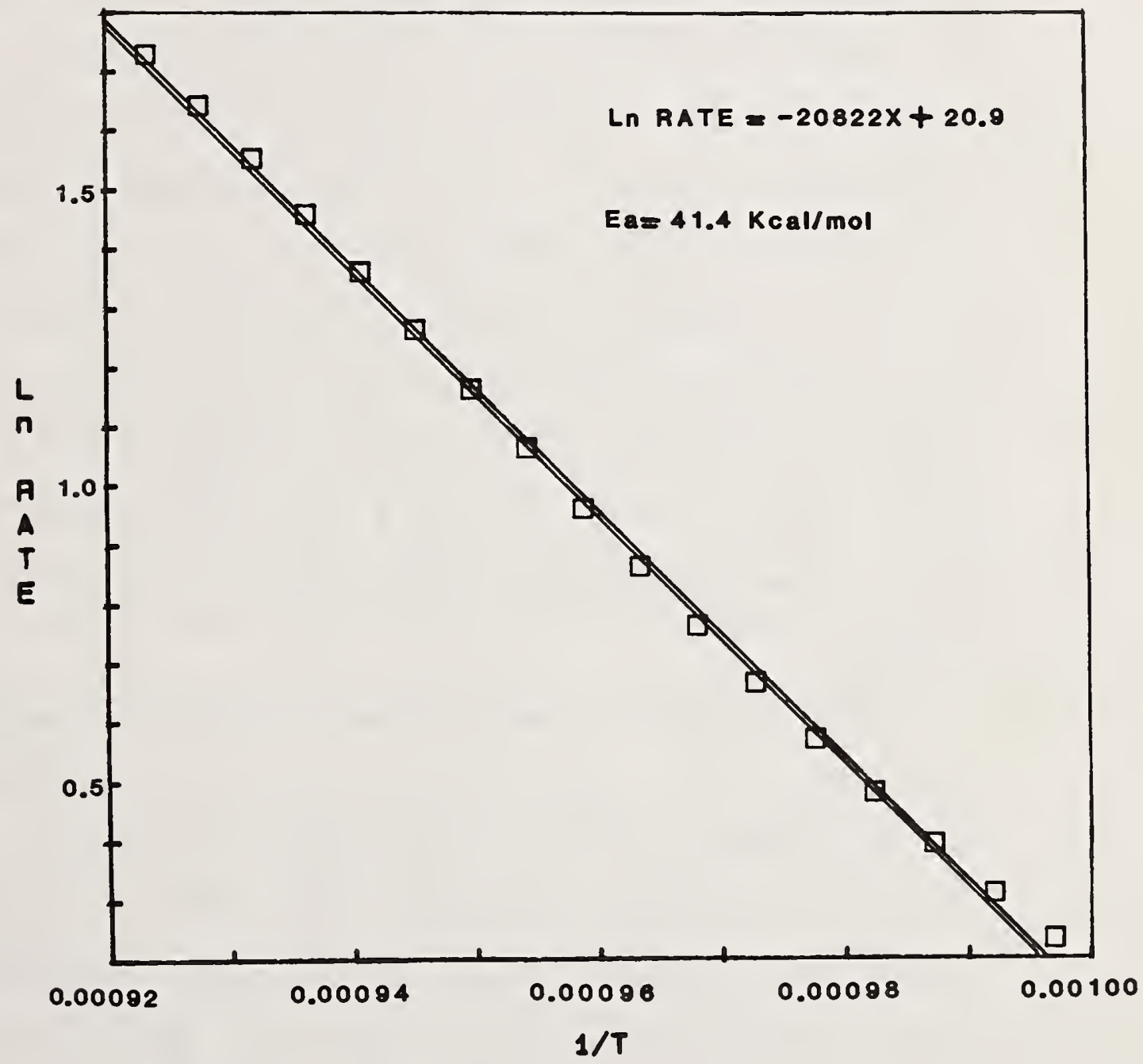

Figure 13. Arrhenius Plot for the Desorption of a TBP Film on Nickel from 814 to $727^{\circ} \mathrm{C}$ 
$41.4 \mathrm{kcal} / \mathrm{mol}$. The large activation energies for the film indicate that all the species are chemically bound, and not just physisorbed. These data can now be used to provide further interpretation to the rate data collected on nickel at $600^{\circ} \mathrm{C}$ and $700^{\circ} \mathrm{C}$ in Figure 10 . During vapor deposition adsorption and desorption occur simultaneously. Therefore, the amount of film present at any one time is a difference between the total amount of adsorption and desorption which has occurred. From Figure 11, it is clear that desorption occurs from 420 to $650^{\circ} \mathrm{C}$. At about $650^{\circ} \mathrm{C}$ the desorption reaches a near zero rate. Further desorption did not occur until $750^{\circ} \mathrm{C}$. This shows at $700^{\circ} \mathrm{C}$ the amount desorbed is controlled by system thermodynamics which require higher activation energies for further desorption. Therefore, for TBP deposited on nickel the thermodynamic equilibrium of the system dictates a reduction in the amount of deposit formed as temperature increases from 600 to $700^{\circ} \mathrm{C}$, as seen in Figure 10 .

These results show that a TGA can be adapted for continuous vapor deposition studies. A substantial substrate effect was observed for the vapor deposition of TBP. The amount of film formed on various substrates in decreasing order was $\mathrm{Cu}>\mathrm{SS}>\mathrm{Ni}>\mathrm{Pt}$. The absence of oxygen greatly reduced the amount of film formed. Temperature studies of TBP on nickel showed that more deposit was formed at $600^{\circ} \mathrm{C}$ than $700^{\circ} \mathrm{C}$. This was caused by desorption becoming more dominant at $700^{\circ} \mathrm{C}$. A desorption experiment was conducted and two types of chemically bound species with differing thermal stabilities were found. Overall, it is very clear that the vapor deposition process is a very complex 
phenomenon, but the versatile nature of the TGA provides many critical insights by continuously measuring film deposit or film removal.

\subsection{Ceramic Vapor Lubrication Studies}

\subsubsection{Design of Vapor Deposition Apparatus}

During previous vapor deposition studies a number of vapor deposition furnaces have been constructed. The first vapor deposition apparatus was designed by Lai [41]. This unit is displayed in Figure 14. A close examination of the vapor deposition oven reveals several drawbacks. First, large amounts of lubricants were required to fill the stainless steel reservoir within oven $C$. The oven was maintained at a high enough temperature to allow considerable degradation of the lubricants. Also, wire and foil specimens were wrapped around a stainless steel cylinder then contacted with the vaporized lubricant. At the test temperatures, surface mobility of metal species has been observed and may have been a factor in the observed deposition rates $[83-86]$.

These factors led Min [87] to construct a modified vapor deposition chamber shown in Figure 15. In this arrangement the lubricant is placed within a stainless steel boat. The boat could hold $4.6 \mathrm{ml}$ of lubricant. Wire specimens were hung from a chromel hook on the specimen holder. The boat was heated to the desired vaporization temperature with carrier gas flowing from the deposition target to the boat. When the target and the boat reached their desired temperatures the flow direction was reversed and the specimen 


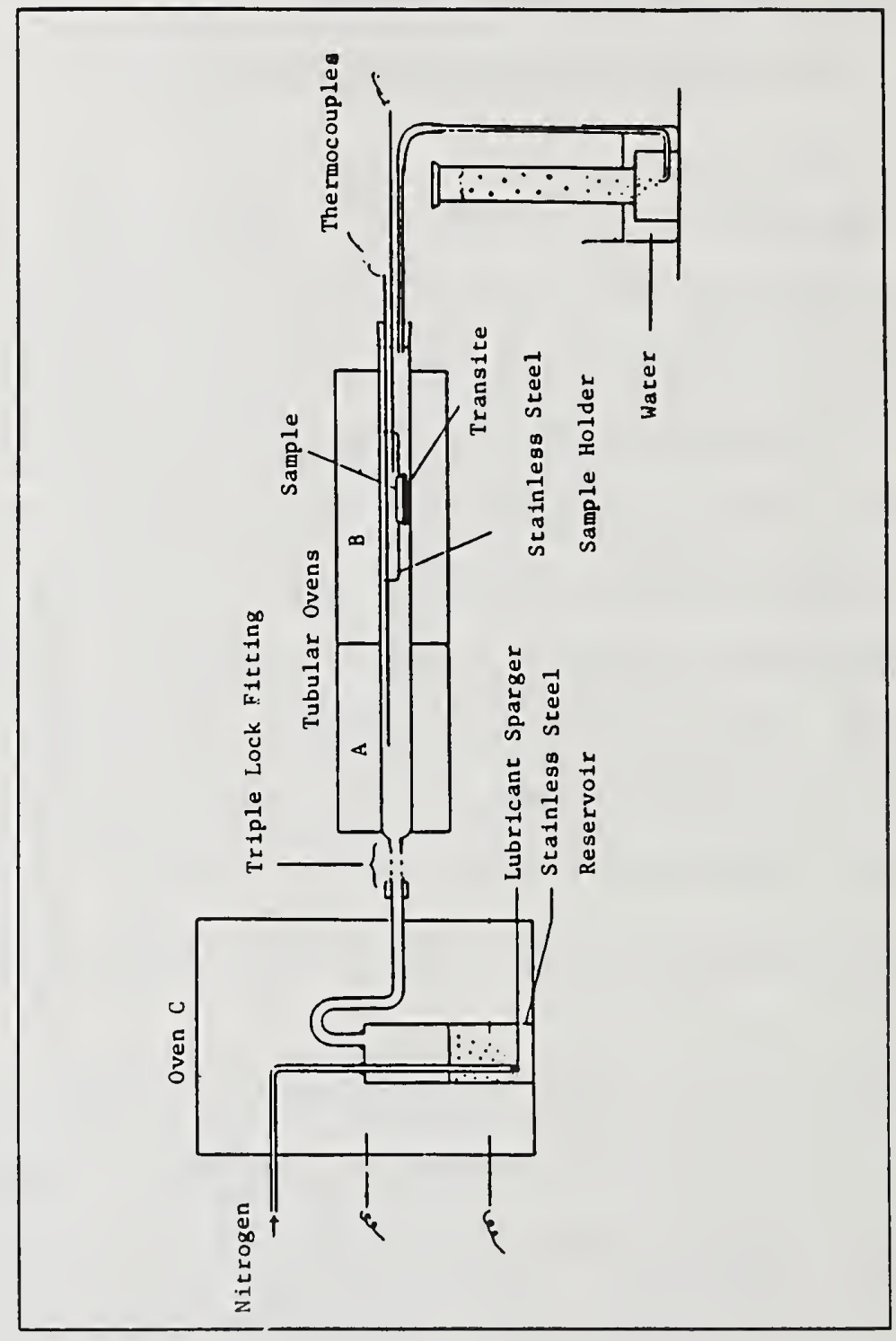

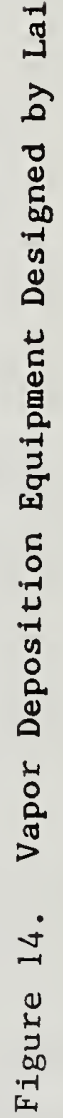




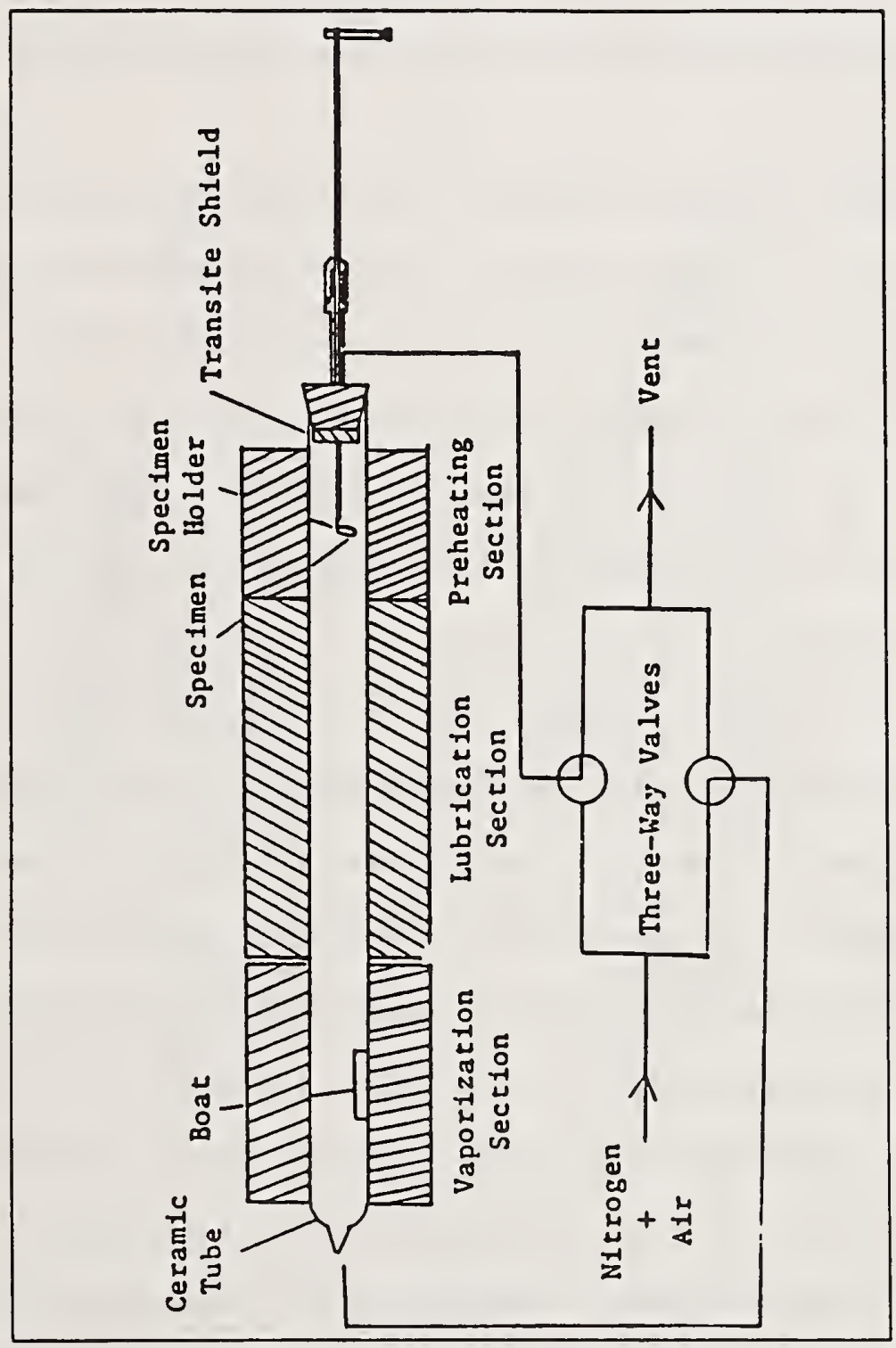

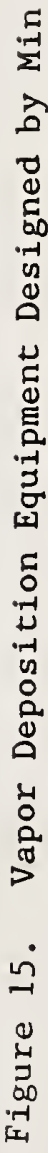


was coated for a given length of time. The reversal of the carrier gas allowed vapor above the boat to achieve a higher saturation level. This resulted in an unsteady state vapor concentration in the carrier gas. This may explain why Min [90] and Pinto [91] observed linear deposition rates after an initial period of more rapid deposit formation.

Gunsel [42] used the vapor deposit apparatus illustrated in Figure 16. In this setup, the specimen was heated to the test temperature in flowing nitrogen in oven 1 . To perform deposition the heated target was pushed along guides into a second oven in which carrier gas and lubricant were flowing. Upon test completion, the sample was removed from the deposition oven cooled and weighed on an electrobalance.

A controlled lubricant flow rate was achieved by injecting lubricant with a syringe pump into a bed of packed glass helices. This allowed intimate contact between the lubricant and heated carrier gas, resulting in complete and controlled vaporization.

Design considerations for vapor deposition reactions has been reviewed by Dapkus [89]. In general, there are two configurations used for vapor phase deposition studies, vertical and horizontal reactors. Vertical reactors position the substrate perpendicular to the gas flow direction. Rotation of the substrate is required to assure uniform depletion of gas constituents. The horizontal design places the substrate parallel to or slightly inclined to the reactant flow direction. This design results in a more uniform and controlled gas flow over the substrate surface. The major disadvantage of the 


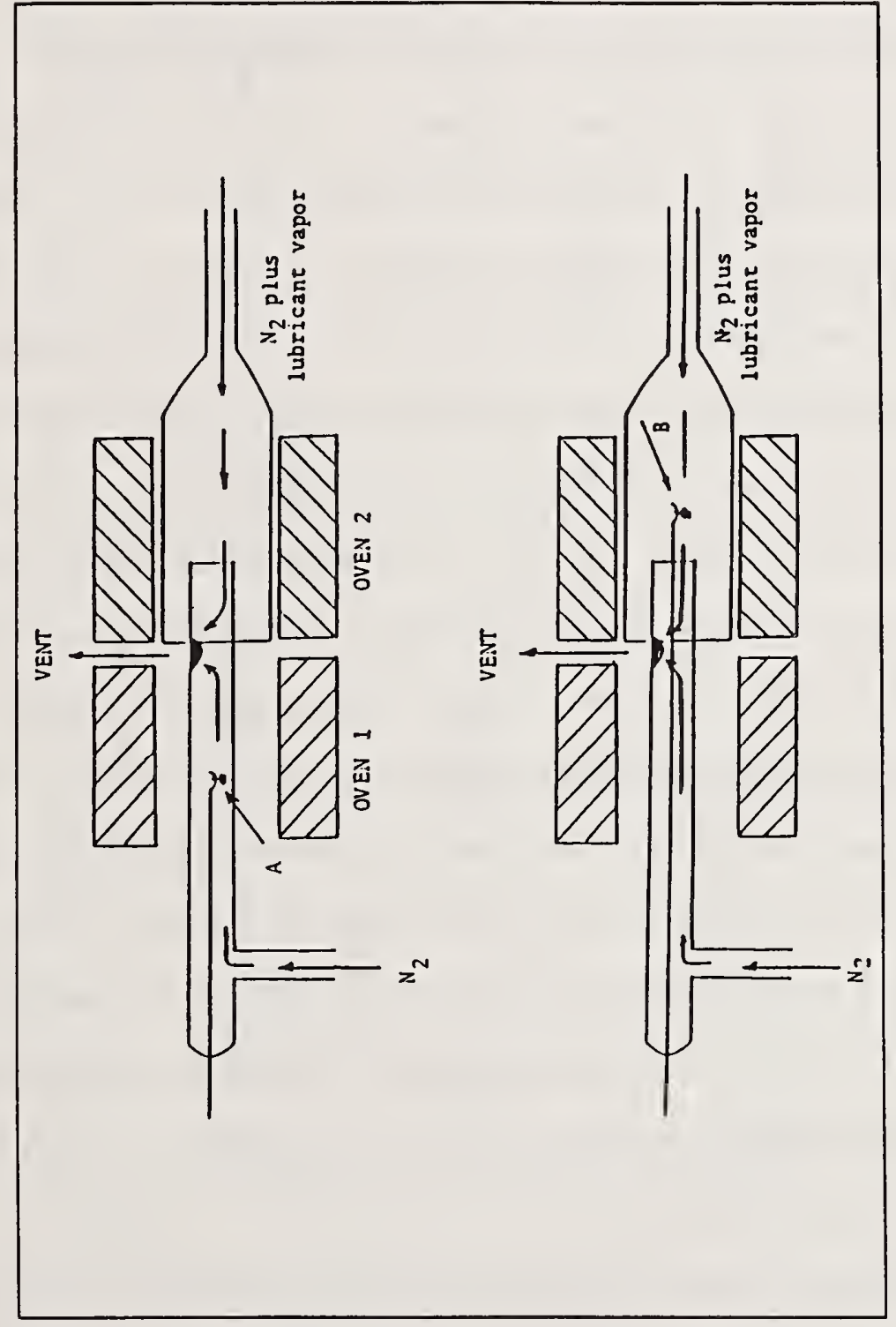

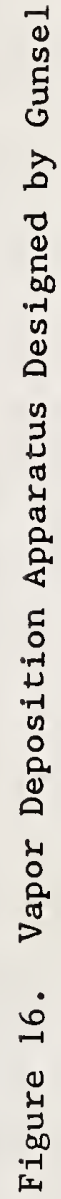


horizontal design is increased interaction of reactant gases with reactor walls in the deposition zone. For this study a horizontal configuration was chosen because of control and simplicity.

A vapor deposition tubular furnace was designed to allow controlled coating up to very high temperatures, $1200^{\circ} \mathrm{C}$, and to coat specimens up to 2 inches in diameter. This was accomplished by using two tubular Mellen furnaces and joining them with a flange. A dimensioned, scale drawing is shown in Figure 17. The function of the first furnace was to vaporize the lubricant while deposition occurred in the second. The temperature limits were $1000^{\circ} \mathrm{C}$ and $1200^{\circ} \mathrm{C}$, respectively, and each furnace was controlled by an independent Eurotherm controller. A 2-1/4" diameter fused quartz tube was inserted within the tubular furnace. Fused quartz was chosen because of high thermal shock resistance, high temperature stability, and relative inertness toward forming coke. Fused quartz can be heated to $1200^{\circ} \mathrm{C}$ and plunged into cold water without resulting in physical damage [90]. Also, with a $1600^{\circ} \mathrm{C}$ softening point, fused quartz maintains its structural integrity to very high temperatures. The chemical inertness allows measurements which are indicative of substrate being examined, and not a combination of substrate and insert wall effects.

To aid in heat transfer within the vaporization portion of the furnace, a series of baffles were designed for inside the fused quartz tube. Figure 18 provides the dimensions of the baffles, and Figure 19 shows a scale drawing of the baffle assembly. The baffles were spaced $1 / 2$ " apart. This was consistent with the spacing criteria for baffles 


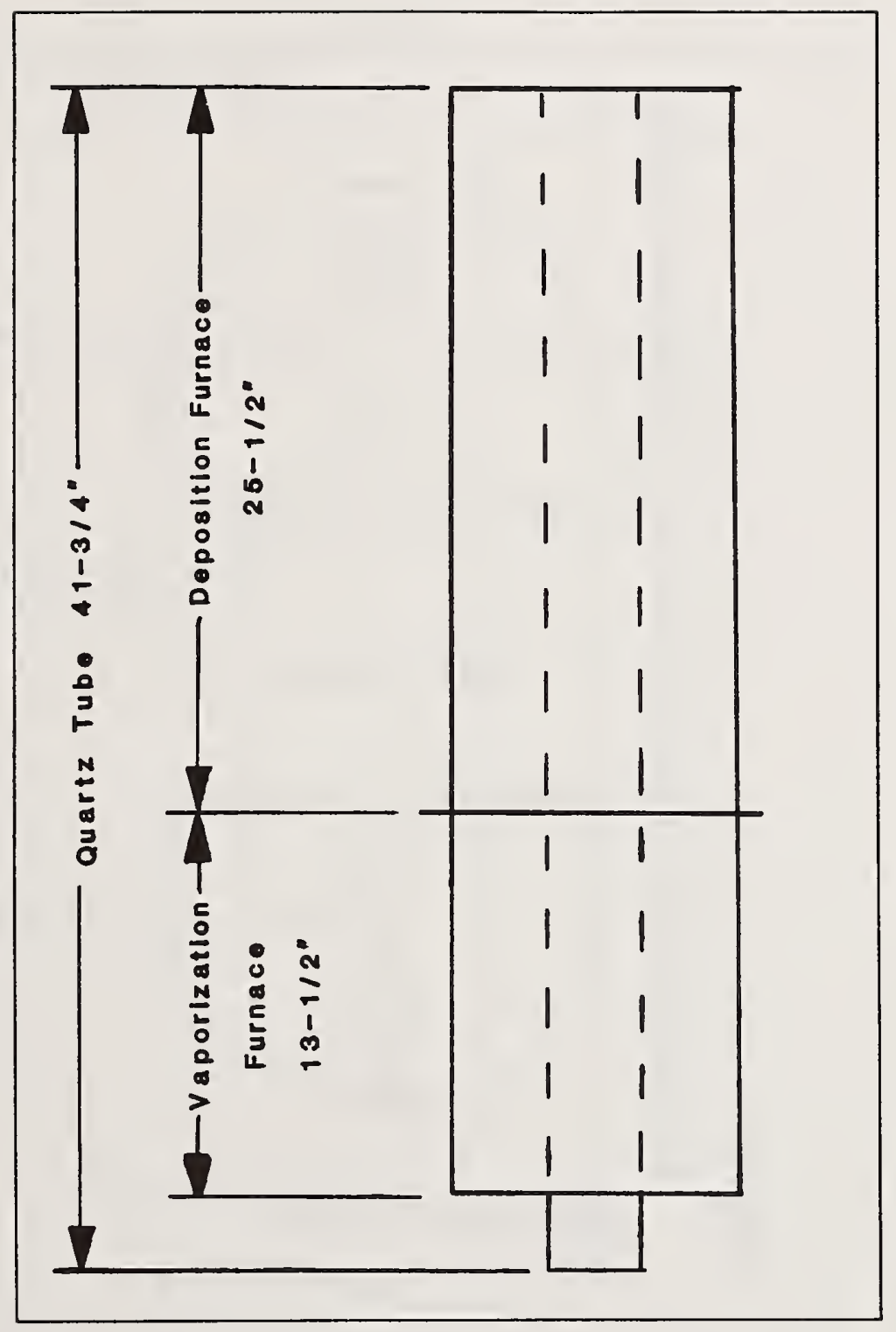

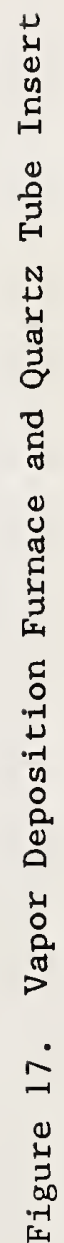




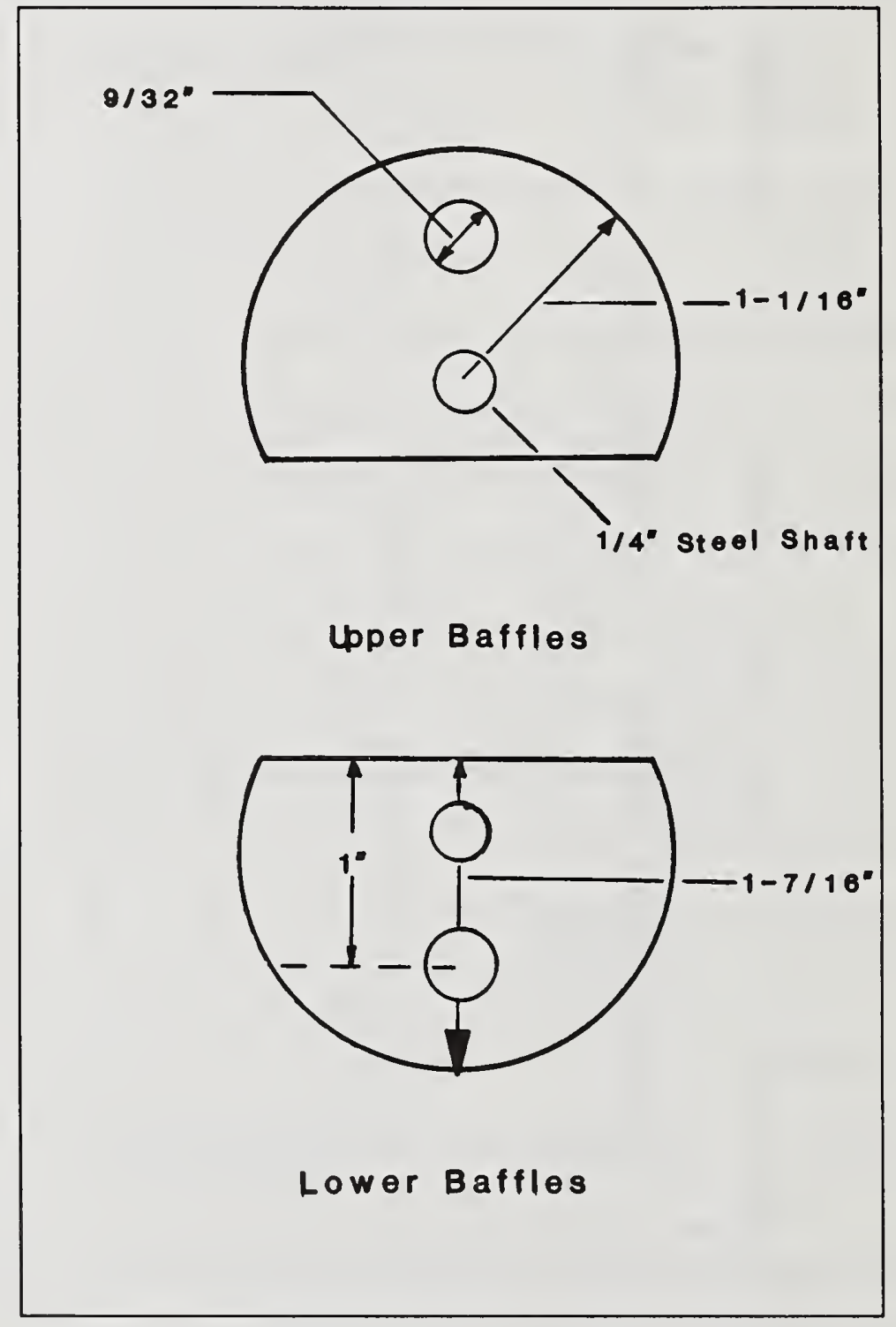

Figure 18. Upper and Lower Baffles 


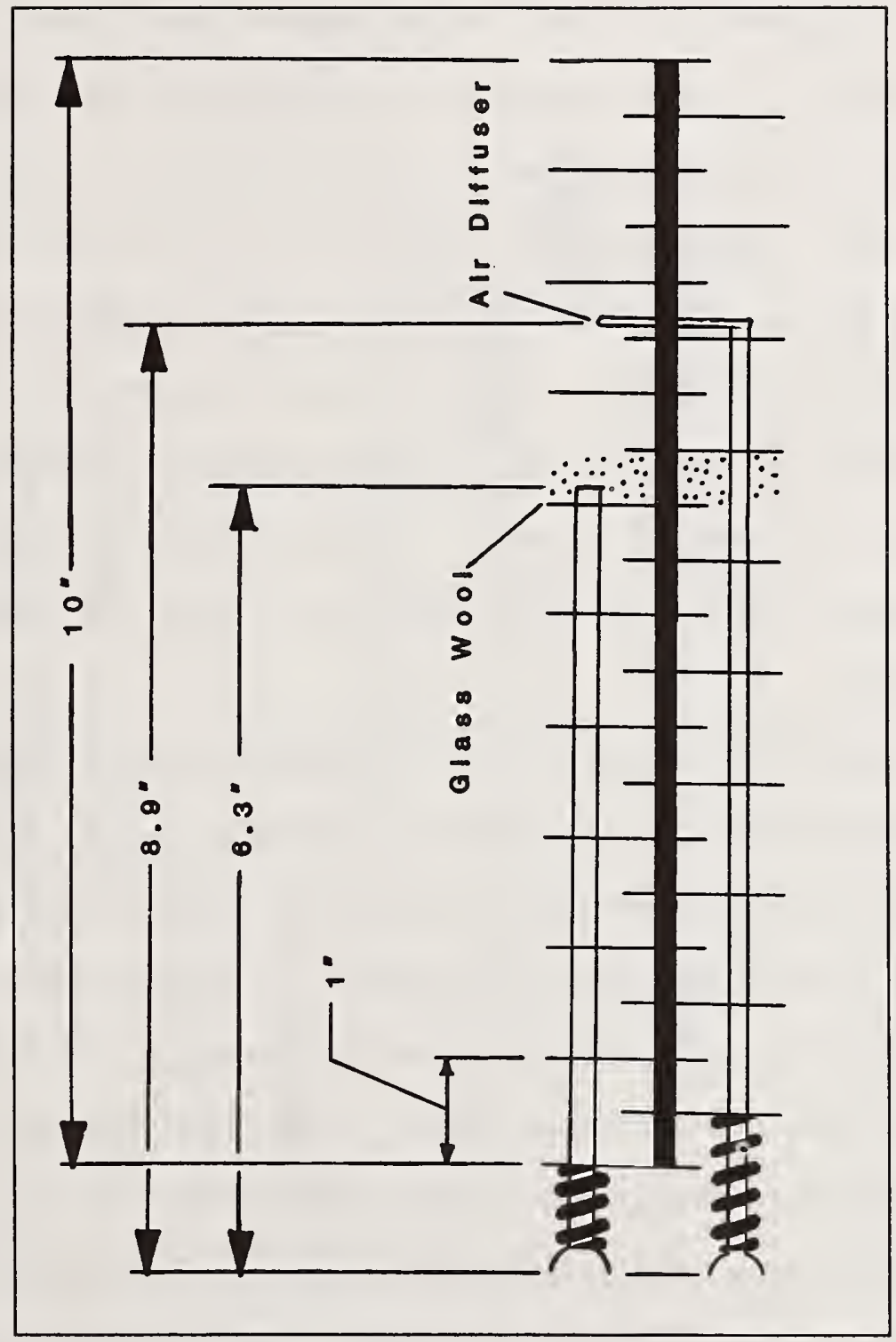

7
0
0
0
0
0
0
4
4
4
0
0
0
0
0
0
3
00
-1
5 
in the exchangers where the rule of thumb dictates a spacing greater than $1 / 5$ the tube diameter, but less than the tube diameter. The rest position of the baffle assembly within the quartz tube was achieved by making a dimple in the quartz tube which the baffle assembly would butt up against. The baffles and support shaft were constructed of 1020 steel. A small clearance existed between the baffles and the quartz tube. This accommodated the steel baffles greater thermal expansion. The steel was chosen because of its high thermal conductivity. The baffles contained a tube which allowed air to be introduced down-stream of the lubricant vaporization if oxygen studies were being conducted. The air tube ended in a loop which contained 10 holes evenly spaced around it. This feature provided a very uniform gas phase distribution of oxygen or any other gas introduced through the tube.

Lubricant was injected onto glass wool and contacted counter currently with the carrier gas. The glass wool provided a large surface area to allow fluid and carrier gas to develop intimate contact while counter current flow also provided more uniform vaporization. Figure 20 is a scale drawing of the front part of the quartz tube and baffle assembly. Controlled lubricant flow rates were introduced to the system using a syringe pump. A syringe was epoxied to a $12 / 1$ male ball joint; thus, allowing the syringe pump to be clamped to the lubricant inlet port. The lubricant flowed through a $1 \mathrm{~mm}$ diameter capillary tubing. The volume of the capillary within the baffle assembly was $0.120 \mathrm{~cm}^{3}$. The quartz tube was fitted with a $66 / 60$ female fused quartz ground joint. This joint was seated with a 


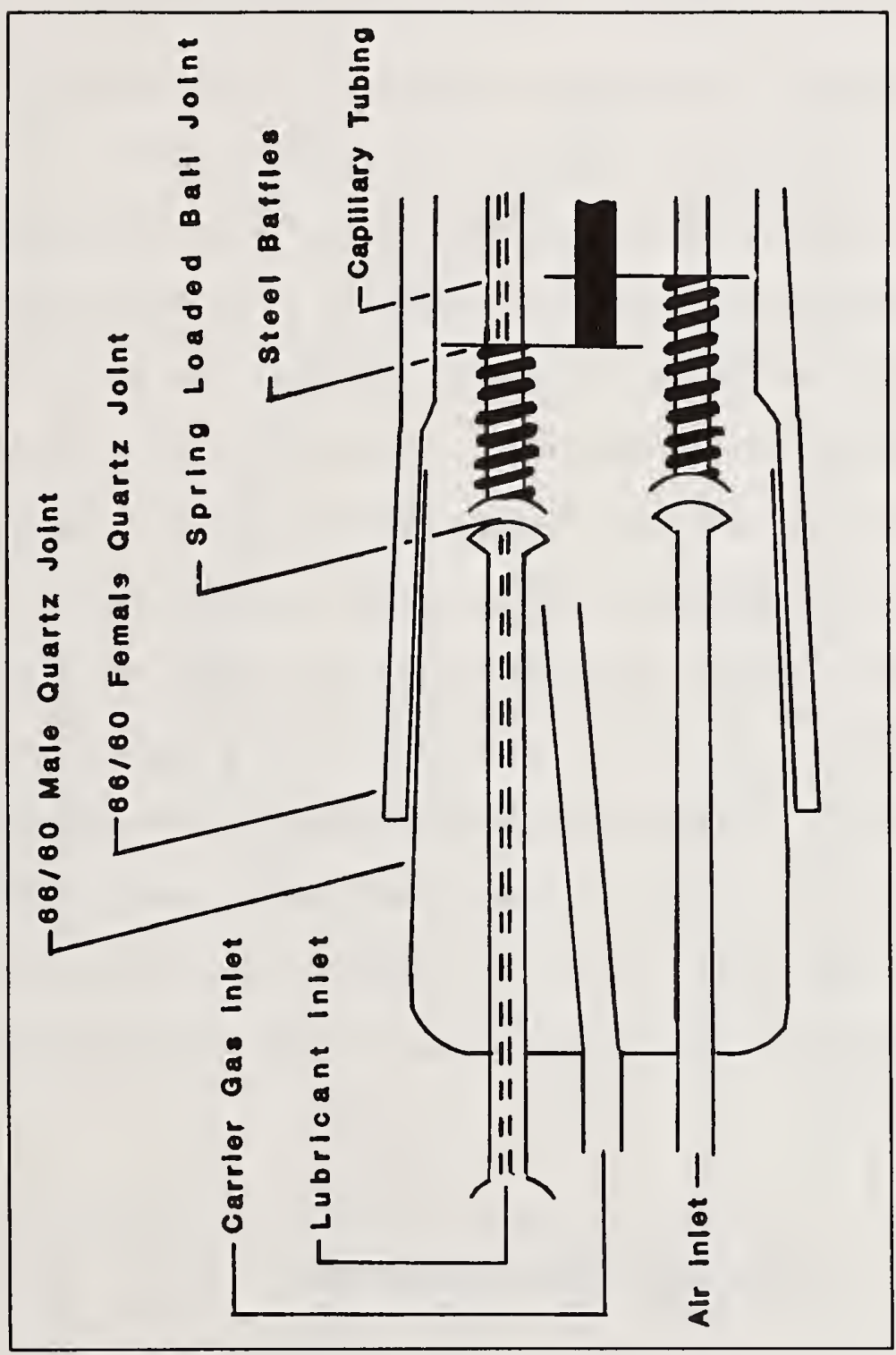

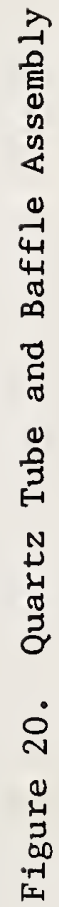


$66 / 60$ male fused quartz ground joint. When the ground joints were fitted together the lubricant and air supply tubes also seated. This was accomplished by using compression spring loaded female ball joints in the baffle assembly. These ball joints interfaced with the male ball joints of the quartz tube cap. Air and carrier gas lines were connected from flow meters to the indicated ports.

A typical temperature distribution for the deposition portion of the quartz tube is shown in Figure 21. In this experiment, the vaporization furnace was set at $300^{\circ} \mathrm{C}$ and the set point on the deposition furnace was $660^{\circ} \mathrm{C}$. The use of a plug of quartz wool improved the flat zone within the furnace. A uniform thermal flat zone existed between 9 and 14 inches from the end of the furnace. All deposition targets were placed in this region and a quartz wool plug was used for all tests. Figure 22 shows a comparison of the wall temperature to the center line temperature with the baffles not in place. The center line temperature and the wall temperature are nearly identical. This was a result of the slow carrier gas flow rates used for all tests and the low heat capacity of the gaseous mixture.

\subsubsection{Vapor Deposition Procedures}

The coating procedure was as follows. A clean wad of glass wool was put in the baffles where the lubricant would emerge from the capillary tube. The baffles were sled into the quartz tube and covered with the quartz tube cap. The syringe pump was connected to 


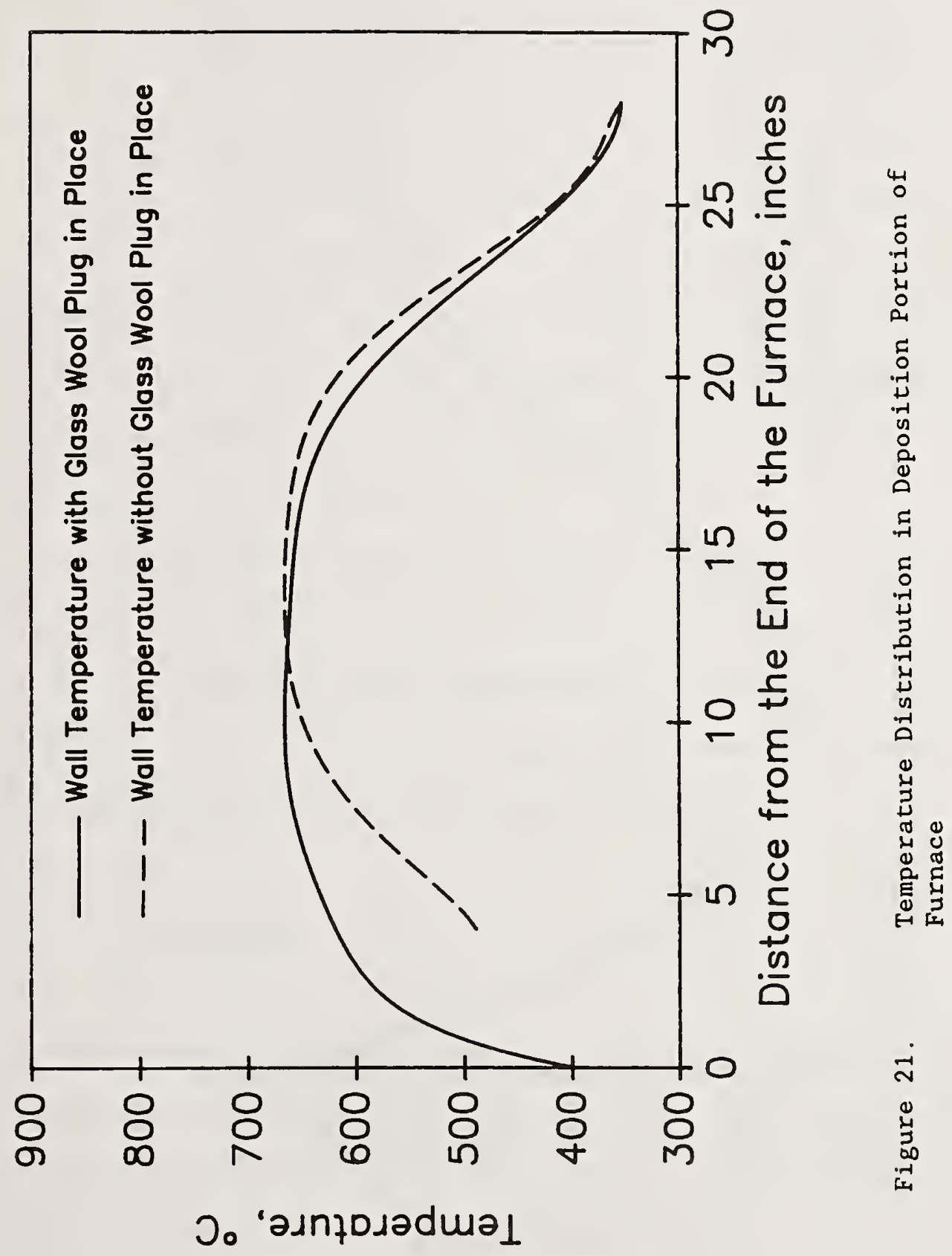




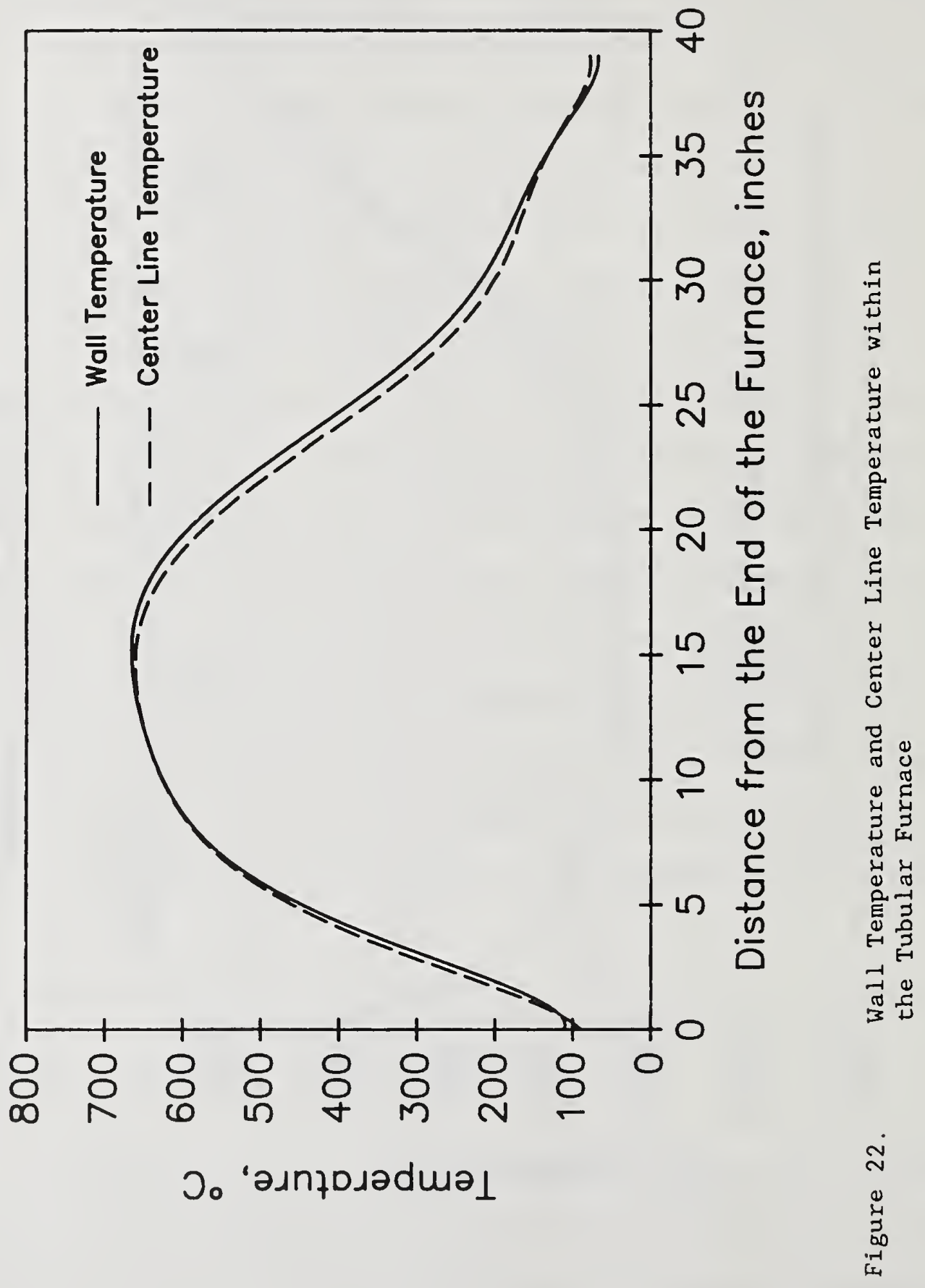


the quartz tube cap and the carrier gas line was connected. The air line was sealed with a plastic cap if oxygen studies were not being performed. Specimens were placed on a silica or alumina flat and slid into the hot zone. A quartz wool plug was put in the end of the tube and the tube was purged with carrier gas for 16 hours at a flow rate of $3 \mathrm{ft}^{3} / \mathrm{hr}$. The ovens were brought up to the desired temperatures over the next five hours. The flow rate was reduced to the test condition of $1.2 \mathrm{ft}^{3} / \mathrm{hr}(0.5 \mathrm{~cm} / \mathrm{s}$ at STP) for 1 hour and deposition was initiated. The sample was coated for a set time. The syringe pump was turred off; then, 30 minutes later the furnace was turned off to allow the samples to oven cool.

Vaporization temperature were chosen by using the vapor pressure chart for hydrocarbons from Meyers [91]. This chart accurately describes the vapor pressure-temperature relationship for phosphate esters. This was verified by comparing chart values to empirical equation results for tributyl phosphate [92].

\subsubsection{SEM Results}

The tubular furnace was used to study the vapor deposition of TBP on different ceramics. Because ceramic materials are not available in a wire form the TGA system could not be used to obtain kinetic data for the ceramics.

Two 1/4" diameter disks, 1/16" thick of $\mathrm{Si}_{3} \mathrm{~N}_{4}, \mathrm{Al}_{2} \mathrm{O}_{3}$, and $\alpha$-SiC were placed on a steel plate 1-1/2" wide and placed within the tubular furnace. The silicon nitride was Kyocera's type SN 220 from lot 6211 
number 8 . The alumina flats were Coors type AD998. This material is 99.8 percent alumina. The silicon carbide was Carborundum's $\alpha$-SiC from batch 2. The specimens were coated for 14 minutes at $700^{\circ} \mathrm{C}$ using $0.73 \%$ TBP. The specimens were oven cooled and the films were examined using an SEM. The micrographs were photographed with the specimens tilted $70^{\circ}$ to the surface normal. This provided an enhanced perspective to the surface film characteristics.

Figure 23 shows an SEM of the lubricant film formed on silicon nitride at a 10,000 and 20,000 fold magnification. The SEM photograph shows a uniform and shallow covering of global structure and much larger filamentous structures. EDAX spectra were taken in two areas in Figure 23 and displayed in Figure 24. The upper spectra was taken from the globular head of the filament in Figure 23. The second spectra was taken from away from the filament head and was representative of nonfilamentous background. The EDAX spectra reveal that the filament head contains iron, while iron was not present in other structures. The most likely source of this iron was from the steel plate which supported the ceramic samples. Because the steel plate was simultaneously coated during the deposition experiment, FeP could have been transported in the vapor phase from the steel tray into the ceramic substrate; thus, providing a source of iron atoms. Filament structures have not been observed in vapor deposition studies using aryl phosphate esters, but they have been observed when nonaromatic hydrocarbons are used. Thus, the alkyl chain of TBP may be responsible for the filamentous growths. This hypothesis is supported by liquid phase decomposition studies of phosphate esters. In the 


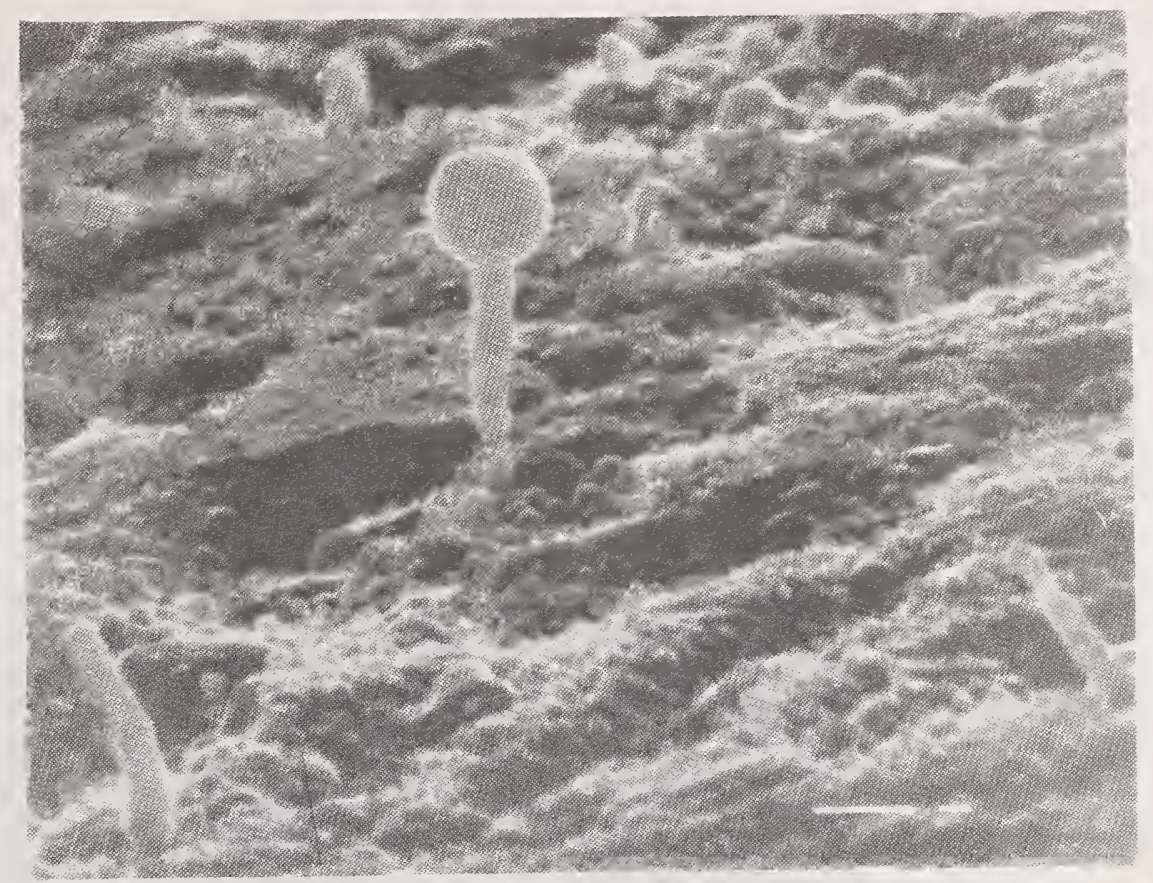

\section{a) $10,000 x$}

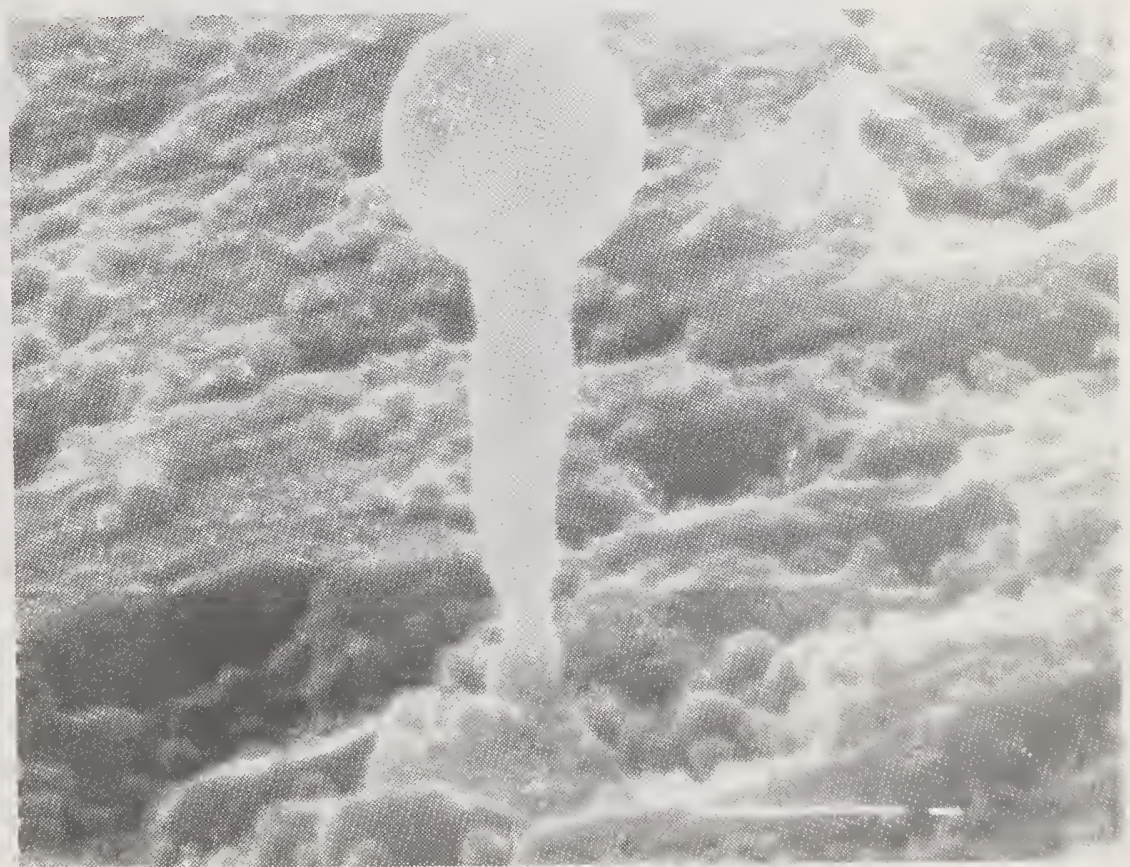

\section{b) $20,000 x$}

Figure 23. SEM Photographs of $\mathrm{Si}_{3} \mathrm{~N}_{4}$ Coated with $0.73 \%$ TBP at $700^{\circ} \mathrm{C}$ 

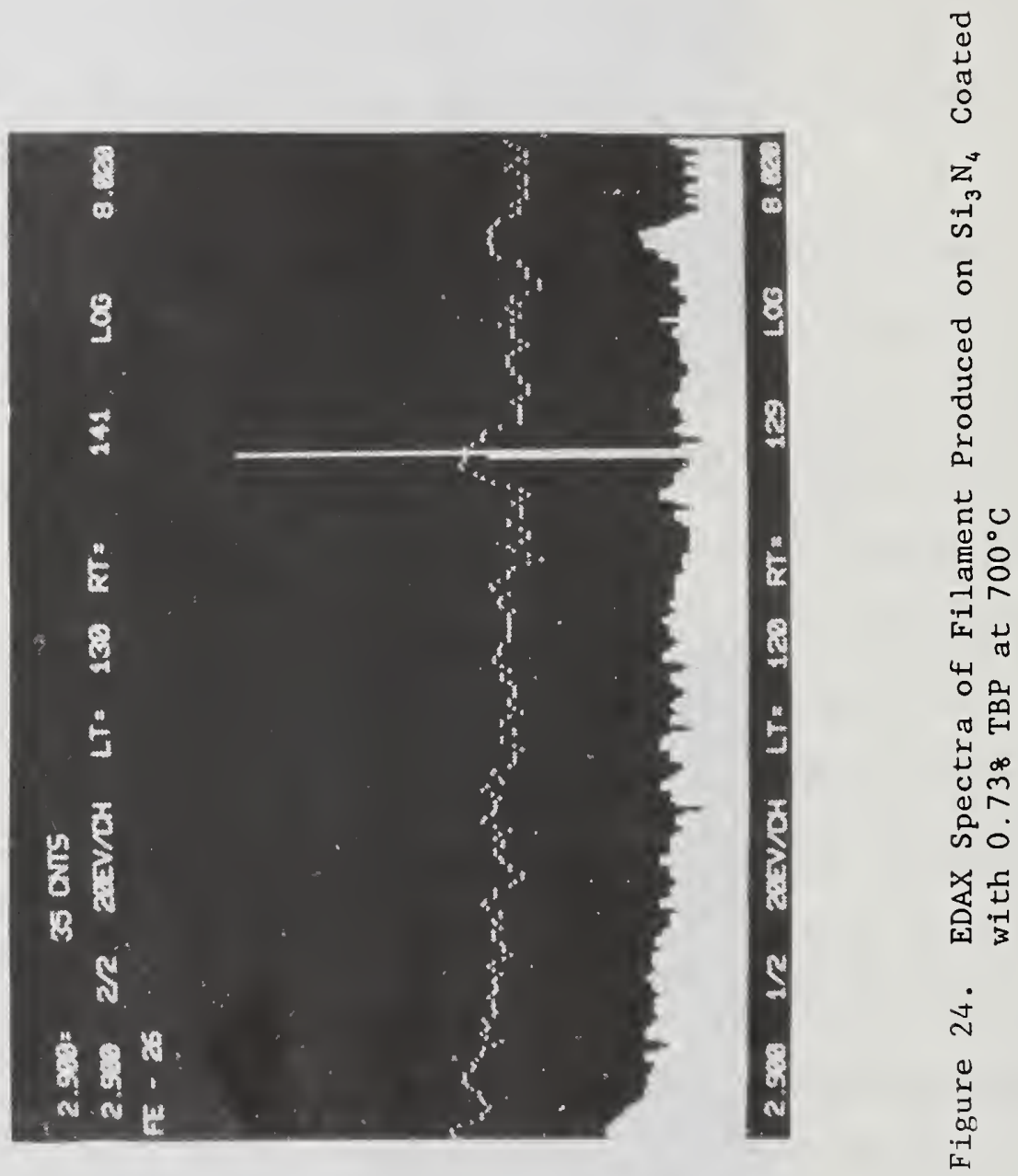
liquid phase Cho and Klaus [19] have shown that phosphate esters decompose forming $\mathrm{P}-\mathrm{O}-\mathrm{P}$ bonds in inert atmospheres. If this happens during vapor deposition, the alkyl substituent could be freed to react with the iron to form the filamentous structures.

Figure 25 shows a $\mathrm{Al}_{2} \mathrm{O}_{3}$ substrate which was coated with $\mathrm{TBP}$ at $3,000 \mathrm{x}$ and $10,000 \mathrm{x}$. Again filaments are formed, but they are different in nature than those produced on $\mathrm{Si}_{3} \mathrm{~N}_{4}$. The filaments are shorter and narrower.

Figures 26 shows the coatings formed on $\alpha$-SiC at $10,000 \mathrm{X}$ and 20,000X. This coating is distinctly different from the $\mathrm{Al}_{2} \mathrm{O}_{3}$ or $\mathrm{Si}_{3} \mathrm{~N}_{4}$. Both worms and globules are observed, but they are much smaller than those previously observed.

These experiments show that iron can effect the nature of films formed during vapor deposition. The fact that each ceramic formed films which had distinctly different features indicates that the deposition is not completely controlled by the iron. Thus the vapor deposition process is substrate sensitive for ceramics.

The formation of filamentous structures has been observed in coke formation studies. Carbon exhibiting growth as filaments can be produced in several ways. Catalyst particles have been observed at the filament top, filament base, or within the filament, depending on the substrate $[61,63,67-69]$. Table 15 displays these findings.

The mechanism for formation of filament with catalysts particles located at the growing tip has been detailed by Baker [61]. In general, it involves the adsorption of a hydrocarbon molecule, followed by decomposition. Carbon diffuses through the catalyst 


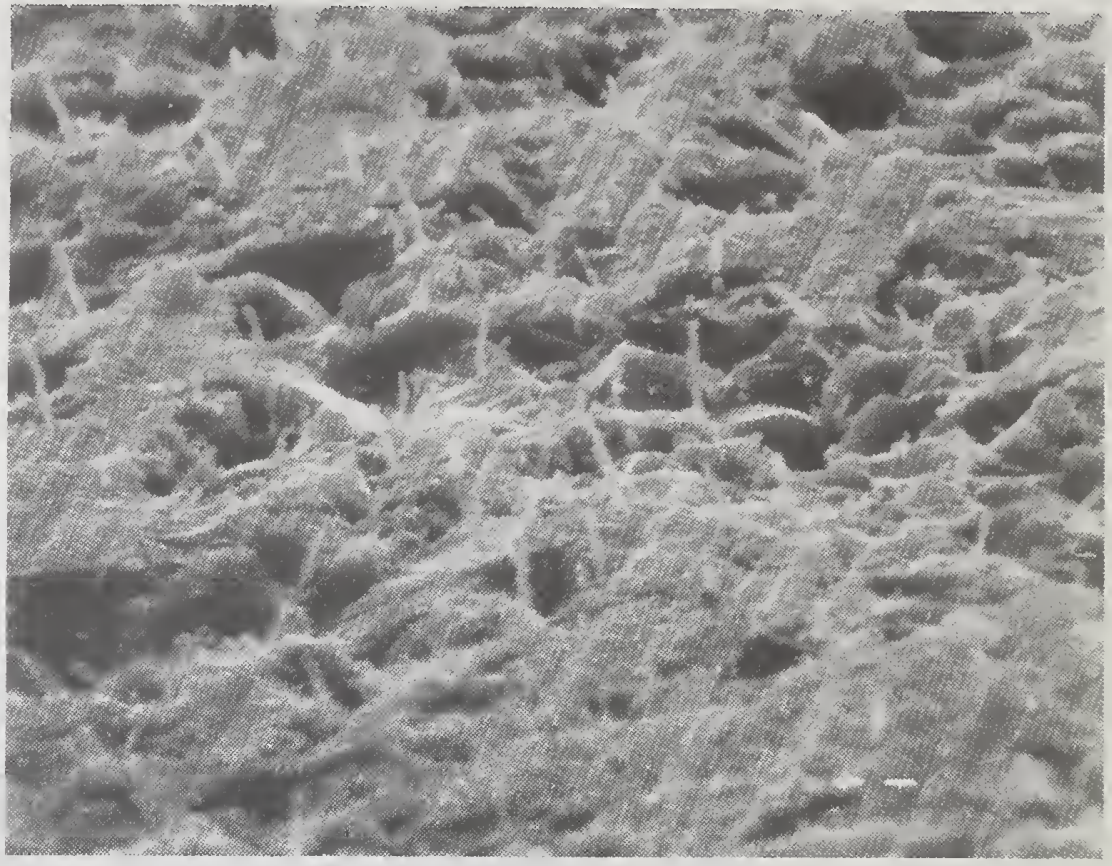

\section{a) $3,000 x$}

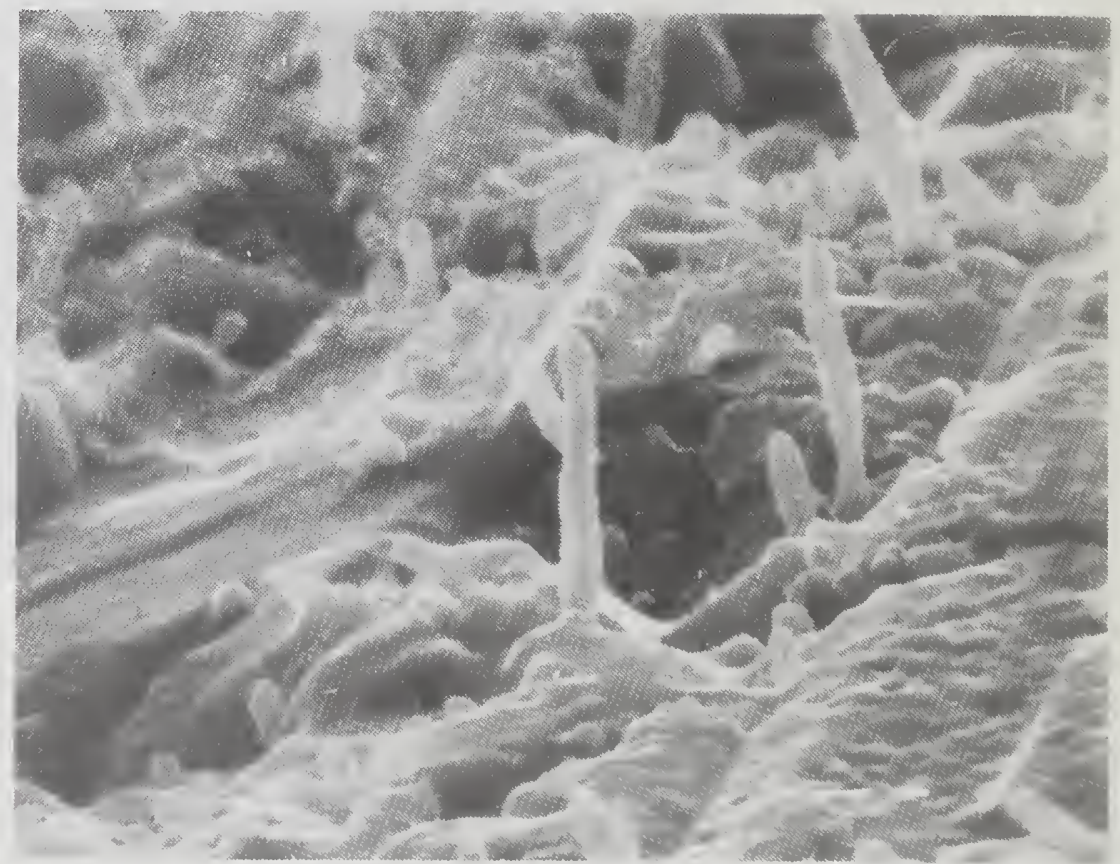

b) $10,000 x$

Figure 25. SEM Photographs of $\mathrm{Al}_{2} \mathrm{O}_{3}$ Coated with $0.738 \mathrm{TBP}$ at $700^{\circ} \mathrm{C}$ 


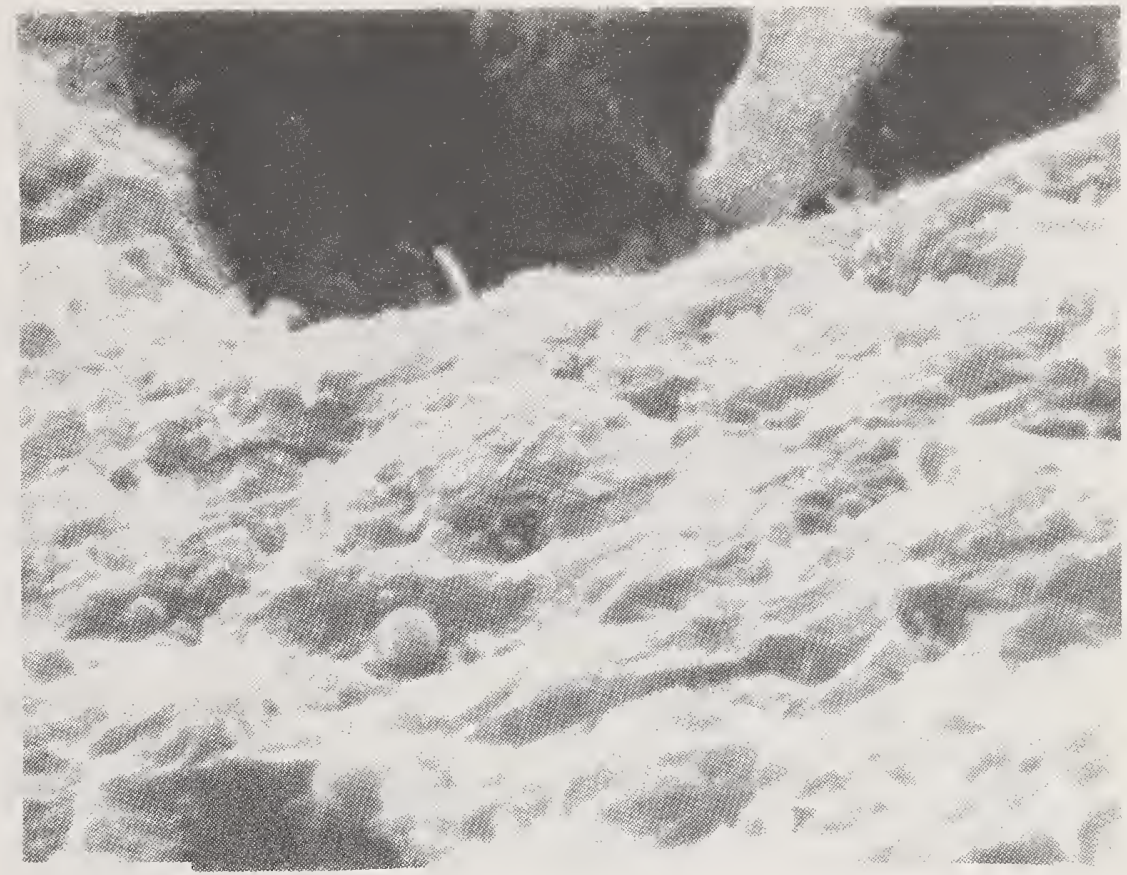

a) $10,000 x$

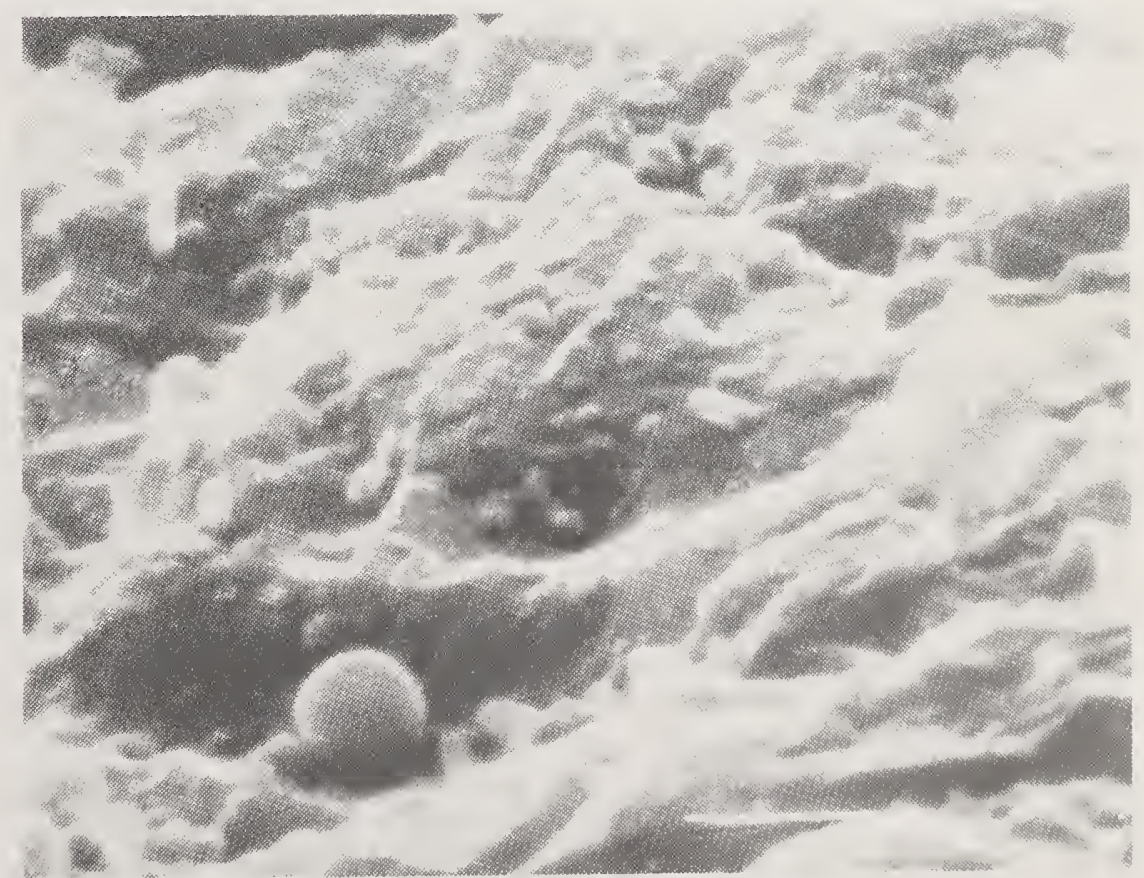

b) $20,000 x$

Figure 26. SEM Photographs of $\alpha-\mathrm{SiC}$ Coated with $0.73 \%$ TBP at $700^{\circ} \mathrm{C}$ 
Table 15. Location of Catalytic Particle within Filaments

\begin{tabular}{|l|c|c|}
\hline \multicolumn{2}{|l|}{ Catalyst Particle Position within Filaments } \\
\hline Base & Middle & Top \\
\hline $\mathrm{Fe}$ & & $\mathrm{FeO}$ \\
$\mathrm{Fe}_{2} \mathrm{O}_{3}$ & $\mathrm{TiO}_{2}$ & $\mathrm{Ni}$ \\
$\mathrm{Cr}$ & & $\mathrm{Co}$ \\
$\mathrm{Pt}-\mathrm{Fe}$ & & $\mathrm{Ni}-\mathrm{Fe}$ \\
\hline
\end{tabular}


particle and precipitates at the rear of the particle. Growth is terminated when diffusion is not rapid enough and the catalyst becomes encapsulated in carbon. This is diagrammed in Figure 27 . It is suggested that the rate determining step in this process is diffusion of carbon through the catalyst particle.

Table 16 shows activation energies observed for coke formation under varying conditions. In many instances, the observed activation energy agrees with the activation energy of diffusion of carbon through the catalyst. But this is not always true. Some authors even observed systems exhibiting a negative activation energy. This phenomenon can occur when equilibrium is established before the rate determining step and the reverse reaction has a larger activation energy than the forward reaction. Clearly, Table 16 shows that the rate controlling step in coke formation is specific to a combination of substrate, temperature, and reacting gases. Thus, many strong parallels exist between coke formation and vapor deposition.

This section has shown that vapor deposited films can be formed on ceramics. Impurities which are present can have a substantial influence on the type and amount of film which is formed. This also suggests that sintering aids and dopants commonly used in the processing of ceramics can be used to control vapor deposition film characteristics. Thus, the vapor lubrication of ceramics can be optimized by controlling the surface features of ceramic substrates to reduce friction and wear of rubbing contacts. This also suggests that on metal surfaces ion implantation can be used to achieve the desired 


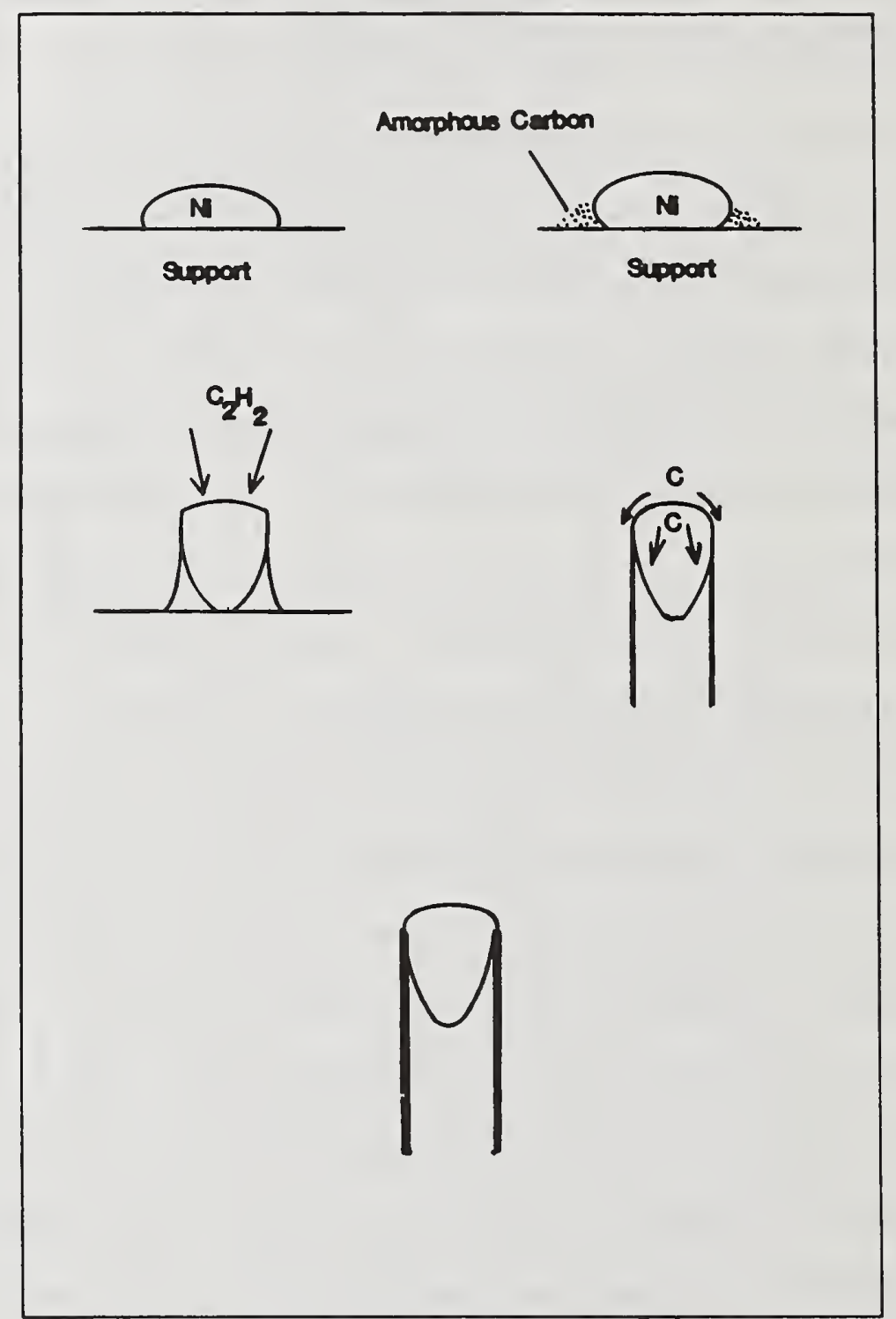

Figure 27. Stages in the Growth of Filaments with a Catalyst Particle in the Growing End 
Table 16. Activation Energies for Coke Formation on Various Substrates

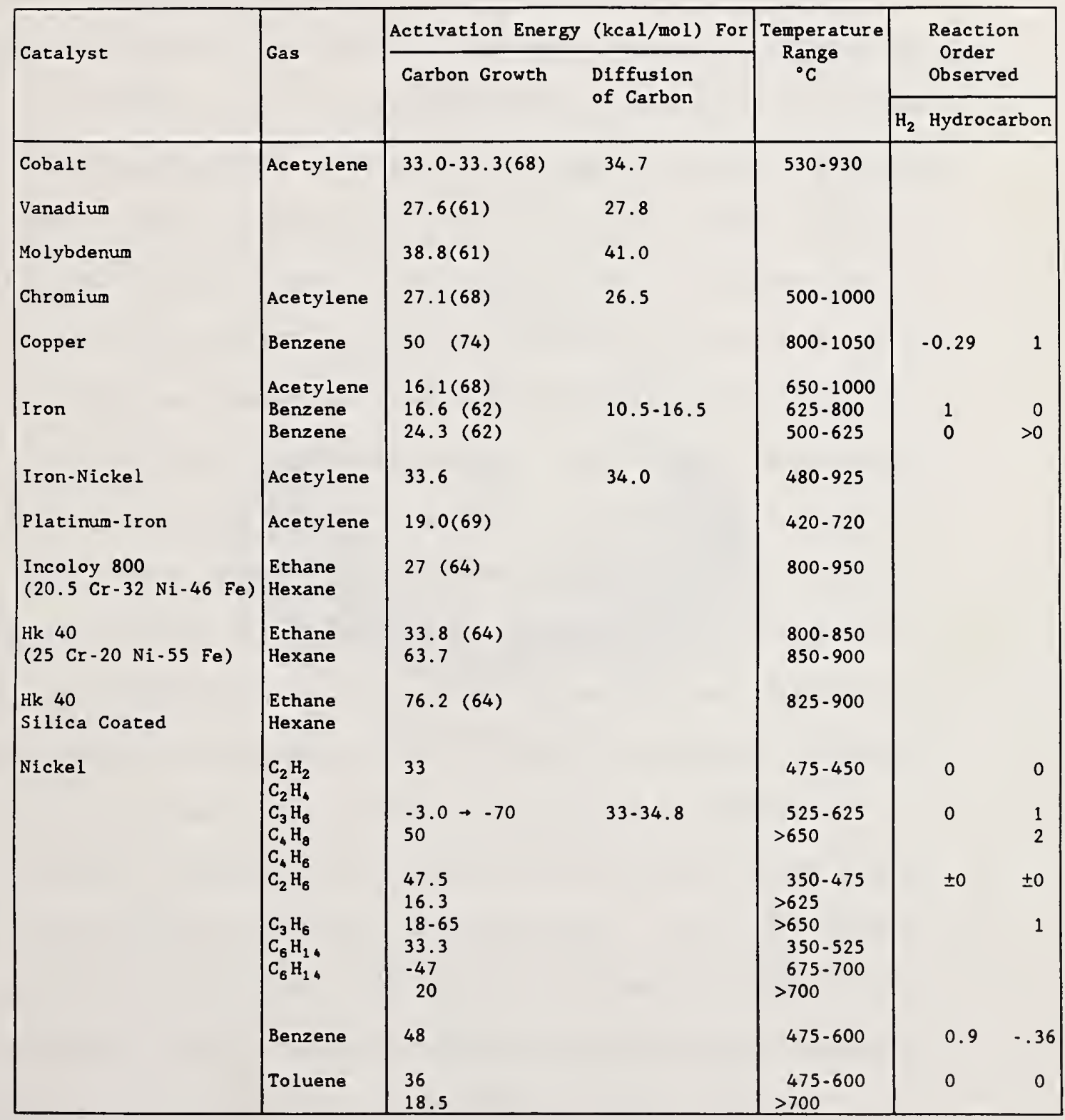


film formation characteristics of reduced friction and wear; thus, optimizing lubrication.

\subsubsection{Performance Testing Equipment}

The preceding section has shown that vapor deposited films form on ceramics. The next step was to determine if these films impart lubricious qualities during performance testing. Performance testing was done using two apparatuses. The first device was a ball on three flat wear tester. Figure 28 shows the geometry of this system which is very similar to a four ball tester. Flats, 1/16" thick and 1/4" in diameter were held in circular recesses within the flat holder displayed in Figures 29 and 30. The flat holder was screwed into a heated four ball test cup. A $1 / 2$ " diameter ball was held in a chuck. The chuck was driven by a rotating spindle at a given speed of rotation. The system was loaded with a pneumatic piston and frictional force was measured by monitoring the torque generated when the rotating ball contacted the flats. A standard four ball wear tester is displayed in Figure 31 illustrating many of these features.

The second performance tester used was a slow speed sliding device which could operate at elevated temperatures. Figure 32 displays this unit. The components included a variable motor driven slide capable of speeds up to $2 \mathrm{~cm} / \mathrm{min}$. The specimen holder was a stainless steel ball bearing holder which was attached to the slide via a frictional force transducer. The test sample was contained within a brick insulated oven heated by SiC heating elements. A $1 " \mathrm{x}$ 
81

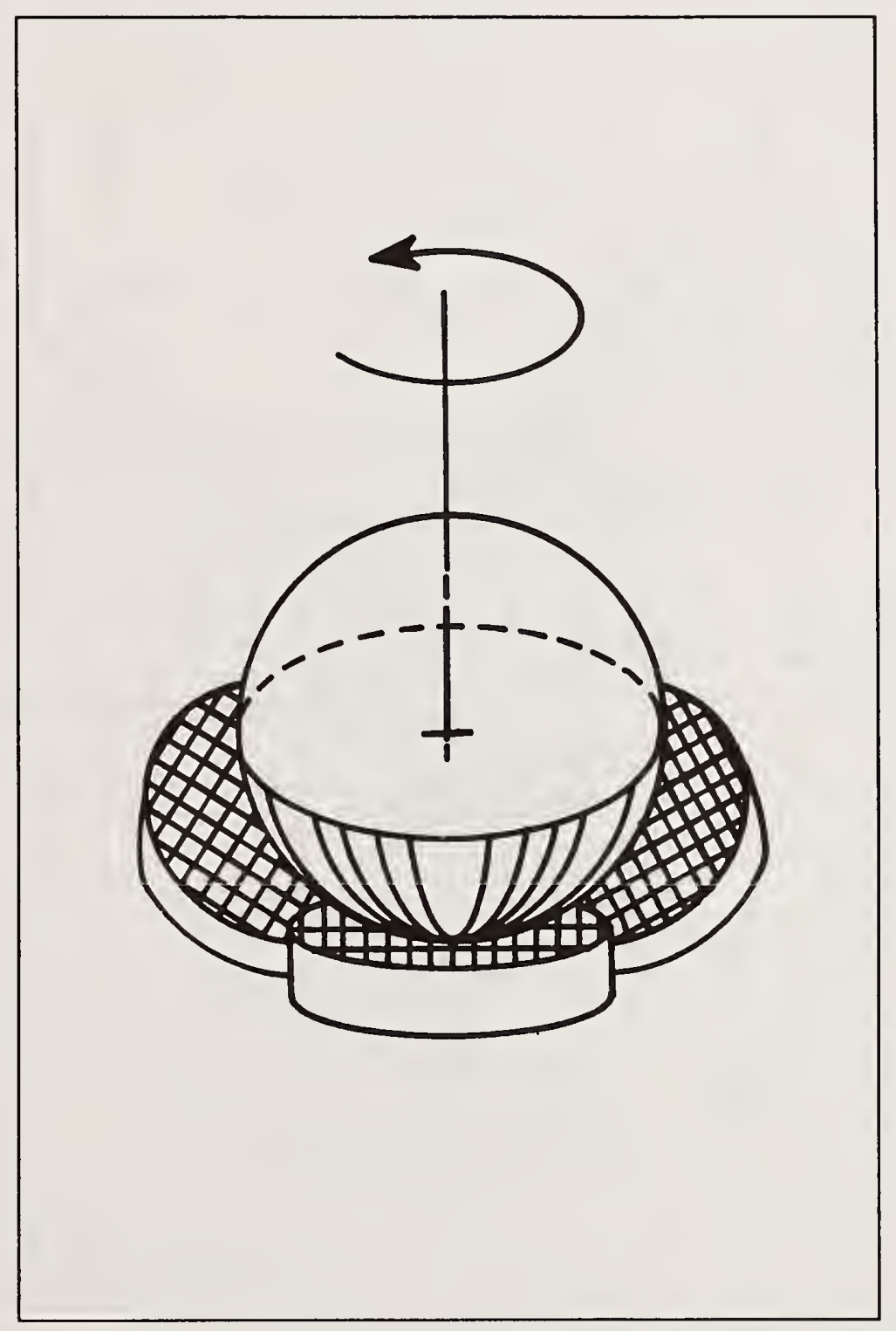

Figure 28. Ball on Three Flat Geometry 


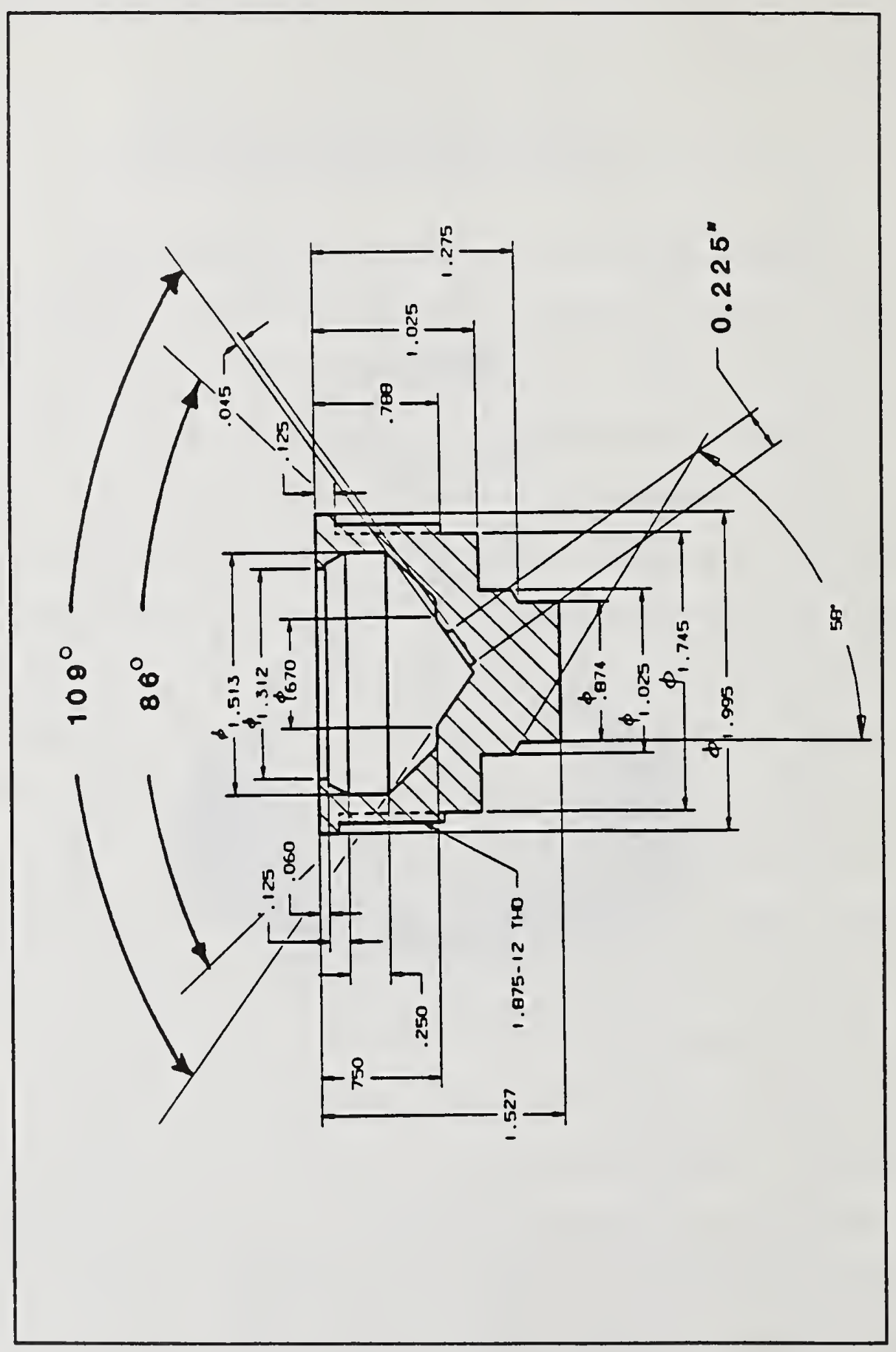

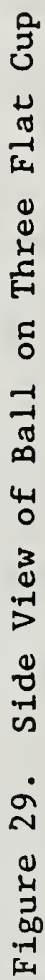




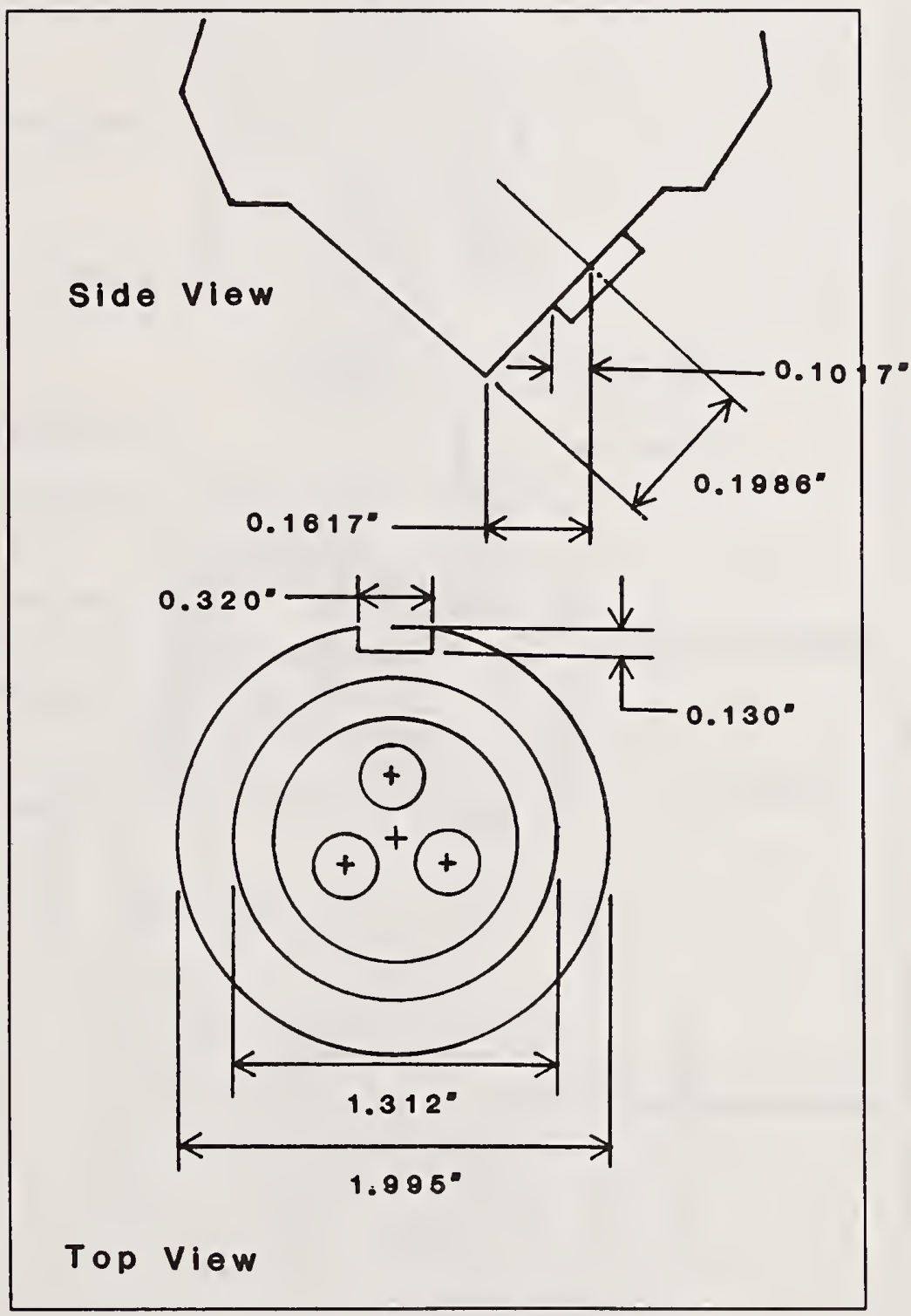

Figure 30. Top and Side View of Ball on Three Flat Cup 


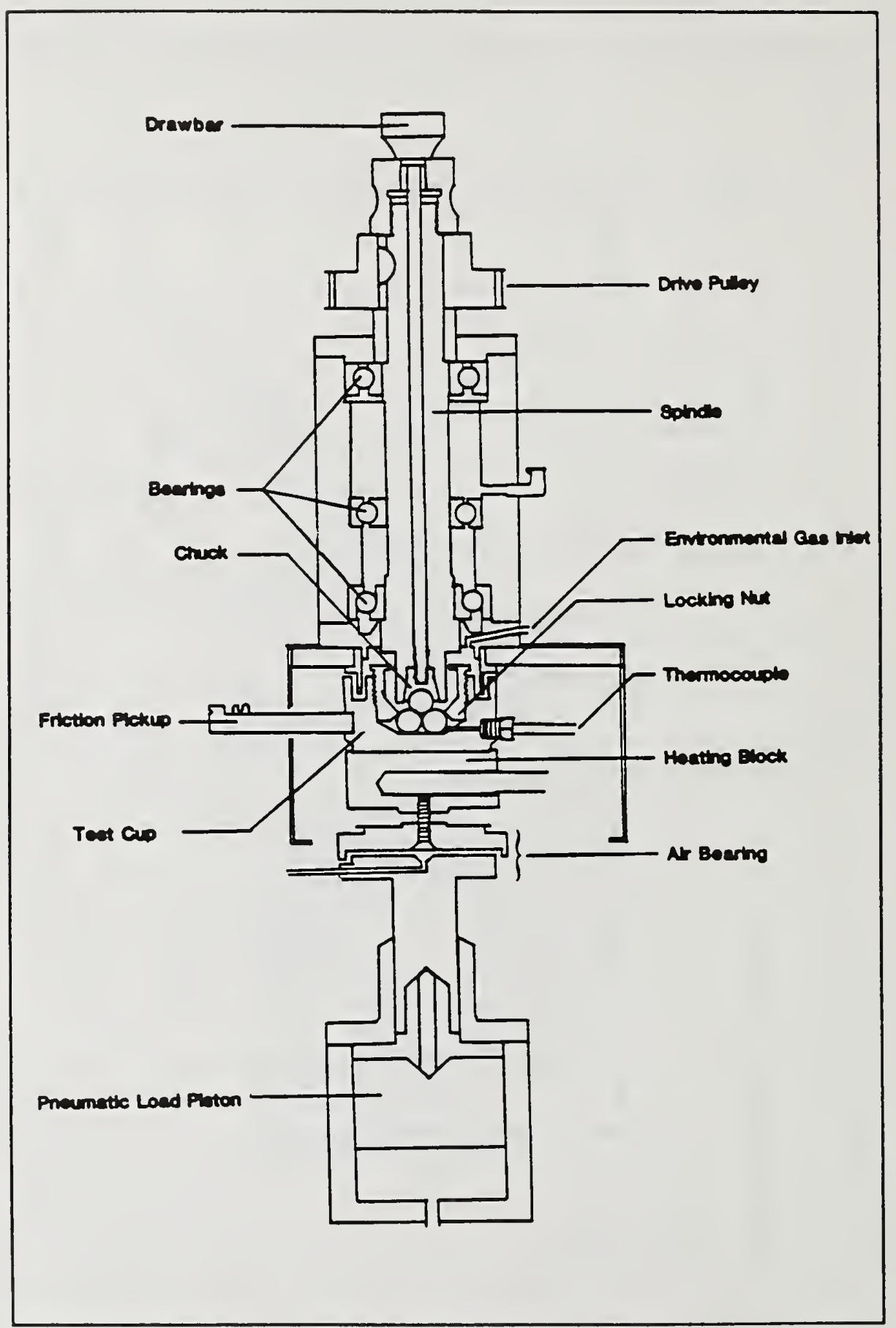

Figure 31. Four Ball Wear Tester 


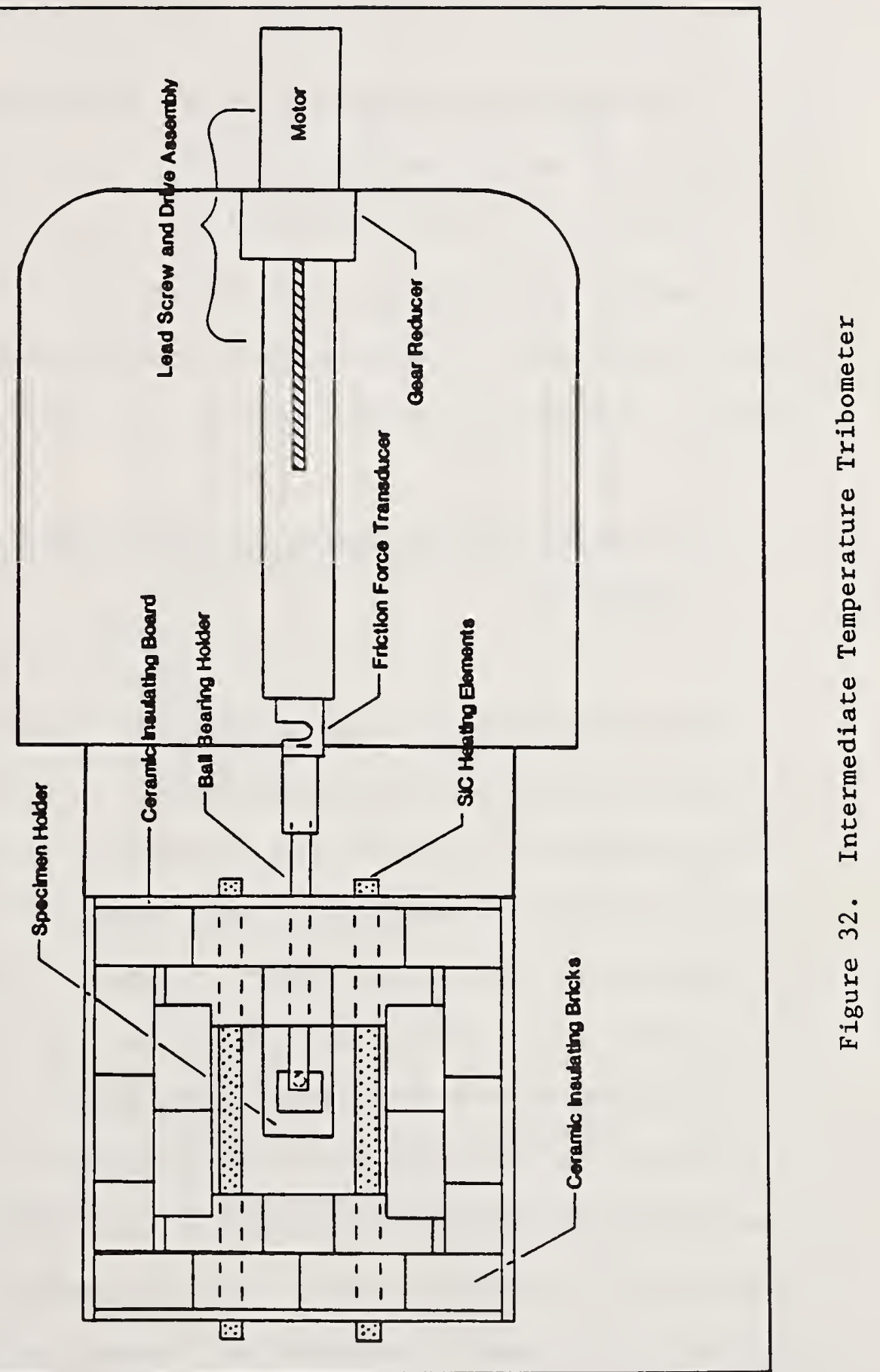


1-3/4" $\mathrm{x} 0.060 "$ alumina specimen was placed within the alumina specimen holder shown in Figure 33. The ball bearing holder with the ball bearing in place was connected to the friction transducer so that the ball would contact the far end of the specimen flat. The ball bearing holder and ball bearing supplied a $16 \mathrm{~N}$ force to the specimen. With the specimen in place and loaded, the top of the oven was covered with ceramic insulating brick. The furnace was turned on and when the desired temperature was reached the motor was turned on, initiating the test. Frictional force was recorded on a strip chart recorder.

\subsubsection{Ball Bearing Holder Design for the Intermediate Temperature Tribometer}

Performance testing in the intermediate temperature tribometer was done using a ball on flat configuration. This geometry was selected because of simplicity and availability of flats and existing supplies of 1/2" ball bearings. A ball bearing holder was designed and constructed. This holder, shown in Figure 34, was designed so that ceramic balls could be tested from room temperatures to $1000^{\circ} \mathrm{C}$. This was accomplished by constructing the holder with a $10^{\circ}$ taper. This follows the guidelines detailed in "Machinery's Handbook" [93], where tapers must be less than $16^{\circ}$ to be self holding. The rod material was 304 stainless steel. This was chosen because of availability and ease of construction. Because the steel has a higher coefficient of expansion than most ceramics, a thermal expansion calculation was performed detailing the bearing position in the holder 


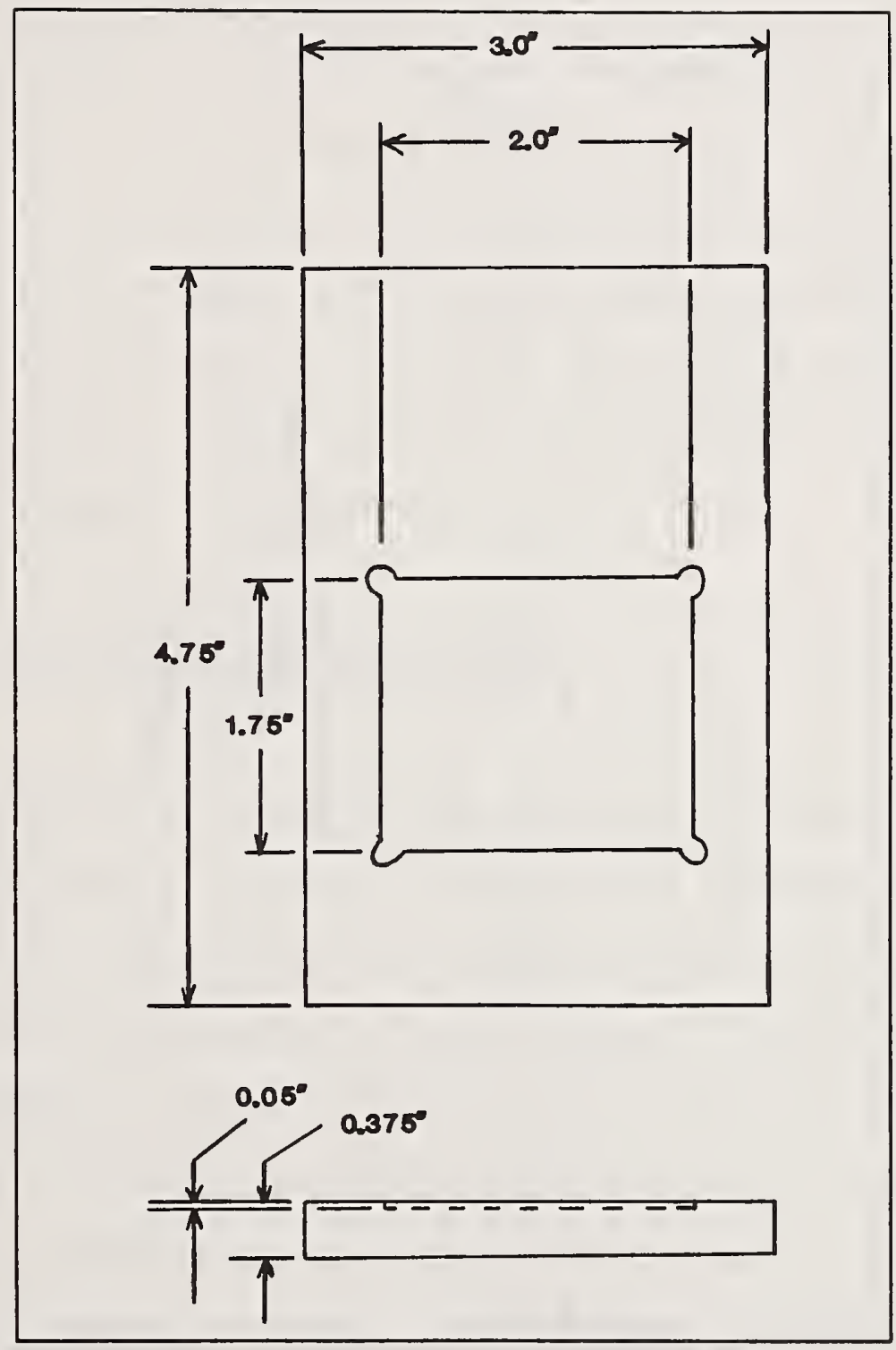

Figure 33. Alumina Specimen Holder Used in the Intermediate Temperature Tribometer 


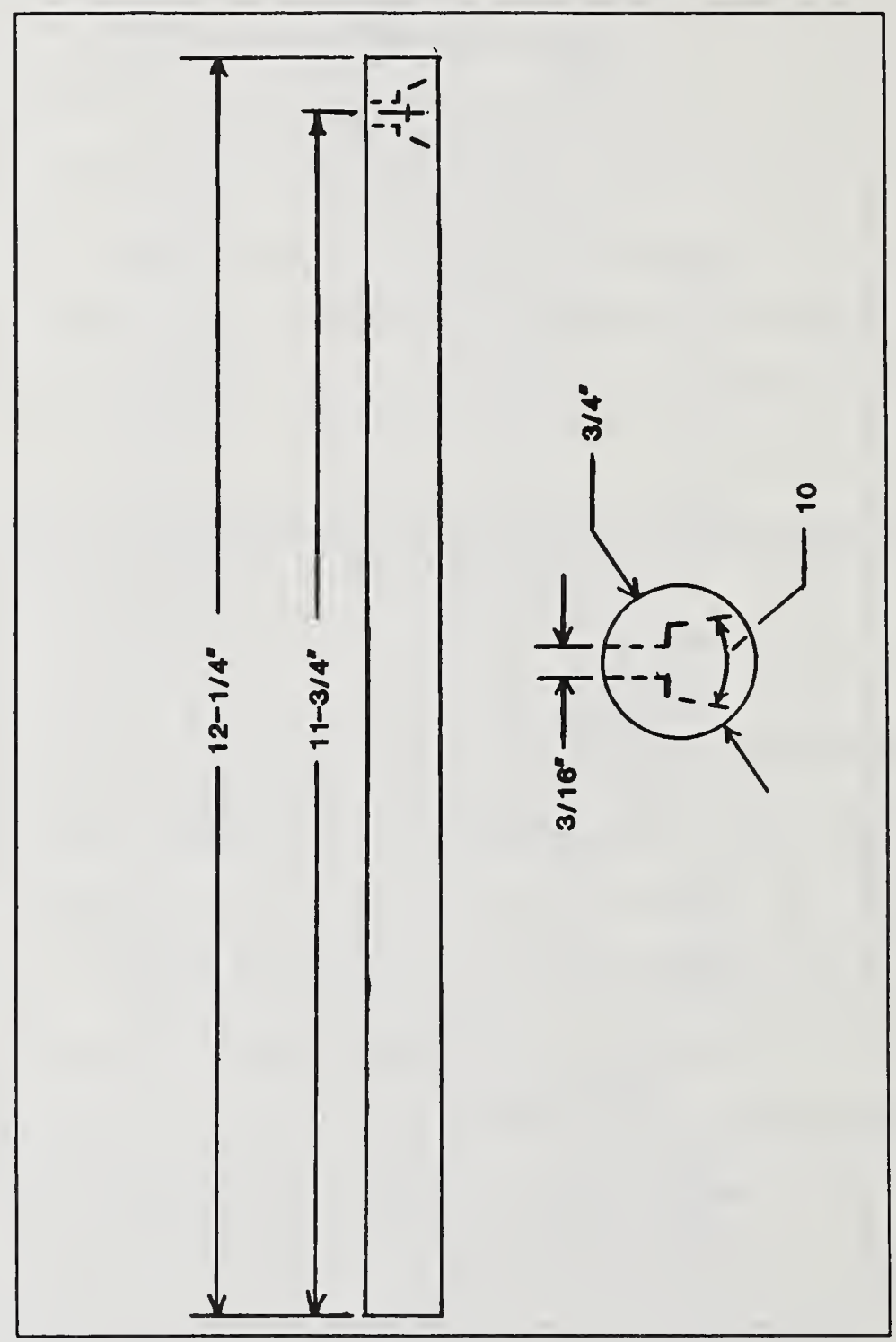

D 
at $1000^{\circ} \mathrm{C}$. Table 17 gives the thermal coefficient of expansion for several ceramics and the 304 stainless steel. The coefficient of expansion for $\alpha$-SiC was chosen for design calculations because it had the largest difference with the stainless steel. Because of the tapered design a possibility existed that materials with a lower coefficient of thermal expansion might completely slip into the holder. Thus any design suitable for the $\alpha$-SiC would be suitable for materials with higher coefficients of thermal expansion. Figures 35 and 36 show the position of an $\alpha$-SiC ball bearing within the holder at 25 and $1000^{\circ} \mathrm{C}$. Clearly, this design accommodates ceramic ball bearings from 25 to $1000^{\circ} \mathrm{C}$.

\subsubsection{Sample Preparation Development}

Having established that vapor deposition coatings form on ceramics, the next step was to conduct some performance tests on $\mathrm{Al}_{2} \mathrm{O}_{3}$. But before conducting ceramic performance testing a cleaning procedure was developed for oxide ceramics. The purpose of this was to minimize the affect of any contaminant films during performance testing. The following procedure was developed to prepare $\mathrm{Al}_{2} \mathrm{O}_{3}$ disks for wear testing in the previously described ball on three flat wear tester. Alumina rod stock, 1/4" in diameter, was held in a vise which was mounted on a magnetic stand. Specimens were cut to an approximate thickness of $0.070^{\prime \prime}$ using a diamond cut off wheel. Each disk had a small burr on one side. This was a remnant of the cutting process. Batches of 37 disks were mounted with the burr side up on a steel 
Table 17. Coefficient of Thermal Expansion for Three Advanced Ceramics and Stainless Steel

\begin{tabular}{|l|c|}
\hline Material & $\begin{array}{c}\text { Coefficient of Linear Thermal Expansion, } \\
\mathrm{cm} / \mathrm{cm}{ }^{\circ} \mathrm{C}\end{array}$ \\
\hline $\mathrm{Al}_{2} \mathrm{O}_{3}$ & $8.28 \times 10^{-6}$ \\
$\alpha-\mathrm{SiC}$ & $3.96 \times 10^{-6}$ \\
$\mathrm{Si}_{3} \mathrm{~N}_{4}$ & $4.57 \times 10^{-6}$ \\
304 Stainless Steel & $19.8 \times 10^{-6}$ \\
\hline
\end{tabular}




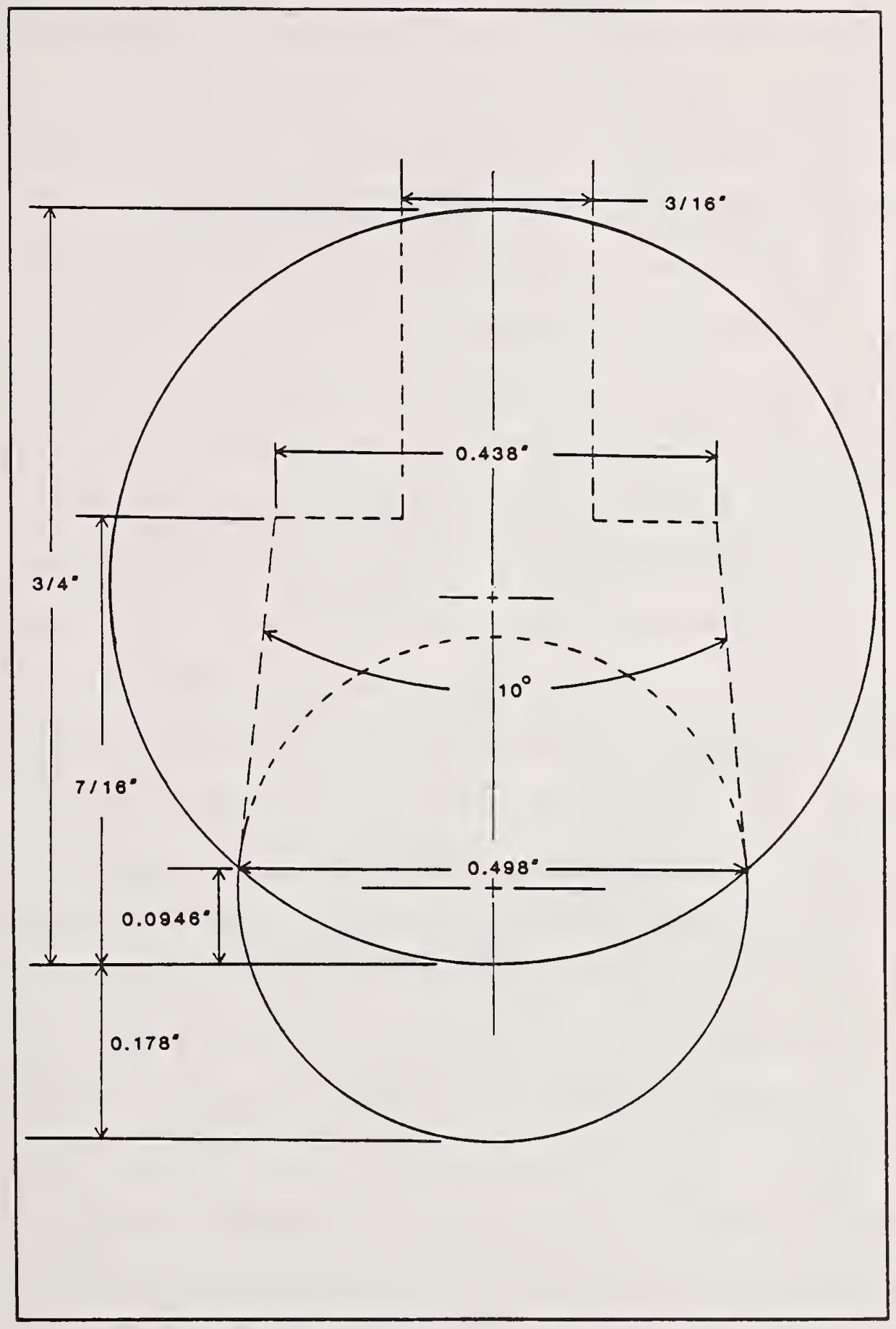

Figure 35. $\alpha-\mathrm{SiC}$ Ball in a Stainless Steel Ball Bearing Holder at $25^{\circ} \mathrm{C}$ 


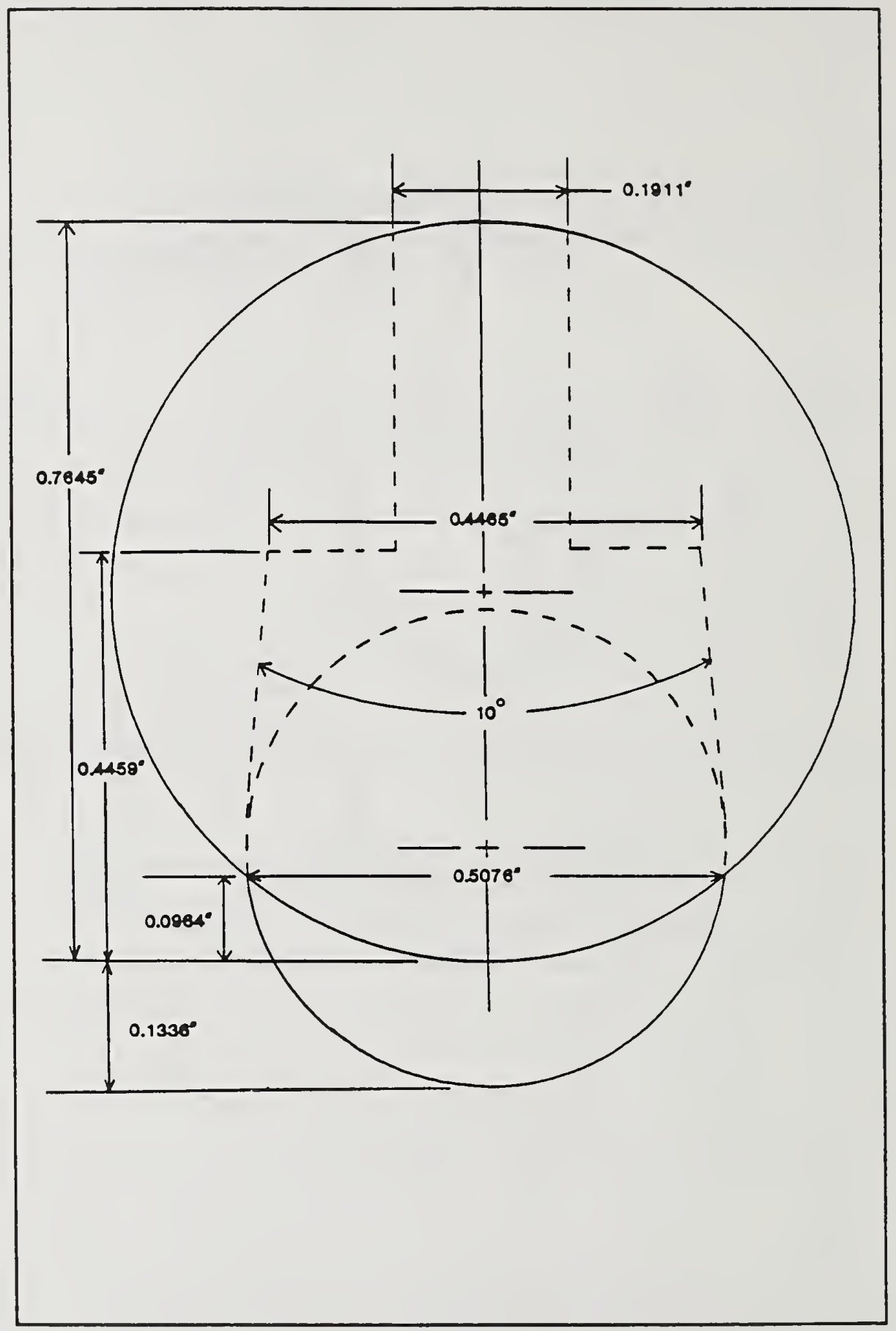

Figure 36. $\alpha$-SiC Ball in a Stainless Steel Ball Bearing Holder at $1000^{\circ} \mathrm{C}$ 
polishing mount. The disks were attached with a high temperature wax. The polishing mount was then placed on the magnetic stand and the diamond cut off wheel was replaced with a $3 / 4$ " wide diamond grinding wheel. The burrs were ground off and the disks were surface ground to a thickness of $0.065^{\prime \prime}$. The polishing mount was removed from the magnetic stand and taken to an automatic polishing wheel. Automatic polishing results in a nondirectional surface finish on the specimens. First a $30 \mu$ diamond impregnated grinding wheel was used followed by a $6 \mu$ diamond impregnated grinding wheel. Specimens were then lapped using 9,6 , then 3 , and finally $1 \mu$ diamond powder. At the conclusion of each lapping step, the specimens were examined using a stereomicroscope. This was done to assure that all scratches from previous polishing steps had been removed. The specimens were removed from the polishing mount by heating the mount on a hot plate until the mounting wax melted. Residual wax was removed by placing the specimens in acetone. Uniformity of specimens was verified by measuring the thickness of each disk with calipers and sizing the disks. Figure 37 shows an SEM photograph of a cleaned and polished specimen at $3,000 \mathrm{X}$ and $10,000 \mathrm{X}$. The scale bar markers in lower left corner of Figure 37 display a unit length for size comparison. The left most mark represents the unit length. The number of marks, $n$, after the first mark indicates how many microns the unit length represents. The general formula is: unit length $=10^{\mathrm{n}-1}$ microns. Thus the first markers in Figure $37 \mathrm{a}$ and $37 \mathrm{~b}$ represent 1 micron. During the alumina sample preparation procedure, the specimens are contacted with numerous contaminants. Table 18 shows a partial 


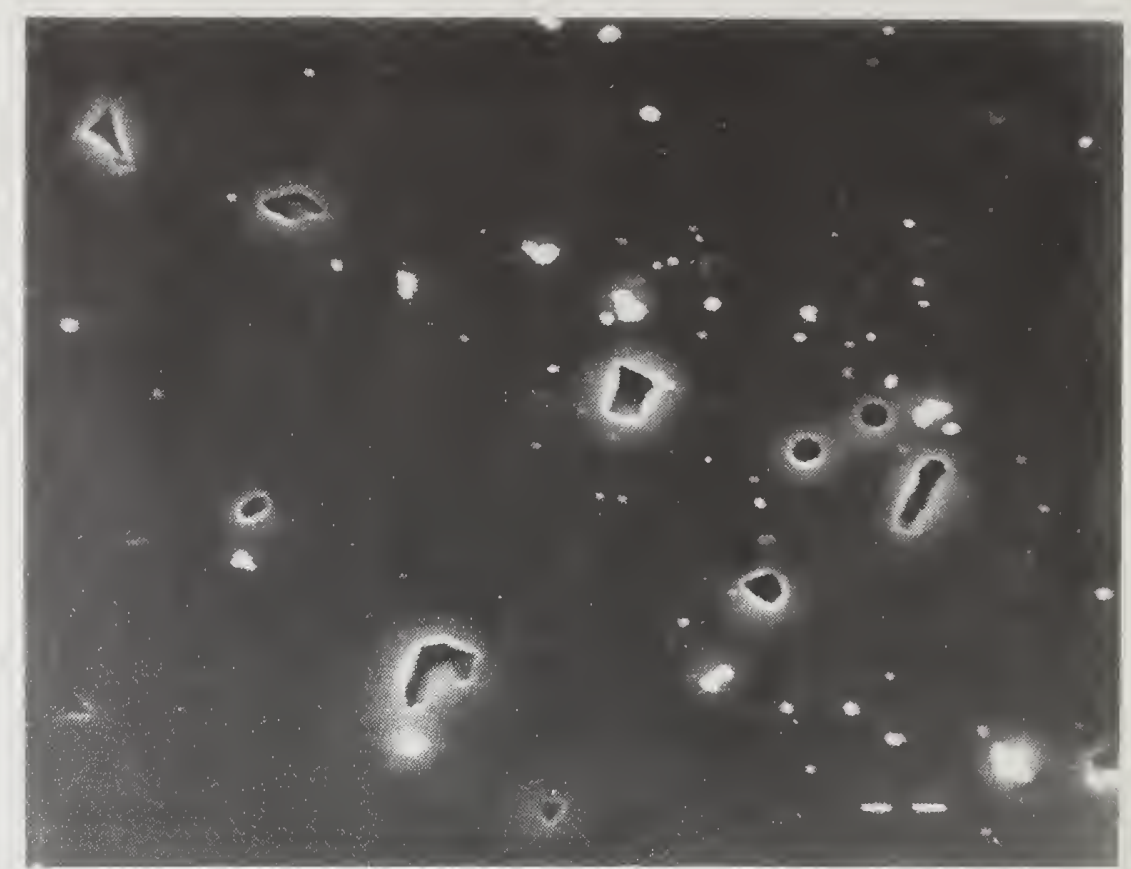

a) $3,000 x$

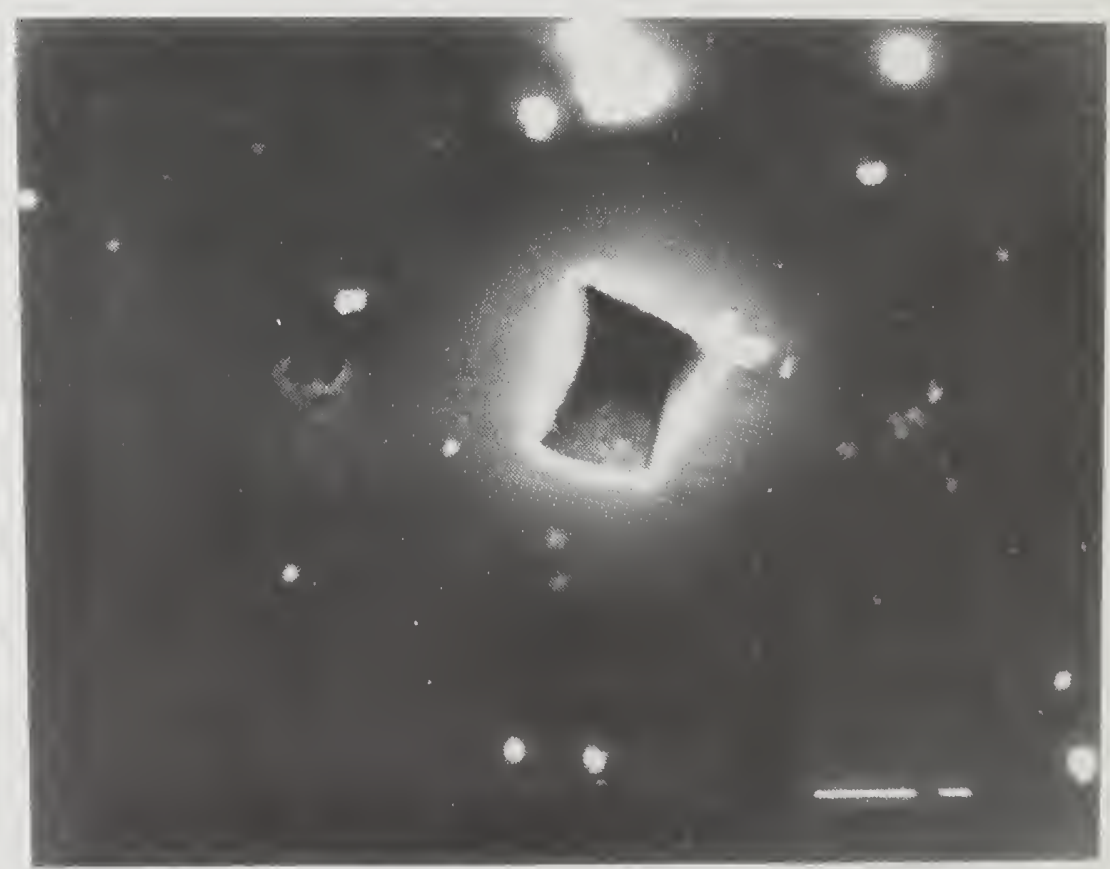

b) $10,000 x$

Figure 37. SEM Photographs of a Polished $\mathrm{Al}_{2} \mathrm{O}_{3}$ Specimen 
Table 18. List of Possible Contaminants in the Sample Preparation of $\mathrm{Al}_{2} \mathrm{O}_{3}$ Specimens

\begin{tabular}{|l|l|}
\hline Contaminants & \multicolumn{1}{|c|}{ Comments } \\
\hline Cutting Fluid & $\begin{array}{l}\text { Semi-synthetic borate amine soap } \\
\text { contains no S, Cl, N, or phenolics } \\
\text { Contains paraffin oil, mineral seal oil, } \\
\text { and lard oil }\end{array}$ \\
$\begin{array}{l}\text { Diamond Abrasive } \\
\text { Diamond Carrier Paste } \\
\begin{array}{l}\text { Solvent Residuals } \\
\text { Odsorbed Gases }\end{array}\end{array}$ & Water and carbon dioxide \\
\hline
\end{tabular}


list of these materials. To ascertain if significant surface contamination was occurring, an alumina sample disk rinsed with a series of solvents was examined using ESCA. The prominent carbon peak in Figure 38 reveals substantial carbon remained after the solvent rinsing. Also the carbon was still prominent after 10 minutes at sputtering at $3 \mathrm{KeV}$ indicating that the carbon contamination is not elemental in nature. Thus the cutting fluid and the lapping oil were the most likely source of carbon contamination. A solubility study was conducted on these fluids in 5 different solvents. One $\mathrm{ml}$ of solvent was placed in a $5 \mathrm{ml}$ Erylmeyer flask. A $20 \mu \ell$ aliquot of oil was added to the flask. The system was given 5 minutes to achieve equilibrium, then the solution was examined visually to see if the system contained only one phase. If only one phase was evident, oil was added until $0.5 \mathrm{ml}$ of oil had been added. Tables 19 and 20 display these results.

Table 19 shows that all fluids except methanol had an excellent solubility for the lapping oil. Table 20 indicates that only pyridine had adequate solubility for the cutting fluid. Therefore, pyridine was chosen as the proper solvent to rinse the alumina specimens. Several other cleaning techniques were explored and the carbon remaining was determined using ESCA and Auger spectroscopy. Table 21 presents these results. Samples with high carbon contaminations discolored when examined by the Auger beam. Sputtering the specimen surface for 10 minutes removed approximately $30 \AA$ of material. A majority of carbon resided in this top $30 \AA$. Figure 38 demonstrates the effect of sputtering. The carbon peak is reduced and oxygen and 


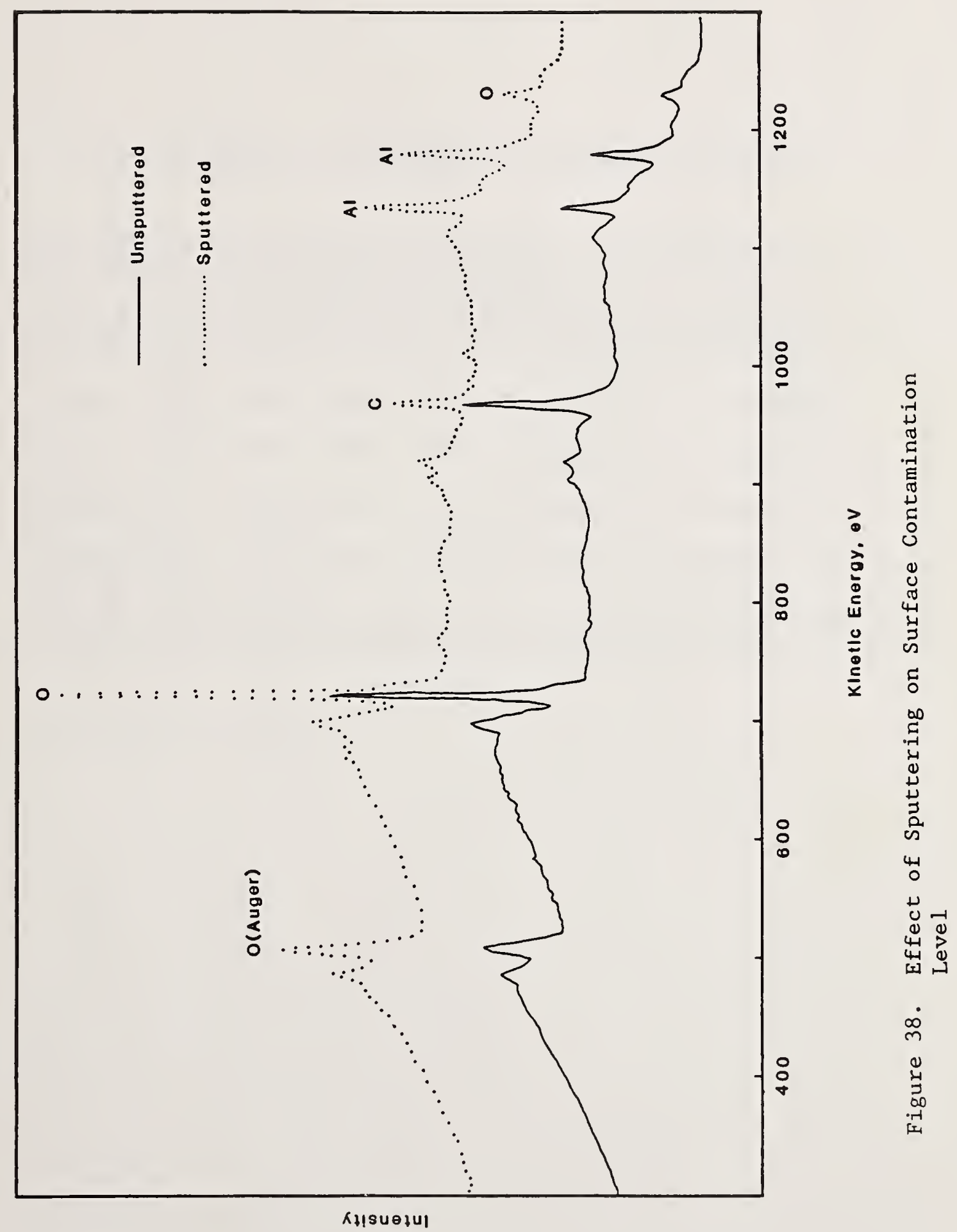


Table 19. Solubility of Lapping Oil in Various Solvents

\begin{tabular}{|l|cccccccccc|}
\hline \multirow{2}{*}{ Solvent } & \multicolumn{7}{|c|}{ Ratio of Volume Oil to Volume Solvents } \\
\cline { 2 - 10 } & 0.02 & 0.04 & 0.06 & 0.08 & 0.1 & 0.2 & 0.3 & 0.4 & 0.5 \\
\hline \multirow{2}{*}{ MEK } & Yes & Yes & Yes & Yes & Yes & Yes & Yes & Yes & Yes \\
Hexane & Yes & Yes & Yes & Yes & Yes & Yes & Yes & Yes & Yes \\
Pyridine & Yes & Yes & Yes & Yes & Yes & Yes & Yes & Yes & Yes \\
Methanol & Yes & Yes & Yes & Yes & Yes & Yes & Yes & Yes & Yes \\
\hline
\end{tabular}


Table 20. Solubility of Cutting Fluid in Various Solvents

\begin{tabular}{|c|c|c|c|c|c|c|c|c|c|}
\hline \multirow[b]{2}{*}{ Solvent } & \multicolumn{9}{|c|}{ Ratio of Volume Oil to Volume Solvents } \\
\hline & 0.02 & 0.04 & 0.06 & 0.08 & 0.1 & 0.2 & 0.3 & 0.4 & 0.5 \\
\hline MEK & & & & & & & & No & \\
\hline THF & & & & & No & No & No & No & No \\
\hline Hexane & & & & & No & No & No & No & No \\
\hline Pyridine & & & & & Yes & Yes & Yes & Yes & Yes \\
\hline Methanol & Yes* & Yes* & Yes* & Yes* & Yes* & Yes* & Yes* & Yes* & No \\
\hline
\end{tabular}

*Stable emulsion formed. 


\begin{tabular}{|c|c|c|c|c|c|c|c|c|}
\hline 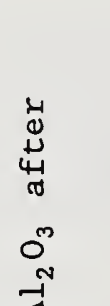 & 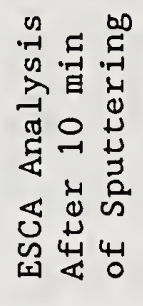 & $\begin{array}{l}\text { ๙ } \\
\text { ㅇ }\end{array}$ & $\begin{array}{l}\hat{n} \\
0 \\
0\end{array}$ & $\begin{array}{l}\text { O } \\
\text { ป } \\
0\end{array}$ & $\begin{array}{l}8 \\
\text { ¿ } \\
\text {. }\end{array}$ & \begin{tabular}{l}
0 \\
\multirow{1}{*}{} \\
$\stackrel{0}{0}$
\end{tabular} & $\begin{array}{l}\text { N } \\
\stackrel{N}{0}\end{array}$ & \begin{tabular}{l}
$\infty$ \\
\multirow{0}{0}{} \\
0
\end{tabular} \\
\hline 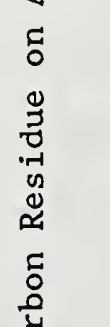 & 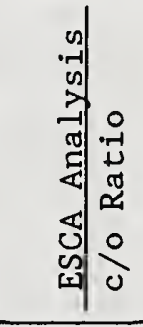 & in & $\underset{0}{ت}$ & \begin{tabular}{l}
\multirow{2}{0}{} \\
0
\end{tabular} & $\begin{array}{l}\infty \\
\text { n? } \\
0\end{array}$ & \begin{tabular}{l}
9 \\
\hdashline \\
0
\end{tabular} & $\stackrel{n}{\sim}$ & $\stackrel{7}{7}$ \\
\hline 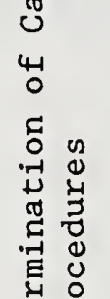 & 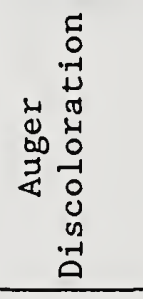 & $\bigotimes_{\nu=1}^{\infty}$ & z & 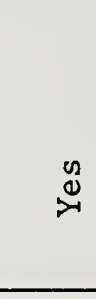 & 之 & $\stackrel{0}{z}$ & $\stackrel{\circ}{z}$ & $\stackrel{\circ}{z}$ \\
\hline 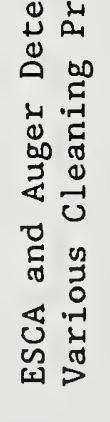 & 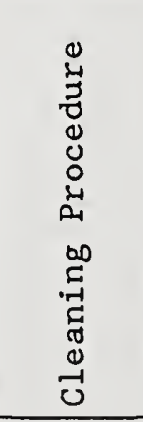 & 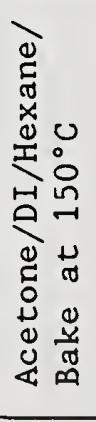 & 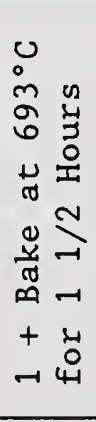 & 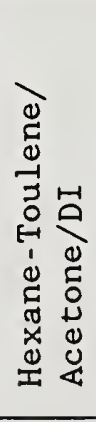 & 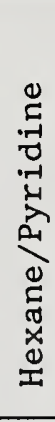 & 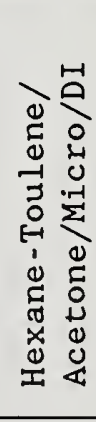 & 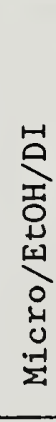 & 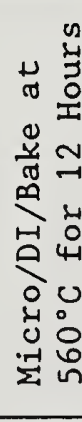 \\
\hline $\begin{array}{l}\vec{N} \\
0 \\
-1\end{array}$ & 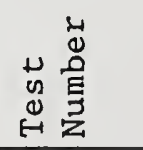 & $\rightarrow$ & $N$ & $m$ & $\checkmark$ & $n$ & 6 & $r$ \\
\hline
\end{tabular}


aluminum relative levels are enhanced after sputtering. This is apparent by examining the $\mathrm{C} / \mathrm{O}$ ratio before and after sputtering in Table 21. The effectiveness of a high temperature bake out is readily apparent in Table 21 after the surface has sputtered for 10 minutes. Thus, after baking out specimens at elevated temperatures the carbon is predominantly present on the surface and is most likely adsorbed $\mathrm{CO}_{2}$ and $\mathrm{CO}$. Also the detergent cleaner Micro was a very effective cleaning agent.

Thus, the developed cleaning procedure consisted of taking the sized disks, in groups of 3 , and placing them in $10 \mathrm{ml}$ acid cleaned vials. Then a $5 \mathrm{ml}$ aliquot of pyridine was placed in each vial. The vials were collectively covered by an acid cleaned petri dish and left to soak in the pyridine overnight. The specimens were then sonicated in an ultrasonic bath for 5 minutes in the pyridine. The pyridine was decanted and residual was removed by placing the vials under flowing de-ionized water. The de-ionized water had a specific resistance of 15 megohm-cm. The water was decanted and $5 \mathrm{ml}$ aliquots of a 28 detergent (Micro) solution was added to each vial. The specimens were sonicated for 5 minutes, the Micro was decanted, the specimens were rinsed with de-ionized water, and the water was drained. The vials containing the specimens were placed in an oven to bake out at $580^{\circ} \mathrm{C}$ overnight. Specimens were allowed to cool to the desired test temperature before testing occurred. The marked improvement in surface contamination level is displayed in Figure 39.

The influence of surface contaminants on performance testing is evident in Figure 40. Alumina samples were tested in a ball on three 


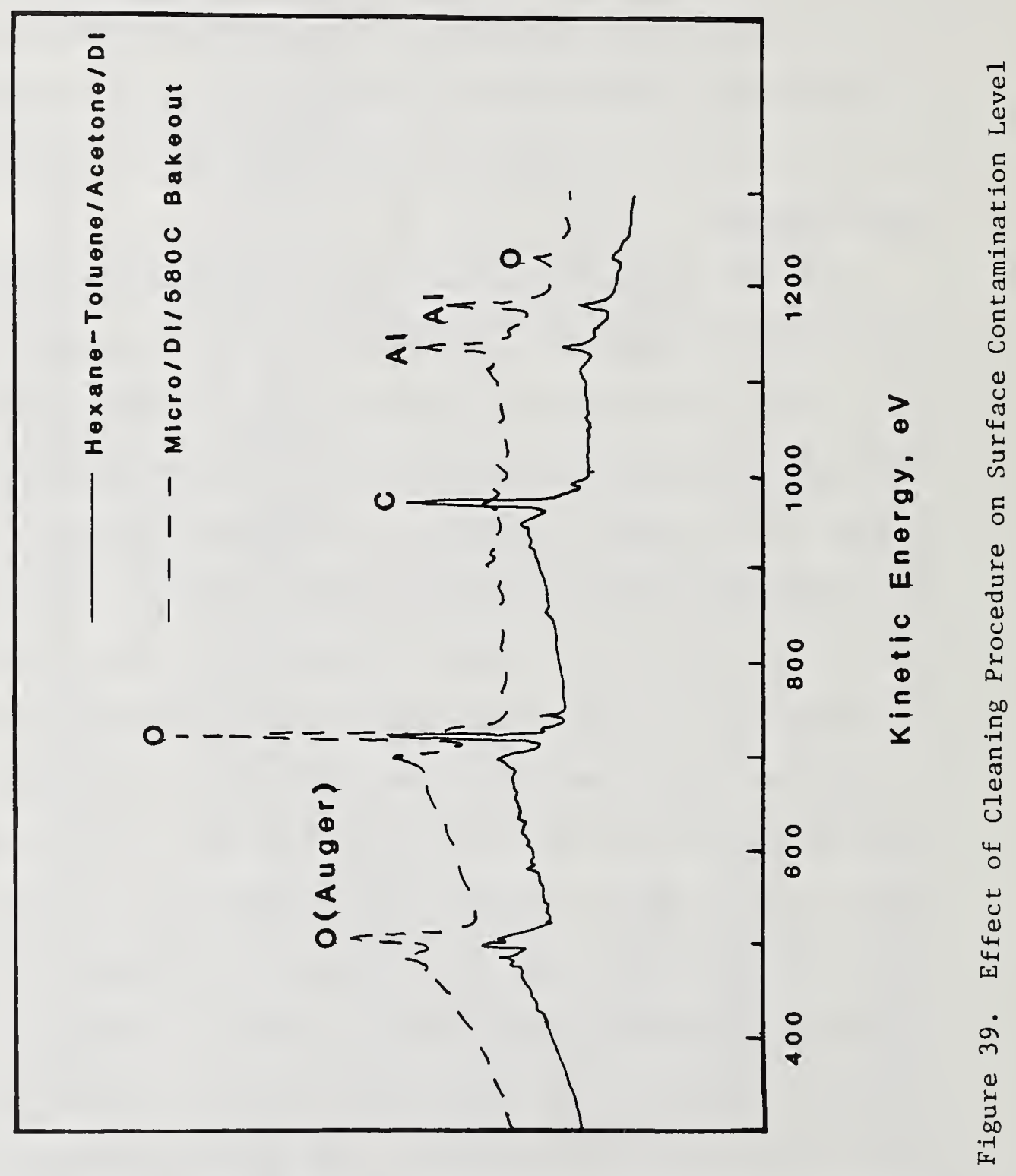

Kt!suefu! 


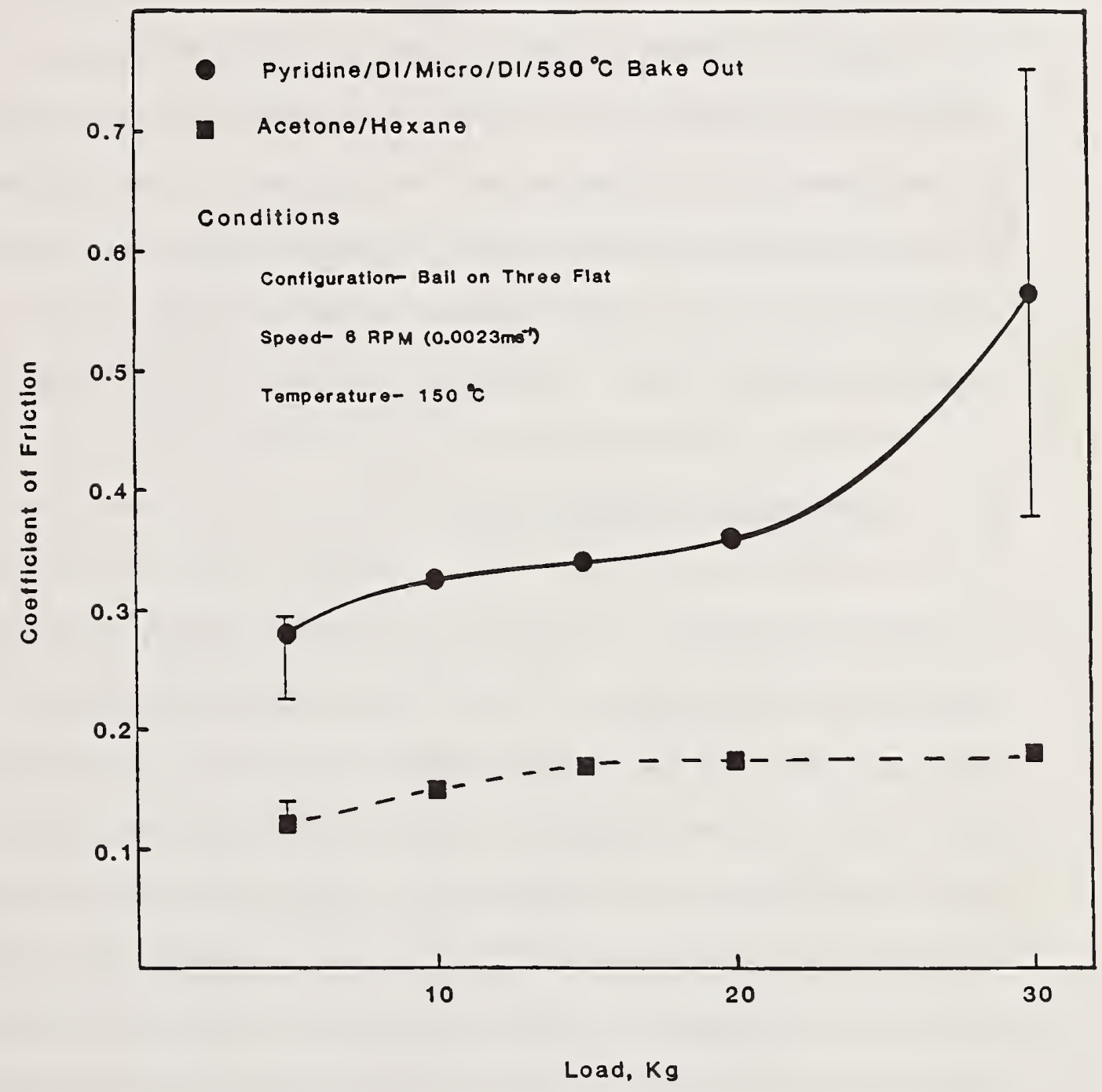

Figure 40. Effect of Cleaning Procedure on Friction Level

- Dry $\mathrm{Al}_{2} \mathrm{O}_{3}$ on $\mathrm{Al}_{2} \mathrm{O}_{3}, 150^{\circ} \mathrm{C}, 6 \mathrm{RPM}$ 
flat configuration at $150^{\circ} \mathrm{C}, 6 \mathrm{rpm}$, and unlubricated. The load was stepped from 5 to $10,15,20,30,40,50$, and 60 kilograms at 5 minute intervals. The friction coefficient was monitored throughout the test. One set of samples was cleaned by rinsing in acetone followed by hexane then baking out at $150^{\circ} \mathrm{C}$. The second set was cleaned using the developed cleaning procedure. The specimens receiving the more thorough cleaning exhibited a much higher friction level before seizing at 22 minutes. Thus surface contaminants can have a pronounced effect on the tribological properties of ceramics.

\subsubsection{Performance Testing Results}

The first attempt to demonstrate the effectiveness of vapor lubrication for ceramics was done in the ball-on-three-flat configuration at $150^{\circ} \mathrm{C}$. Cleaned alumina disks were placed in the flat holder and flats were marked to identify their relative position. The flats were worn-in at $600 \mathrm{rpm}$ at room temperature using $1.5 \mathrm{mls}$ of deionized water as a lubricant. The load was stepped from $2 \mathrm{kgs}$ to 10 $\mathrm{kgs}$ in $2 \mathrm{~kg}$ increments. Each load increment lasted 10 minutes. The samples were removed and uniform $0.380 \mathrm{~mm}$ diameter wear scars were measured on each specimen. The purpose of the wear in was to lessen the load severity of the coated ball on three flat test by lowering the mean contact pressure. The samples were sonicated in a 28 micro solution to remove remaining alumina debris. The specimens were then rinsed in de-ionized water and placed in the vapor deposition tubular furnace to coat. TCP was chosen as the coating lubricant because it 
exhibited superior performance results in previous studies as detailed in the literature survey. The flats were coated at $700^{\circ} \mathrm{C}$ for 30 minutes using $0.58 \mathrm{TCP}$. An approximate coating thickness is obtained by assuming that $\mathrm{Al}_{2} \mathrm{O}_{3}$ produces similar deposits as quartz. A 375 $\mu \mathrm{g} / \mathrm{cm}^{2}$ deposit results when quartz is exposed to $\mathrm{TCP}$ at $700^{\circ} \mathrm{C}$ for 30 minutes [65]. This is equivalent to a $3.50 \mu$ thick coating. The disks were transported from the oven into a covered petri dish on a hot plate. The samples were then taken to the wear tester which was preheated to $150^{\circ} \mathrm{C}$. The specimens were reloaded with care taken to relocate each specimen in its original position. The wear test was conducted at $10 \mathrm{kgs}$, at $6 \mathrm{rpm}$ for 2 hours. A baseline test was conducted following the same procedure except specimens were not coated. Figure 41 displays the results. The vapor coated specimen showed no difference in performance from the uncoated samples. The high initial friction of the vapor coated sample was an artifact caused by the specimens not being precisely aligned. The steady state friction of both tests are identical, within experimental error. Figure 42 shows an optical transmission picture of one of the worn coated disks. The jagged appearance of the vapor coating indicates that the coating was brittle at $150^{\circ} \mathrm{C}$ and most likely failed in the first seconds of testing. A second explanation for the film failure is that because the substrate was coated at $700^{\circ} \mathrm{C}$ then cooled to $150^{\circ} \mathrm{C}$ a large amount of residual stress could build up at the coatingsubstrate interface if a difference in linear thermal expansion coefficients existed. Manasevit et al. [94] observed high residual 


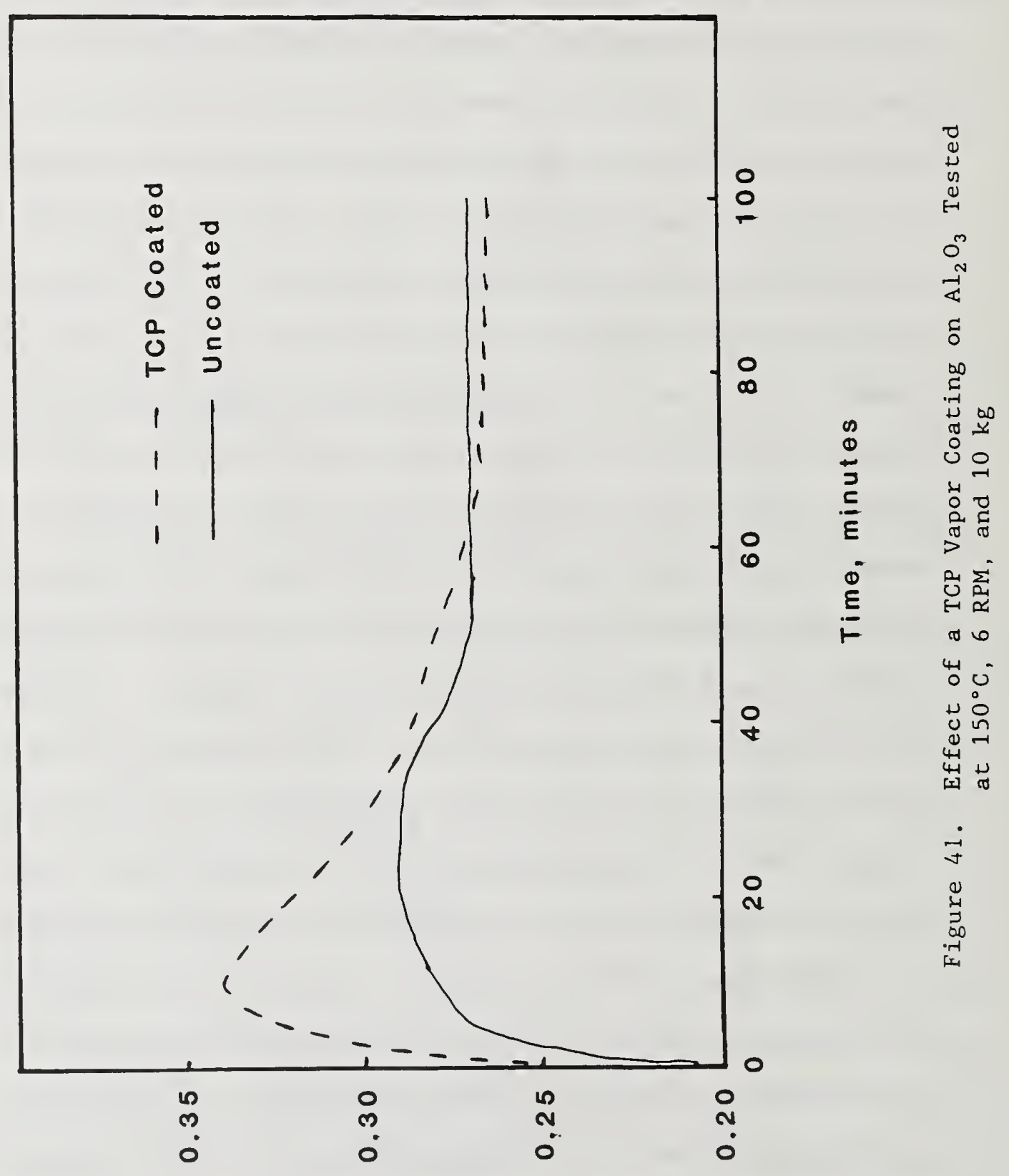

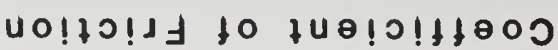




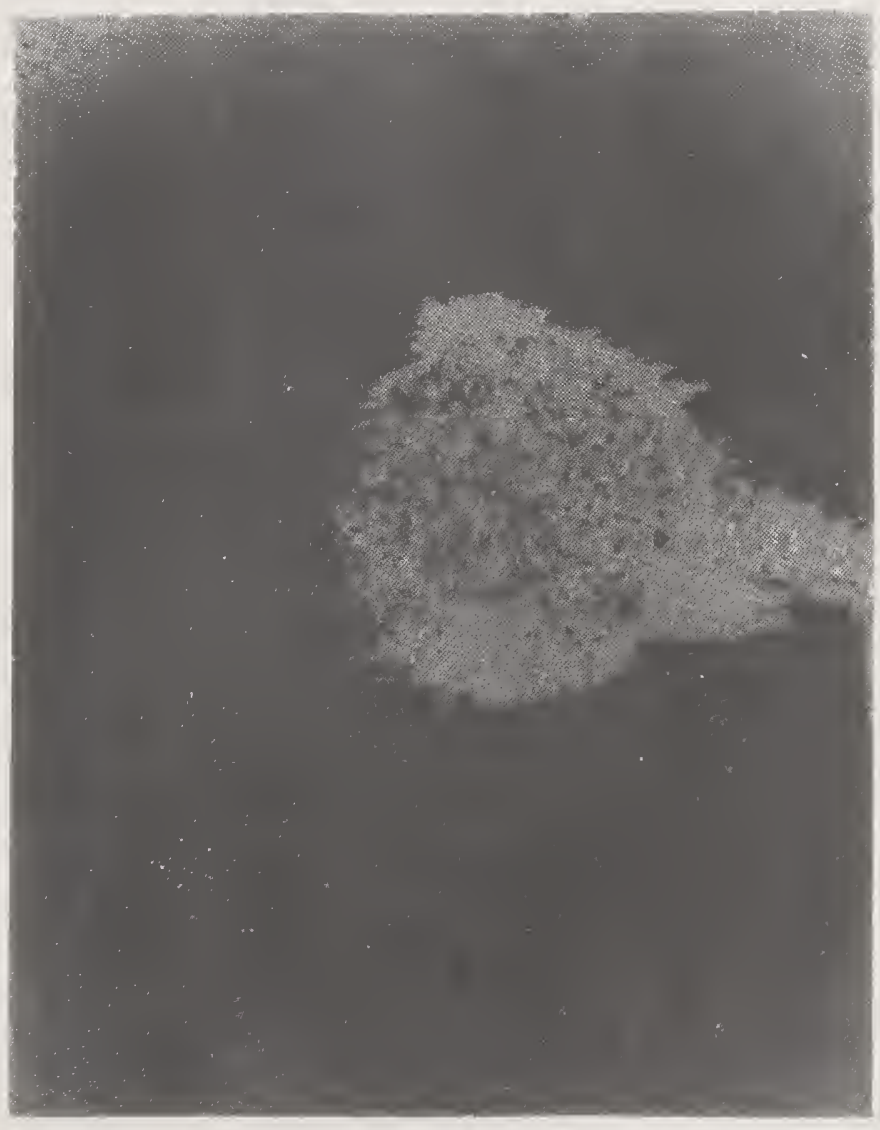

0
0

0
0
0

夜

4

동

要

as

$\stackrel{\circ}{\circ}$

م.

다유

䒠

م.

म

至

红

.

है

(

皆

$\stackrel{\text { \ }}{9}$

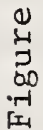


stress levels when substrates and coatings had differing coefficients of linear thermal expansion.

Vapor deposited coatings were also tested using the intermediate temperature tribometer at $700^{\circ} \mathrm{C}$. A cleaned alumina flat, $13 / 4^{\prime \prime} \mathrm{x} 1$ " $\mathrm{x} 0.060 "$ was placed in the tubular furnace and coated with $0.5 \%$ TCP at $700^{\circ} \mathrm{C}$ for 30 minutes. This produced a coating approximately $3.5 \mu$ thick. The flat was a 968 Alumina from Kyocera. The coated flat was transported in a petri dish on a hot plate and placed in the alumina sample holder. The oven was heated to $700^{\circ} \mathrm{C}$ and the test was conducted in a ball on flat configuration under a $1.6 \mathrm{~kg}$ load. The sliding speed was $1.5 \mathrm{~cm} / \mathrm{min}$. The resulting friction trace is shown in Figure 43. The friction of an uncoated specimen tested at $700^{\circ} \mathrm{C}$ is also shown in Figure 43. Clearly, the TCP coating reduced the friction on the alumina flat. This is very significant because the coating parameters chosen were not optimized to provide a lowest coefficient of friction. Thus, an even greater reduction in friction would be anticipated if a parametric study examining the effect of lubricant type concentration, oxygen concentration, coating time, and coating temperature was conducted. The fact that coefficient of friction increased as the sliding distance increased could be caused by two factors. First, the TCP coating could be entrapping wear particles as the sliding proceeds. This would result in three body wear which would lead to higher friction. An alternative explanation is that as the exposure time to the $700^{\circ} \mathrm{C}$ atmosphere increased, the lubricant desorbed. Coating desorption at high temperatures was displayed in Figure 11. The result of this experiment indicate that 


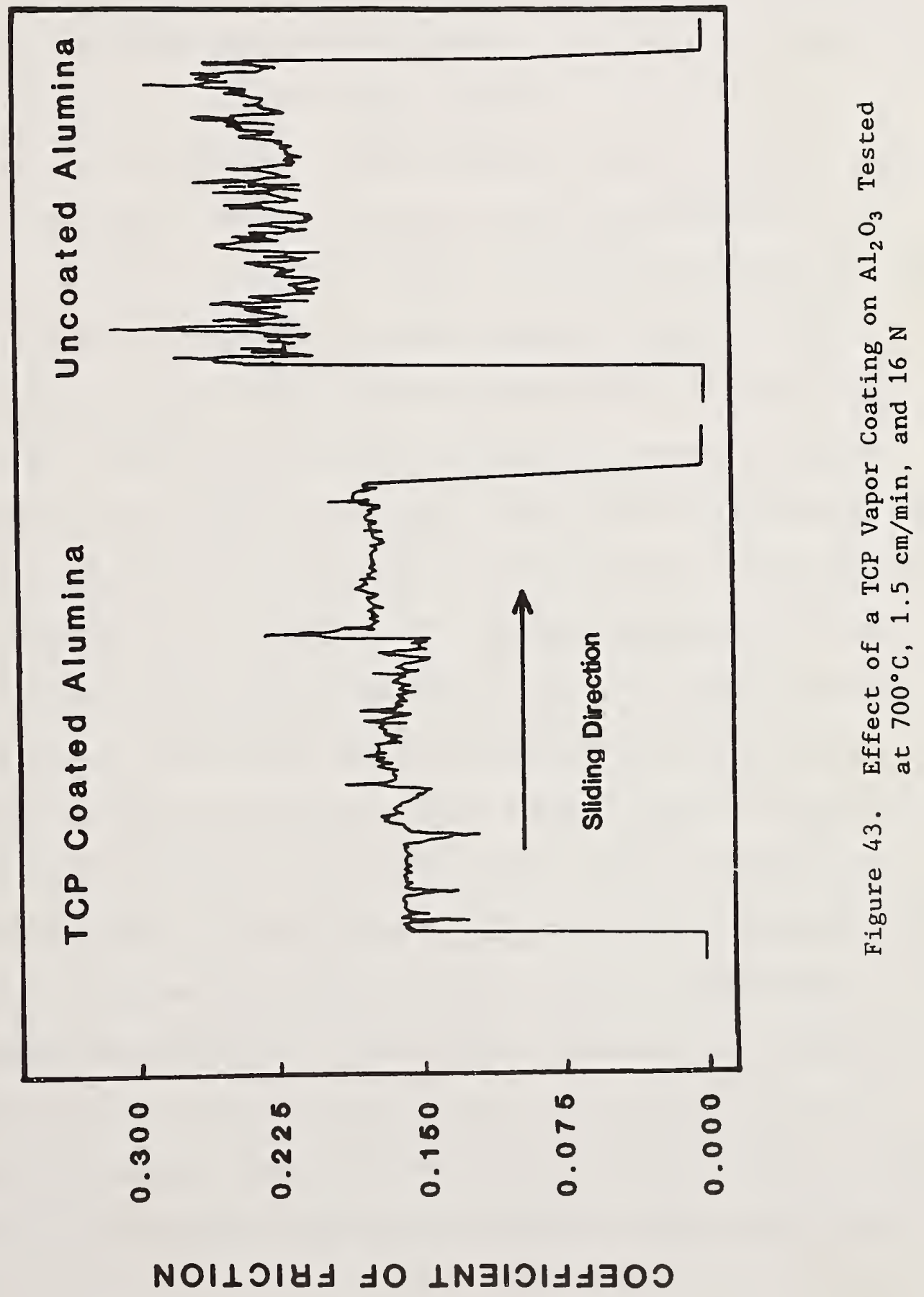


vapor lubricants have a great potential for lubricating ceramics at elevated temperatures. 
Chapter 4

CONCLUSIONS

Vapor deposition studies were conducted on metal and ceramic systems. Films formed on these substrates when they were exposed to lubricant vapors at elevated temperatures.

A TGA was adapted for vapor deposition studies. The TGA allowed continuous kinetic data acquisition for the film formation process. The TGA was used to study film formation on metals using TCP and TBP. These two fluids showed very similar deposition characteristics. Substrate material strongly influenced the amount and rate of film formation. The order of activity in decreasing order was copper $>$ stainless steel $>$ nickel $>$ platinum. These systems exhibited a rapid initial rate followed by a reduced steady state rate. This implies that the surface is initially active, but becomes passive as more deposit forms. The passivation process may involve metal particle encapsulation. The concentration of oxygen present was found to strongly influence the amount of film formed. Nickel was shown to form much more deposit at $600^{\circ} \mathrm{C}$ than $700^{\circ} \mathrm{C}$. This occurrence of decreasing amount of film formation with increasing temperature may be related to increasing desorption rates at higher temperatures. A desorption experiment on a coated nickel substrate determined that two different types of material form during vapor deposition. The activation energies of the desorbed species indicate that the species were chemically bound and they have differing thermal stabilities. 
Because ceramic substrates are not available in wire form, deposition studies were conducted using circular disk $1 / 4^{\text {" }}$ in diameter. A tubular furnace was designed and constructed for this portion of the study. The deposition of TBP on $\mathrm{Si}_{3} \mathrm{~N}_{4}, \mathrm{Al}_{2} \mathrm{O}_{3}$, and $\alpha$ SiC was investigated using SEM. The films produced were surface sensitive. Globular and filamentous structures were observed. The filaments contained iron particles in their growing tips. The iron was transported from the steel tray which supported the flats. This suggests that dopants and sintering aids can be selected to provide optimum vapor deposition characteristics for ceramic surfaces.

Performance testing was conducted on vapor coated alumina using a ball on three flat tester and an intermediate temperature tribometer. Before performance testing was conducted on the ball on three flat tester, a cleaning procedure was developed for oxide ceramics. ESCA and Auger spectroscopy were used to determine the qualitative amount of contaminants remaining after various procedures. The best cleaning procedure consisted of soaking samples in pyridine overnight, followed by soaking samples in a detergent solution and finally baking samples overnight at $580^{\circ} \mathrm{C}$ before testing. Dry ball on three flat tests showed that the recommended cleaning procedure resulted in a higher coefficient of friction in dry sliding than a standard solvent rinse. This demonstrates the importance that surface contaminants have in tribology

A ball on flat sliding experiment was performed on a coated $\mathrm{Al}_{2} \mathrm{O}_{3}$ flat at $700^{\circ} \mathrm{C}$ using the intermediate temperature tribometer. TCP coated flats displayed a reduced friction level compared to uncoated 
flats; 0.160 to 0.230 . This demonstrated that a vapor-deposited coating, even under unoptimized conditions, provides tribological benefits. 
Chapter 5

FUTURE WORK

This study indicates that vapor deposition coatings form on ceramics and these coatings have lubricious qualities. Much more work needs to be done in this area to demonstrate the effectiveness of vapor lubrication for adiabatic diesel applications.

The fact that deposition is surface sensitive on ceramics indicates that the effect of various solid solutions, dopants, and other substrates needs to be investigated. Much physical information could be gained by conducting in situ SEM experiments. Chemical structural information could be obtained using a high temperature in situ raman system. This experimental approach would allow the coating to be more thoroughly characterized as it is formed.

There is a great need for in situ performance testing of vapor lubricated ceramics at actual engine contact temperatures. The effect of load, speed, temperature, atmosphere, with various vapor lubricants needs to be explored.

The performance data coupled with chemical and physical data on the vapor deposit would provide a pathway for designing better lubricants for a given high temperature application. 


\section{ACKNOWLEDGEMENT}

The authors wish to acknowledge the ECUT Tribology Program, Office of Energy Conservation and Utilization Technology (ECUT) of the Department of Energy for their partial support. 
REFERENCES

1. Godfrey, D.J., Materials and Design, Vol. 4, June/July (1983).

2. Ceramic Technology for Advanced Heat Engines, Oak Ridge National Laboratory, Metals and Ceramics Division, July (1983).

3. "Technological and Economic Assessment of Advanced Ceramic Materials," Charles River Associates, Incorporated, NBS-GCR 84470-1 (1984).

4. Bryzik, J. and Kamo, R., SAE Paper No. 830314 (1983).

5. Wallace, F.J., Kac, T.K., Alexander, W.D., Cole, A., and Tarabad, M., SAE Paper No. 830312 (1983).

6. Siegla, D.C. and Amann, C.A., SAE Paper No. 840435 (1984).

7. Sliney, H.E., ASLE Special Publication SP-15, 1-6 (1982).

8. Breznak, J., Breval, E., and MacMillan, N.H., J. of Mat. Sci., $\underline{20}$ (1985).

9. Shimauchi, T., Murakami, T., Nakagaki, T., Tsuya, Y., and Umeda, K., SAE Paper No. 840429 (1984).

10. Kamo, R., Tozzi, L., and Sekar, R., "Light Duty Vehicle Diesel Engine Assessment Program - Passenger Car Diesel of the Future". From Proceedings of the Twentieth Automotive Technology Development Contractors' Coordination Meeting, p. 261, April (1983).

11. Klaus, E.E., "New Directions in Lubrication, Materials, Wear, and Surface Interactions Tribology in the $80^{\prime} \mathrm{s}$, Ed. Loomis, W.R., 354-375 (1985).

12. Blake, E.S., Hammann, W.C., Edwards, J.W., Reichard, T.E., and Ort, M.R., J. Chem. Eng. Data, Vol. $\underline{6}$, No. 1, 87-89 (1961).

13. Wells, J.G., Lubrication Fundamentals, Marcel Dekker Inc., (1980).

14. Ballentine, O.M., WADC Technical Report 54-417, March (1955).

15. Beane, IV, G.A., Gschwender, L.J., and Snyder, Jr., C.E., SAE Paper No. 851834 (1985).

16. Jones, Jr., W.R., "New Directions in Lubrication, Materials, Wear, and Surface Interactions Tribology in the $80^{\prime} \mathrm{s}, "$ Ed. Loomis, W.R., 402-439 (1985). 
17. Snyder, Jr., C.E. and Dolle, Jr., R.E., ASLE Trans., Vol. $\underline{19}$, No. 3, 171-180 (1975).

18. Jones, Jr., and Snyder, Jr., C.E., ASLE Preprint 79-AM-1B-1 (1979).

19. Cho, L. and Klaus, E.E., ASLE Trans., Vol. 24, No. 1, 119-124 (1980).

20. Tamborski, C., Chen, G.J., Anderson, D.R., and Snyder, Jr., C.E., Ind. Eng. Chem. Prod. Res. Dev., Vol. 22, No. 2 (1983).

21. Sliney, H.E., Trib. Int., Vol. 15, No. 5, 303-315 (1982).

22. Gardos, M., IDA/DARPA Talk, December 12, 1984, Tribology Workshop, IDA, VA, December (1984).

23. Gardos, M.N. and McConnell, B.D., ASLE Special Publication SP-9 (1982).

24. Fusaro, R.L., NASA Technical Memorandum 82959 (1982).

25. Fusaro, R.L., NASA Technical Memorandum 83339 (1983).

26. Fusaro, R.L., ASLE Trans. Vol. 26, No. 2, 209-221 (1982).

27. Fusaro, R.L., ASLE Special Publication, SP-15, 14-24 (1982).

28. Sliney, H.E., Thin Solid Films, 64, 211-217 (1979).

29. Kihara, J., Watabe, K., Doya, K., and Takashima, A., "Effect of Addition of Alkyl and Phenyl Phosphorous Compounds to Mineral Oil on Their Lubricity in Hot Rolling of Low Carbon Steel," The International Symposium on Metalworking Lubrication Century 2 Emerging Technology Conferences, San Francisco, CA, 183-186 (1980).

30. Parikh, N., Kulkarni, K., Benedyk, J., and Bock, F., "LubricantOxide-Stain Rate Interactions in Hot Forging of Steel," Proceedings from the Second International Conference on Lubrication Challenges in Metalworking and Processing, Chicago, IL, 137-146 (1979).

31. Chen, C.C., "State-of-Technology in Isothermal Forging Lubrication," Proceedings from the Second International Conference on Lubrication challenges in Metalworking and Processing, Chicago, IL, 147-155 (1979). 
32. Sharan, R. and Prasad, S.N., "Role of Lubricants in Metal and Die Wear During Forging," Proceedings from the International Symposium on Metalworking Lubrication Century 2 - Emerging Technology Conferences, San Francisco, CA, 77-82 (1980).

33. Dean, …, "The Effect of a Lubricant on Damage in Drop Forging Dies," Proceedings from the International Symposium on Metalworking Lubrication Century 2 - Emerging Technology Conferences, San Francisco, CA, 69-75 (1980).

34. Lahoti, G.D., Nogpal, V., and Altan, T., "Selection of Lubricants in Hot Forging and Extrusion," Proceedings from the First International Conference on Lubrication Challenges in Metalworking and Processing, Chicago, IL, 52-59 (1978).

35. Nachtman, E.S., "Synthetic Metalworking Lubricants: Some Operating Considerations," Proceedings from the International Symposium on Metalworking Lubrication Century 2 - Emerging Technology Conferences, San Francisco, CA, 49-54 (1980).

36. Schmidt, A.B., "The Evolution of the Die Casting Lubricant," Proceedings from the International Symposium on Metalworking Lubrication Century 2 - Emerging Technology Conferences, San Francisco, CA, 151-157 (1980).

37. Klaus, E.E. and Lai, C.W., U.S. Patent 3,978,908 (1976).

38. Klaus, E.E., Duda, J.L., and Naidu, S.K., "Quarterly Progress Report," Tribology Project, ORNL Subcontract (19X-89616C), January-March (1986).

39. Klaus, E.E., Graham, E.E., and Duda, J.L., "Quarterly Progress Report," Tribology Project, ORNL Subcontract (19X-89616C), January-March (1986).

40. Klaus, E.E., Duda, J.L. and Naidu, S.K., "Quarterly Progress Report," Tribology Project, ORNL Subcontract (19X-89616C), JulySeptember (1986).

41. Lai, C.W., M.S. Thesis, The Pennsylvania State University (1974).

42. Gunsel, S., Ph.D. Thesis, The Pennsylvania State University (1986).

43. Klaus, E.E., Duda, J.L., and Naidu, S.K., "Quarterly Progress Report," Tribology Project, ORNL Subcontract (19X-89616C), April-June (1986)

44. Klaus, E.E., Duda, J.L., and Graham, E.E., "Quarterly Progress Report," Tribology Project, ORNL Subcontract (19X-89616C), April-June (1984). 
45. Klaus, E.E., Graham, E.E., and Duda, J.L., "Quarterly Progress Report," Tribology Project, ORNL Subcontract (19X-89616C), October-December (1984).

46. Klaus, E.E., Duda, J.L., and Naidu, S.K., "Quarterly Progress Report," Tribology Project, ORNL Subcontract (19X-89616C), October-December (1985).

47. Klaus, E.E., Graham, E.E., and Duda, J.L., "Quarterly Progress Report," Tribology Project, ORNL Subcontract (19X-89616C), April-June (1985).

48. Hsu, S.M., "Anti-wear and Lubricity Additives for Lubricants," Proceedings from the 25th MFPG Symposium on Engineering Design, Washington, DC, November (1976).

49. Vinogradov, V.V., Arkharova, V.V., and Petrov, A.A., Wear, Vol. 4, 274-291 (1961).

50. Bartz, W.J., ASLE Lub. Eng., Vol. 36, No. 10, 579-585 (1979).

51. Spear, K.E., Pure and Appl. Chem., Vol. 54, No. 7, 1297-1311, (1982).

52. Hitchman, M.L. and Almed, W., Vacuum, Vol. 34, No. 10/11, 979986, (1984).

53. Scott, B.A., Olbricht, W.L., Meyerson, B.A., Reimer, J.A., and Wolford, D.J., J. Vac. Sci. Technol. A, Vol. 2, No. 2, 450-456, (1984).

54. Nagel, S.R., MacChesney, J.B., and Walker, K.L., IEEE J. of quantum Electron., Vol. QE-18, No. 4, 459-476, (1982).

55. Bryant, W.A., J. of Mat. Sci., Vol. 12, 1285-1306, (1977).

56. Bunshah, R.F., "Hard Coating for Wear Resistance," Proceedings from the Second International Conference on Lubrication Challenges in Metalworking and Processing, Chicago, IL, 45-51, (1979).

57. Kern, W. and Schnable, G.L., IEEE Trans. on Electron Devices, Vol. ED-26, No. 4, 647-657, (1979).

58. Holmen, A., Lindvaag, O.A., and Trimm, D.L., ACS Symposium Series 202, 45-48 (1981).

59. Marek, J.C. and Albright, L.F., ACS Symposium Series 202, 123150 (1981). 
60. Figoli, N.S., Beltramini, J.N., Barra, A.F., Martinelli, E.E., Sad, M.R., and Parera, J.M., ACS Symposium Series 202, 239-252 (1981).

61. Baker, R.T.K., Yates, D.J.C., and Dumesic, J.A., ACS Symposium Series 202, 1-22 (1981).

62. LaCava, A.I., Fernandez-Raone, E.D., Isaacs, L.L., and Carabello, M., ACS Symposium Series 202, 89-108 (1981).

63. Baker, R.T.K. and Chludzinski, Jr., J.J., J. Catal. 64, 464 (1980).

64. Brown, D.E., Clark, J.T.K., Foster, A.I., McCarroll, J.J., and Sims, M.M., ACS Symposium Series 202, 23-44 (1981)..

65. Klaus, E.E., Duda, J.L., and Naidu, S.K., ORNL Subcontract 19X89616C, Summary Report, July 14, 1986.

66. Marek, J.C. and Albright, L.F., ACS Symposium Series 202, 151176 (1981).

67. Baker, R.T.K., Barber, M.A., Harris, P.S., Feates, F.S., and Waite, R.J., J. Catal. 26, 51-62 (1972).

68. Baker, R.T.K., Harris, P.S., Thomas, R.B., and Waite, R.J., J. Catal. 30, 86-95 (1973).

69. Baker, R.T.K. and Waite, R.J., J. Catal. 37, 101-105 (1975).

70. Baker, R.T.K., Catal. Rev-Sci Eng. 19, (2), 161-209 (1979).

71. Haldeman, R.G. and Botty, M.C., J. Phys. Chem. $\underline{63}, 489-495$ (1959).

72. McCarty, J.G., Hou, P.Y., Sheridan, D., and Wise, H., ACS Symposium Series 202, 253-282 (1981).

73. Prater, C.D. and Lago, R.M., Adv. in Catal. 8, 293-339 (1956).

74. LaCava, A.I., Fernandez-Raone, E.D., and Caraballo, M., ACS Symposium Series 202, 109-122 (1981).

75. Trimm, D.L., Catal. Rev.-Sci. Eng., 16 (2), 155-189 (1977).

76. Lobo, L.S. and Trimm, D.L., Nature Physical Sci. 274, 15-16 (1971).

77. Derbyshire, F.J. and Trimm, D.L., Carbon 13, 189-192 (1975).

78. Petzke, W.H., Gottschalch, V., and Butler, E., Kristall und Technik $\underline{9}$ (7), 763-770 (1974). 
79. Leys, M.R. and Vennvliet, H., J. of Crystal Growth 55, 145-153 (1981).

80. Zaouk, A., Salvetat, E., Sakaya, J., Maury, F., and Constant, G., J. of Crystal Growth 55, 135-144 (1981).

81. Stringfellow, G.B. and Hall, Jr., H.T., J. of Crystal Growth 43, 47-60 (1978).

82. Shaw, D., J. of Crystal Growth $\underline{8}, 117-128$ (1971).

83. Wu, N.L. and Phillips, J., "Reaction Enhanced Sintering of Platinum Thin Films During Ethylene Oxidation," J. Appl. Phys. 59 (3) 769-770 (1986).

84. Wu, N.L. and Phillips, J., "Catalytic Etching of Platinum During Ethylene Oxidation," J. Phy. Chem. $\underline{89}$ (4) 591-600 (1985).

85. Rice, F.O. and Glasebrook, A.L., J. Am. Chem. Soc. 56, 2381-2383 (1934).

86. Pearson, T.G., Purcell, R.H., and Saigh, G.S., J. Chem. Soc., 409-424 (1938).

87. Min, W., M. S. Thesis, The Pennsylvania State University (1980).

88. Pinto, N.D., M.S. Thesis, The Pennsylvania State University.

89. Dapkus, P.D., Ann. Rev. Mater. Sci. 12, 243-269 (1982).

90. Creyke, W.E.C., Sainsburg, I.E.J., and Morrell, R., "Design with Nonductile Materials," Applied Science, 222 (1982).

91. Myers, Jr., H.S., Ph.D. Thesis, The Pennsylvania State University, June (1952).

92. Schulz, W.W., Narratil, J.D., and Talbot, A.E., "Science and Technology of Tributyl Phosphate - Volume I, Synthesis, Properties, Reactions and Analysis," CRC Press, Inc. (1984).

93. Oberg, E. and Jones, F.D., "Machinery's Handbook," 19 th ed. (1973).

94. Manasevit, H.M. and Simpson, W.I., J. Electrochem. Soc. 116, No. 12, 1725-1732 (1969).

95. Arnold, J. Chem. Phys., 1, 170 (1933).

96. Bahlke and Kay, Ind. Eng. Chem., 21, 942 (1929).

97. Gambill, Chem. Eng., 121-124, August 25 (1958). 
98. Nelson and Obert, Chem. Eng., 203-208, July (1954).

99. Herning and Zipperer, Gas-u. Wasserfach, 79, (49), 69 (1936).

100. Friend and Alder, "Transport Properties in Gases, "Cambel and Fenn (ed.), Northwestern University Press, Evanston, IL, 128-131 (1958).

101. Wilke, C.R. and Lee, C.Y., Ind. Eng. Chem., 47, 1253 (1955).

102. LaBas, "The Molecular Volumes of Liquid Chemical Compounds," Longmans, London, (1915).

103. Hirschfelder, Bird, and Spotz, Trans. Am. Soc. Mech. Engrs., 71, 921 (1949).

104. Weast, R.C., "Handbook of Chemistry and Physics," CRC Press, 56 th ed., (1975-1976).

105. Bird, R.B., Stewart, W.E., and Lightfoot, E.N., "Transport Phenomena," (1960).

106. Ranz, W.E. and Marshall, Jr., W.R., Chem. Eng. Prog., 48, $141-$ 146 or $173-180$ (1950). 
APPENDIX A

Physical Constants for TCP, TBP, and Argon at Various Temperatures

Table 22. Physical Constants for Argon at Various Temperatures

\begin{tabular}{|c|c|c|c|}
\hline $\mathrm{T},{ }^{\circ} \mathrm{C}$ & $\begin{array}{c}\text { Viscosity, } \\
\mu \text { Poise }\end{array}$ & $\begin{array}{c}\text { Heat Capacity, } \\
\mathrm{cal} / \mathrm{g} \cdot{ }^{\circ} \mathrm{C}\end{array}$ & $\begin{array}{c}\text { Thermal Conductivity, } \\
\mathrm{cal} / \mathrm{cm} \cdot \mathrm{s}{ }^{\circ} \mathrm{C} \times 10^{-} \mathrm{C}\end{array}$ \\
\hline & & & \\
200 & 310 & 0.1246 & 4.23 \\
300 & 360 & 0.1246 & 5.30 \\
400 & 440 & 0.1246 & 6.35 \\
500 & 445 & 0.1246 & 7.33 \\
600 & 490 & 0.1246 & 8.14 \\
700 & 525 & 0.1246 & 8.93 \\
800 & 560 & 0.1246 & 9.67 \\
900 & & 0.1246 & 10.50 \\
1000 & & 0.1246 & \\
\hline
\end{tabular}

Table 23. Physical Constants for Tributyl Phosphate Ester at Various Temperatures

\begin{tabular}{|r|r|c|c|}
\hline T, ${ }^{\circ} \mathrm{C}$ & $\begin{array}{c}\text { Viscosity, } \\
\mu \text { Poise }\end{array}$ & $\begin{array}{c}\text { Heat Capacity, } \\
\text { cal/g. }{ }^{\circ} \mathrm{C}\end{array}$ & $\begin{array}{c}\text { Thermal Conductivity, } \\
\text { cal/cm. } \cdot{ }^{\circ} \mathrm{C} \times 10^{-7}\end{array}$ \\
\hline & & & \\
200 & 72.0 & 0.4984 & 4.17 \\
300 & 89.1 & 0.5829 & 6.04 \\
400 & 105.8 & 0.6674 & 8.21 \\
500 & 122.1 & 0.7519 & 10.68 \\
600 & 137.9 & 0.8364 & 13.41 \\
700 & 153.3 & 0.9209 & 16.42 \\
800 & 168.2 & 1.005 & 19.66 \\
900 & 182.6 & 1.090 & 23.15 \\
1000 & 196.6 & 1.174 & 26.84 \\
\hline
\end{tabular}


Table 24. Physical Constants for Tricresyl Phosphate Ester at Various Temperatures

\begin{tabular}{|l|l|c|c|}
\hline T, ${ }^{\circ} \mathrm{C}$ & $\begin{array}{c}\text { Viscosity, } \\
\mu \text { Poise }\end{array}$ & $\begin{array}{c}\text { Heat Capacity, } \\
\text { cal/g } \cdot{ }^{\circ} \mathrm{C}\end{array}$ & $\begin{array}{c}\text { Thermal Conductivity, } \\
\text { cal/cm } \cdot \mathrm{s}{ }^{\circ} \mathrm{C} \times 10^{-7}\end{array}$ \\
\hline & & & \\
200 & 51.2 & 0.4618 & 2.75 \\
300 & 70.2 & 0.5401 & 4.41 \\
400 & 84.0 & 0.6183 & 6.04 \\
500 & 97.6 & 0.6966 & 7.90 \\
600 & 110.8 & 0.7749 & 9.99 \\
700 & 123.8 & 0.8532 & 12.28 \\
800 & 136.5 & 0.9311 & 14.78 \\
900 & 148.8 & 1.010 & 17.48 \\
1000 & 160.9 & 1.088 & 20.36 \\
\hline
\end{tabular}

viscosity of the phosphate esters was calculated using Arnolds correlation [95]:

$$
\mu=\frac{27.0 \sqrt{\mathrm{M} \mathrm{T}^{3 / 2}}}{\mathrm{~V}_{\mathrm{b}}^{2 / 3}\left(\mathrm{~T}+1.47 \mathrm{~T}_{\mathrm{b}}\right)}
$$

where $\mu=$ viscosity, micropoise

$$
\mathrm{M}=\text { molecular weight }
$$

$\mathrm{T}_{\mathrm{b}}=$ normal boiling point, $\mathrm{K}$

$\mathrm{T}$ = temperature, $\mathrm{K}$

$\mathrm{V}_{\mathrm{b}}=$ molar liquid volume at the normal boiling point, $\mathrm{cm}^{3} / \mathrm{mol}$

Heat capacity of the phosphate esters was estimated using the Bahlke and Kay [96] equation for petroleum vapors. 
125

$$
C_{p}=\frac{(4-s)(t+670)}{6450}
$$

where $\mathrm{C}_{\mathrm{p}}=$ heat capacity, cal $/ \mathrm{g}{ }^{\circ} \mathrm{C}$

$$
t=\text { temperature, }{ }^{\circ} \mathrm{F}
$$

$\mathrm{s}=$ specific gravity at $60^{\circ} \mathrm{F}$

Thermal conductivity was obtained using the Gambill [97] group averaged Prandtl numbers where for polar gases

$$
\frac{\mathrm{C}_{\mathrm{p}} \mu}{\kappa}=0.86
$$

Thus

$$
\kappa=1.163 \mathrm{C}_{\mathrm{p}} \mu
$$


APPENDIX B

Physical Constants for Mixtures of 18 Phosphate Ester in Argon at Various Temperatures

Table 25. Physical Constants for a Mixture of 18 Tributyl Phosphate Ester and 998 Argon

\begin{tabular}{|r|c|c|c|c|}
\hline T, ${ }^{\circ} \mathrm{C}$ & $\begin{array}{l}\text { Density, } \\
\mathrm{g} / \mathrm{cm}^{3} \times 10^{-4}\end{array}$ & $\begin{array}{c}\text { Viscosity, } \\
\mu \text { Poise }\end{array}$ & $\begin{array}{c}\text { Thermal Conductivity, } \\
\mathrm{cal} / \mathrm{cm} \cdot \mathrm{s} \cdot{ }^{\circ} \mathrm{C} \times 10^{-6}\end{array}$ & $\begin{array}{c}\text { Heat Capacity, } \\
\mathrm{cal} / \mathrm{g} \cdot{ }^{\circ} \mathrm{C}\end{array}$ \\
\hline & & & & \\
200 & 10.9 & 303.9 & & 0.1459 \\
300 & 8.96 & 353.1 & 1.54 & 0.1508 \\
400 & 7.63 & 392.5 & 2.05 & 0.1558 \\
500 & 6.65 & 436.8 & 2.62 & 0.1607 \\
600 & 5.88 & 481.0 & 3.22 & 0.1657 \\
700 & 5.28 & 515.5 & 3.86 & 0.1706 \\
800 & 4.79 & 550.1 & 4.55 & 0.1755 \\
900 & & & 5.27 & 0.1855 \\
1000 & & & 6.04 & \\
\hline
\end{tabular}

Table 26. Physical Constants for a Mixture of 18 Tricresyl Phosphate Ester and 998 Argon

\begin{tabular}{|r|c|c|c|c|}
\hline $\mathrm{T},{ }^{\circ} \mathrm{C}$ & $\begin{array}{l}\text { Density, } \\
\mathrm{g} / \mathrm{cm}^{3} \times 10^{-4}\end{array}$ & $\begin{array}{l}\text { Viscosity, } \\
\mu \text { Poise }\end{array}$ & $\begin{array}{c}\text { Thermal Conductivity, } \\
\mathrm{cal} / \mathrm{cm} \cdot \mathrm{s} \cdot{ }^{\circ} \mathrm{C} \times 10^{-6}\end{array}$ & $\begin{array}{c}\text { Heat Capacity, } \\
\mathrm{cal} / \mathrm{g} \cdot{ }^{\circ} \mathrm{C}\end{array}$ \\
\hline & & & & \\
200 & 11.1 & 303.6 & & 0.1534 \\
300 & 9.18 & 352.9 & 1.33 & 0.1600 \\
400 & 7.82 & 392.3 & 1.77 & 0.1667 \\
500 & 6.81 & 436.6 & 2.26 & 0.1734 \\
600 & 6.03 & 480.9 & 2.79 & 0.1801 \\
700 & 5.41 & 515.4 & 3.35 & 0.1868 \\
800 & 4.90 & 549.8 & 3.94 & 0.1934 \\
900 & & & 4.57 & 0.2001 \\
1000 & & & 5.25 & 0.2068 \\
\hline
\end{tabular}


Density was calculated using the Nelson-Obert [98] compressibility factor, $z$, in the following equation:

$$
\delta=\frac{\overline{\mathrm{M}} \mathrm{P}}{\mathrm{RT} z}
$$

where $z$ = compressibility factor and was 1.0 for all temperatures above $200^{\circ} \mathrm{C}$

$$
\begin{aligned}
\mathrm{Mw}^{-} & =\text {average molecular weight of the gas } \\
\mathrm{P} & =\text { pressure, atmospheres } \\
\mathrm{T} & =\text { temperature, } \mathrm{K} \\
\mathrm{R} & =\text { gas constant } 82.057 \mathrm{~atm} \cdot \mathrm{cm}^{3} / \mathrm{K} \cdot \mathrm{mol}
\end{aligned}
$$

The viscosity of the gas mixture was calculated using the correlation [99]

$$
\mu \mathrm{m}=\frac{\sum \mathrm{y}_{i} \mu_{i}\left(\mathrm{M}_{i}\right)^{1 / 2}}{\sum \mathrm{y}_{i}\left(\mathrm{M}_{i}\right)^{1 / 2}}
$$

where $\mu \mathrm{m}=$ viscosity of the mixture, $\mu$ Poise

$$
\begin{aligned}
& y_{i}=\text { mole fraction of component } i \\
& \mu_{i}=\text { viscosity of component } i, \mu \text { Poise } \\
& M_{i}=\text { molecular weight of component } i
\end{aligned}
$$


Thermal conductivity of the mixture was calculated with the equation [100]

$$
k_{m}=\frac{\sum y_{1} k_{1}\left(M_{1}\right)^{1 / 3}}{\sum y_{1}\left(M_{i}\right)^{1 / 3}}
$$

where $\mathrm{km}=$ thermal conductivity of the mixture, $\mathrm{cal} / \mathrm{g} \cdot{ }^{\circ} \mathrm{C}$

$k_{1}=$ thermal conductivity of component $\mathrm{i}, \mathrm{cal} / \mathrm{g} \cdot{ }^{\circ} \mathrm{C}$

$y_{i}=$ mole fraction of component $i$

$M_{i}=$ molecular weight of component $i$

The heat capacity of the mixture was calculated by using

$$
\mathrm{C}_{\mathrm{pm}}=\sum \mathrm{x}_{1} \mathrm{Cp}_{\mathrm{i}}
$$

where $\mathrm{C}_{\mathrm{pm}}=$ heat capacity of the mixture, cal $/ \mathrm{g} \cdot{ }^{\circ} \mathrm{C}$

$$
\begin{aligned}
\mathrm{Cp}_{1} & =\text { heat capacity of component } i, \mathrm{cal} / \mathrm{g} \cdot{ }^{\circ} \mathrm{C} \\
\mathrm{x}_{1} & =\text { mass fraction of component } i
\end{aligned}
$$


APPENDIX C

Estimation of Diffusion Coefficients for Phosphate Esters in Argon at Various Temperatures

To calculate diffusion coefficients the Wikle and Lee modification [101] of the Hirschfelder, Bird, and Spotz equation was used.

$$
D_{G}=\frac{B T^{3 / 2} \sqrt{1 / M_{1}+1 / M_{2}}}{P r^{2}{ }_{12} I_{D}}
$$

where

$$
D_{G}=\text { gas diffusivity } \mathrm{cm}^{2} / \mathrm{s}
$$

$$
\begin{aligned}
\mathrm{B} & =\left(10.7-2.46 \sqrt{1 / \mathrm{M}_{1}+1 / \mathrm{M}_{2}}\right) \times 10^{-4} \\
\mathrm{~T} & =\text { absolute temperature, } \mathrm{K} \\
\mathrm{M}_{1}, \mathrm{M}_{2} & =\text { molecular weights of components } 1 \text { and } 2 \\
\mathrm{P} & =\text { absolute pressure, atm } \\
\mathrm{r}_{12} & =\text { collision diameter, angstroms } \\
& =\frac{\left(\mathrm{r}_{\mathrm{o}}\right)_{1}+\left(\mathrm{r}_{\mathrm{O}}\right)_{2}}{2} \\
\mathrm{r}_{\mathrm{O}} & =1.18\left(\mathrm{~V}_{\mathrm{b}}\right)^{1 / 3} \\
\mathrm{~V}_{\mathrm{b}} & =\text { molal volume of liquid at normal boiling point, } \mathrm{cm}^{3} / \mathrm{g} \\
\mathrm{I}_{\mathrm{D}} & =\text { collision integral for diffusion, function of } \mathrm{k}_{\mathrm{B}} \mathrm{T} / \epsilon_{12} \\
\epsilon_{12} & =\left[\begin{array}{l}
\epsilon_{1} \\
\mathrm{k}_{\mathrm{B}}
\end{array}\right]\left(\frac{\epsilon_{2}}{\mathrm{k}_{\mathrm{B}}}\right) \\
\mathrm{k}_{\mathrm{B}} & =\text { Boltzmanns constant } 1.38 \times 10^{-6} \text { Erg/K } \\
& =\text { energy of molecular interaction, ergs. }
\end{aligned}
$$


Table 27 shows constants needed to make this calculation and Table 28 displays the diffusion coefficients for tricresyl and tributyl phosphate ester in argon at temperatures ranging from 200 to $800^{\circ} \mathrm{C}$.

Table 27. Constants Needed to Calculate Diffusion Coefficients

\begin{tabular}{|c|c|c|c|}
\hline \multirow[b]{2}{*}{ Property } & \multicolumn{3}{|c|}{ Fluid } \\
\hline & $\begin{array}{l}\text { Tributyl Phosphate } \\
\text { Ester }\end{array}$ & $\begin{array}{l}\text { Tricresyl Phosphate } \\
\text { Ester }\end{array}$ & Argon \\
\hline Density, $\mathrm{g} / \mathrm{cm}^{3}$ & 0.9727 & 1.1955 & \\
\hline Molecular Weight & 266.32 & 368.37 & 39.9 \\
\hline$\epsilon / k_{B}, \quad K$ & $646.47(103)$ & $785.62(102)$ & $124.0(102)$ \\
\hline$r_{0}$, angstroms & 8.217 & 9.458 & $3.418(102)$ \\
\hline $\mathrm{V}_{\mathrm{b}}, \mathrm{cm}^{3} / \mathrm{g} \mathrm{mol}$ & $337.7(102)$ & $515(101)$ & \\
\hline $\mathrm{r}_{12} *$, angstrom & 5.818 & 6.438 & \\
\hline Boiling Point, ${ }^{\circ} \mathrm{C}$ & $289(104)$ & $410(104)$ & \\
\hline$\epsilon_{12} / k_{B} *, K$ & 283.13 & 312.12 & \\
\hline$I_{D}-200^{\circ} \mathrm{C}$ & 0.575 & 0.596 & \\
\hline $500^{\circ} \mathrm{C}$ & 0.488 & 0.50 & \\
\hline $600^{\circ} \mathrm{C}$ & 0.47 & 0.484 & \\
\hline $700^{\circ} \mathrm{C}$ & 0.459 & 0.47 & \\
\hline $800^{\circ} \mathrm{C}$ & 0.447 & 0.46 & \\
\hline
\end{tabular}

*Property value of phosphate ester with argon. 
Table 28. Diffusion Coefficients of Phosphate Esters in Argon at Various Temperatures

\begin{tabular}{|l|l|l|}
\hline \multirow{2}{*}{ Temperature, ${ }^{\circ} \mathrm{C}$} & \multicolumn{2}{|c|}{ Fluid } \\
\cline { 2 - 3 } & Tributyl Phosphate & Tricresyl Phosphate \\
\hline & & \\
200 & $0.0923 \mathrm{~cm}^{2} / \mathrm{s}$ & $0.0715 \mathrm{~cm}^{2} / \mathrm{s}$ \\
500 & $0.2272 \mathrm{~cm}^{2} / \mathrm{s}$ & $0.1779 \mathrm{~cm}^{2} / \mathrm{s}$ \\
600 & $0.2832 \mathrm{~cm}^{2} / \mathrm{s}$ & $0.2206 \mathrm{~cm}^{2} / \mathrm{s}$ \\
700 & $0.3412 \mathrm{~cm}^{2} / \mathrm{s}$ & $0.2673 \mathrm{~cm}^{2} / \mathrm{s}$ \\
800 & $0.4057 \mathrm{~cm}^{2} / \mathrm{s}$ & $0.3162 \mathrm{~cm}^{2} / \mathrm{s}$ \\
\hline
\end{tabular}


APPENDIX D

Calculation of Back Diffusion in the TGA

The possibility of adapting a vapor delivery system to a TGA system offers great promise. But there cannot by any possibiligy of vaporized lubricant back diffusing into the TGA microbalance mechanism. This appendix presents a mathematical model showing the significance of back diffusion under test conditions.

The actual and idealized situations are detailed in Figure 44. In the actual case the purge gas flow would be laminar in nature. Also the lubricant is introduced with its momentum directed away from the balance. the idealized case assumes potential flow and a uniform concentration of lubricant vapor at the lubricant introduction point.

The following assumptions are used in this model:

1. Potential flow

2. Constant density

3. Constant diffusion coefficient

4. Steady state

5. No radial gradients

6. No angular gradients

7. No reactions occurring

8. Isothermal conditions

9. $V_{z}$ is constant 


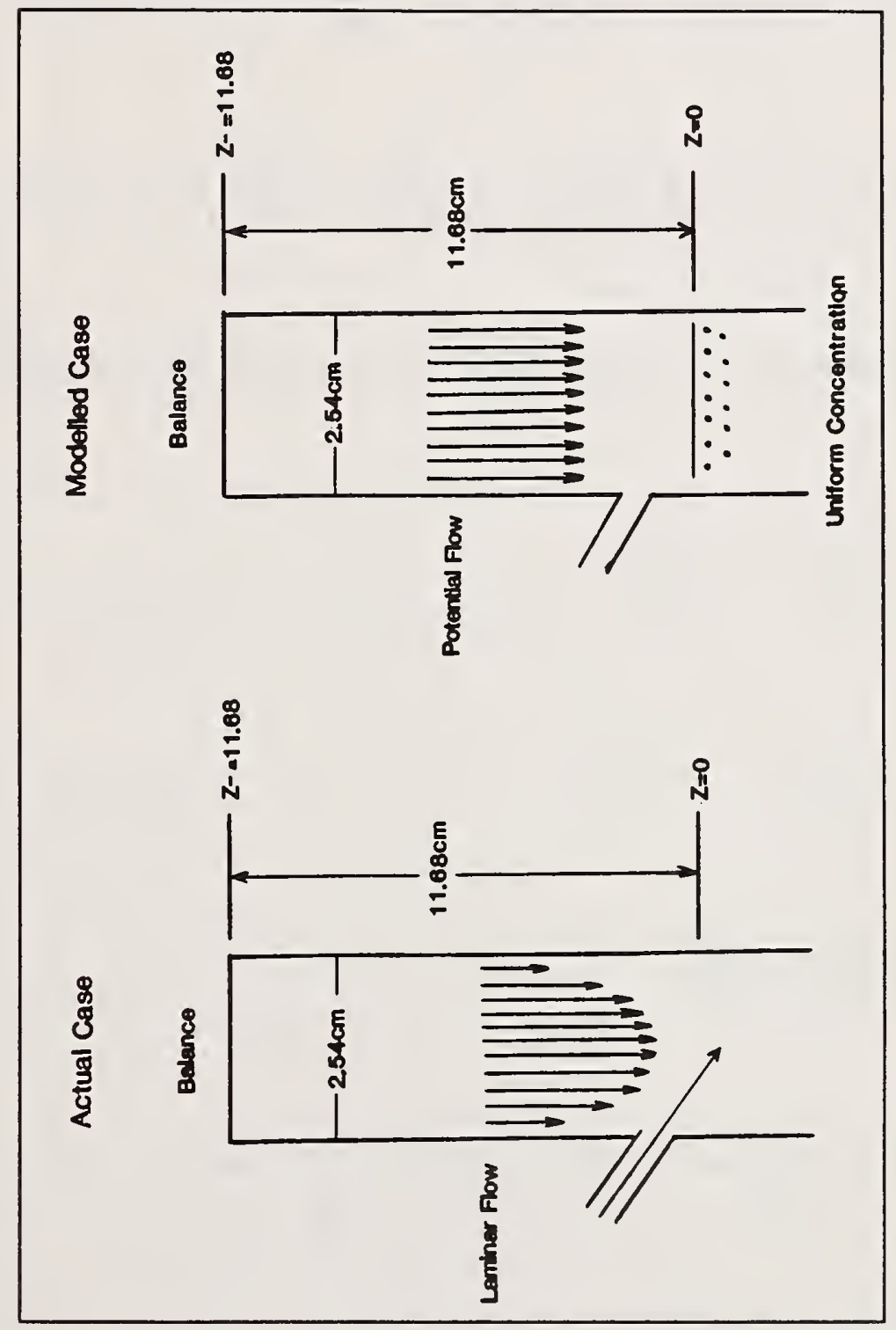


The equation of species continuity for constant density and diffusion coefficient is

$$
\begin{aligned}
& \frac{\partial C_{A}}{\partial t}+V_{r} \frac{\partial C_{A}}{\partial r}+V_{\theta} \frac{1}{r} \frac{\partial C_{A}}{\partial \theta}+V_{z} \frac{\partial C_{A}}{\partial z}= \\
& D_{A B}\left(\frac{1}{r} \frac{\partial}{\partial r}\left(r \frac{\partial C_{A}}{\partial r}\right)+\frac{1}{r^{2}} \frac{\partial^{2} C_{A}}{\partial \theta^{2}}+\frac{\partial^{2} C A}{\partial z^{2}}\right)+R_{A}[105]
\end{aligned}
$$

Assumptions $4,5,6$, and 7 reduce the continuity equation to

$$
\begin{gathered}
\mathrm{V}_{z} \frac{\partial C_{A}}{\partial z}=D_{A B} \frac{\partial^{2} C_{A}}{\partial z^{2}} \\
\text { letting } \frac{V_{z}}{D_{A B}}=\Psi \text { yields } \\
\Psi \frac{\partial C_{A}}{\partial z}=\frac{\partial^{2} C_{A}}{\partial z^{2}}
\end{gathered}
$$$$
\text { letter } \mu=\frac{\partial C_{A}}{\partial z} \text { means } \frac{\partial \mu}{\partial z}=\frac{\partial^{2} C_{A}}{\partial z^{2}} \text { thus } \frac{\partial \mu}{\partial z}=\Psi \mu
$$

Solving this yields

$$
\begin{aligned}
\ln \mu & =\Psi z+\text { constant }(\alpha) \\
m & =\alpha \exp (\Psi z)
\end{aligned}
$$


but

$$
\mu=\frac{\partial \mathrm{C}_{\mathrm{A}}}{\partial \mathrm{z}}
$$

thus

$$
\frac{\partial \mathrm{C}_{\mathrm{A}}}{\partial \mathrm{z}}=\alpha \exp (\Psi z)
$$

thus

$$
\mathrm{C}_{\mathrm{A}}=\frac{\alpha}{\Psi} \exp (\Psi \mathrm{z})+\text { constant' }(\beta)
$$

\section{Boundary conditions}

$$
\text { at } \begin{aligned}
\mathbf{z} & =0 & \mathrm{C}_{\mathrm{A}} & =\mathrm{C}_{\mathrm{A} 。} \\
\mathbf{z} & =-\infty & \mathrm{C}_{\mathrm{A}} & =0
\end{aligned}
$$

when $z=-\infty$

$$
\mathrm{C}_{\mathrm{A}}=\beta
$$

thus

$$
\beta=0
$$


at $z=0$

$$
\mathrm{C}_{\mathrm{A}}=\frac{\alpha}{\Psi}
$$

thus

$$
\frac{\alpha}{\Psi}=C_{A \circ}
$$

thus

$$
C_{A}=C_{A o} \exp (\Psi z)
$$

A purge rate of $25 \mathrm{~cm}^{3} / \mathrm{min}$ yields a linear velocity of $4.93 \mathrm{~cm} / \mathrm{min}$ at $25^{\circ} \mathrm{C}$. The assumed average temperature upper bound from the lubricant introduction point to the balance is $200^{\circ} \mathrm{C}$.

Thus

$$
\mathrm{V}_{\mathrm{z}}=7.824 \mathrm{~cm} / \mathrm{min}
$$

From Appendix $C$ the diffusion coefficient for tributyl phosphate ester in argon at $200^{\circ} \mathrm{C}$ is $0.0923 \mathrm{~cm}^{2} / \mathrm{s}$. Note that this is the lubricant with the highest coefficient of diffusion and the actual 
diffusion temperature is probably less than $200^{\circ} \mathrm{C}$ thus this estimate will be conservative.

$$
\Psi=\frac{V_{z}}{D_{A B}}=\frac{7.824 \mathrm{~cm} / \mathrm{min}}{\left(0.0923 \mathrm{~cm}^{2} / \mathrm{s}\right) \frac{60 \mathrm{sec}}{\mathrm{min}}}=1.413 \mathrm{~cm}^{-1}
$$

Thus

$$
C_{A \circ}=C_{A \circ} \exp (6.419 Z)
$$

A typical vapor phase concentraion is 18 or 7.6 Torr

thus

$$
C_{A}=7.6 \exp (1.413 Z)
$$

This distance from the point of lubricant introduction to the TGA balance is $11.768 \mathrm{~cm}$.

thus

$$
\begin{aligned}
& C_{A}=7.6 \exp [(1.413)-11.68] \\
& C_{Z}=5.168 \times 10^{-7} \text { Torr }=0
\end{aligned}
$$

Thus the vaporized lubricants will not affect the microbalance. 
APPENDIX E

Calculation of Mass Transfer Rates and Resistance for the Vapor Deposition Process

\section{Conditions}

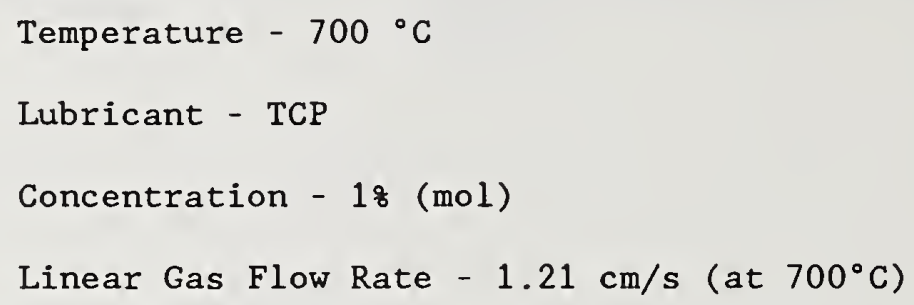

Flow around a circular disk sitting on a flat plate will be approximated by forced convection around a submerged sphere for laminar flow, one starts with the heat transfer equation

$$
\frac{h_{m} D}{k_{f}}=2.0+0.6\left[R_{e}\right]^{0.5}\left[P_{r}\right]^{1 / 3}
$$

by using mass transfer - heat transfer dimensionless group analogies this equation is transformed to

$$
\begin{aligned}
& \frac{\mathrm{k}_{\mathrm{m}} \mathrm{D}}{\mathrm{D}_{\mathrm{AB}}}=2.0+0.6\left[\mathrm{R}_{\theta}\right]^{0.5}\left[\mathrm{~S}_{\mathrm{c}}\right]^{1 / 3} \\
& \mathrm{k}_{\mathrm{m}}=\frac{\mathrm{D}_{\mathrm{AB}}}{\mathrm{D}} 2.0+0.6\left[\frac{\mathrm{DV} \rho}{\mu}\right]^{0.5}\left[\frac{\mu}{\rho \mathrm{D}_{\mathrm{AB}}}\right]^{1 / 3}
\end{aligned}
$$


where $R_{e}=$ Reynolds Number

$\mathrm{S}_{\mathrm{c}}=$ Schmidt Number

$k_{m}=$ mass transfer coefficient $\mathrm{cm} / \mathrm{s}$

$\mathrm{D}=$ sphere diameter; for this case use disk diameter, $\mathrm{cm}$

$\mathrm{V}=$ linear gas flow rate, $\mathrm{cm} / \mathrm{s}$

All other quanities are previously defined note TCP was chosen because it had the lower diffusion coefficient thus resulting in a more conservative estimate.

$$
\begin{aligned}
& \mathrm{k}_{\mathrm{m}}= \frac{0.2673}{0.6350}\left[2.0+0.6\left[\frac{(0.6350)(1.21)\left(5.41 \times 10^{-4}\right)}{\left(5.15 \times 10^{-4}\right)}\right]^{0.5}\right. \\
& {\left.\left[\frac{\left(5.15 \times 10^{-4}\right)}{\left(5.41 \times 10^{-4}\right)(0.2673)}\right]^{1 / 3}\right] } \\
& k_{m}=0.4209\left[2.0+0.6[0.8]^{0.5}[3.56]^{1 / 3}\right] \\
& k_{m}=1.188 \mathrm{~cm} / \mathrm{s}
\end{aligned}
$$

The rate of mass transfer to the substrate surface is given by

$$
r_{m}=k_{m} a\left(C_{A B}^{\prime}-C_{A S}^{\prime}\right)
$$




$$
\text { where } \begin{aligned}
r_{\mathrm{m}} & =\text { mass transfer rate, } \mathrm{g} / \mathrm{s} \\
\mathrm{a} & =\text { surface area, } \mathrm{cm}_{2} \\
\mathrm{C}^{\prime}{ }_{\mathrm{AB}} & =\text { bulk concentration, } \mathrm{g} / \mathrm{cm}^{3} \\
C^{\prime}{ }_{\mathrm{AS}} & =\text { surface concentration, } \mathrm{g} / \mathrm{cm}^{3}
\end{aligned}
$$

$$
\mathrm{C}_{\mathrm{AS}}=0 \text {, assuming an instantaneous surface reaction }
$$

$$
\mathrm{C}_{\mathrm{TOT}}=\frac{\mathrm{P}}{\mathrm{RT}}=1.252 \times 10^{-5} \frac{\mathrm{mol}}{\mathrm{cm}^{3}}
$$

$$
\begin{aligned}
& \mathrm{C}_{\mathrm{TCP}}=1.252 \times 10^{-7} \frac{\mathrm{mol}}{\mathrm{cm}^{3}} \\
& C_{\mathrm{TCP}}^{\prime}=4.612 \times 10^{-5} \frac{\mathrm{g} \mathrm{TCP}}{\mathrm{cm}^{3}}
\end{aligned}
$$

$$
a=0.6334 \mathrm{~cm}^{2}
$$

$$
\begin{aligned}
& r_{m}=[1.188 \mathrm{~cm} / \mathrm{s}]\left[0.6334 \mathrm{~cm}^{2}\right] 4.612 \times 10^{-5} \frac{\mathrm{g} \mathrm{TCP}}{\mathrm{cm}^{3}} \\
& \mathrm{R}_{\mathrm{m}}=3.47 \times 10^{-5} \frac{\mathrm{g} \mathrm{TCP}}{\mathrm{s}}
\end{aligned}
$$

The maximum initial deposition rate observed was $2.564 \times 10^{-7} \mathrm{~g} / \mathrm{s}$.

Because the mass transfer rate is much greater than the deposition rate the vapor deposition process is not mass transfer controlled. 


\section{APPENDIX F}

Calculation of Flow Regime During Vapor Deposition Testing

1) Tubular Furnace

Conditions

Temperature $-700^{\circ} \mathrm{C}$

Carrier Gas - Argon

Lubricant - Tributyl Phosphate Ester

Concentration - 18

Volumetric Flow Rate $-1.2 \mathrm{ft}^{3} / \mathrm{hr}$ at $25^{\circ} \mathrm{C}$

Reynolds number

$$
\mathrm{R}_{\mathrm{e}}=\frac{\mathrm{DV}_{\mathrm{z}} \rho}{\mu}
$$

where $\mathrm{D}=$ tube diameter, $5.7 \mathrm{~cm}$

$$
\begin{aligned}
\mathrm{V}_{2} & =\text { linear velocity of gas } \\
\rho & =\text { gas density } \\
\mu & =\text { gas viscosity }
\end{aligned}
$$

Tube diameter $=5.7 \mathrm{~cm}$

$$
\begin{aligned}
\mathrm{v}_{\mathrm{z}} & =\left[\frac{1.2 \mathrm{ft}}{\mathrm{hr}}\right]\left[\frac{12 \mathrm{in}}{\mathrm{ft}}\right]^{3}\left[\frac{2.54 \mathrm{~cm}}{\mathrm{in}}\right]^{3}\left[\frac{1 \mathrm{hr}}{3600 \mathrm{~s}}\right]\left[\frac{4}{\Pi(5.7 \mathrm{~cm})^{2}}\right] \\
& =0.370 \mathrm{~cm} / \mathrm{s} \text { at } 25^{\circ} \mathrm{C}
\end{aligned}
$$




$$
\mathrm{V}_{\mathrm{z}}=(0.370) \frac{973.15}{298.15}=1.21 \mathrm{~cm} / \mathrm{s} \text { at } 700^{\circ} \mathrm{C}
$$

Using values from Table 24 in Appendix B

$$
\begin{aligned}
& R_{e}=\frac{(5.7 \mathrm{~cm})(1.21 \mathrm{~cm} / \mathrm{s}) 5.28 \times 10^{-4} \mathrm{~g} / \mathrm{cm}^{3}}{5.155 \times 10^{-4} \mathrm{~g} / \mathrm{cm} \cdot \mathrm{s}} \\
& R_{e}=7.05
\end{aligned}
$$

therefore flow during vapor deposition testing in the tubular furnace is laminar.

2) TGA System

Conditions

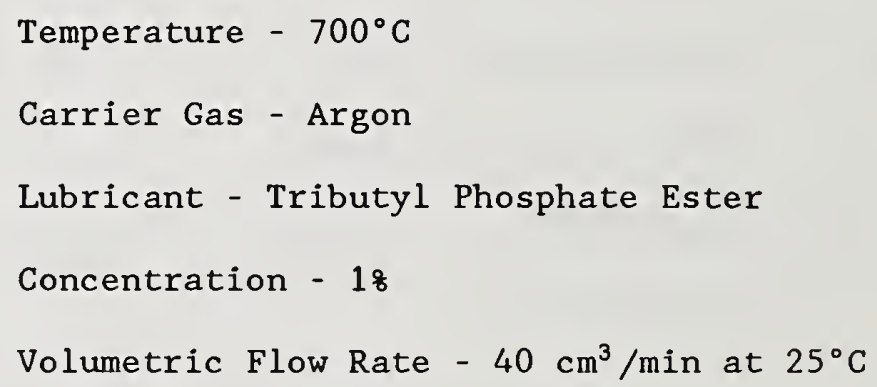


SHEET (See instructions) REPORT NO.

NIST/SP-754

September 1988

4. TITLE AND SUBTITLE

Vapor Phase Deposition Studies of Phosphate Esters on Metal and Ceramic Surfaces

5. AUTHOR(S)

Douglas E. Deckman, Stephen M. Hsu, and E. Erwin Klaus

6. PERFORMING ORGANIZATION (If joint or other than NBS, see instructions)

7. ContracUGrant No.

NATIONAL INSTITUTE OF STANDARDS AND TECHNOLOOY

(formorly NATIONAL BUREAU OF STANDARDS)

U.S. DEPARTMENT OF COMMERCE

CATHERSBURQ, MD 20099

9. SPONSORING ORGANIZATION NAME AND COMPLETE ADDRESS (Strect, CIty, Stote, ZIP)

SAME AS ITEM 非 6 ABOVE.

10. SUPPLEMENTARY NOTES

Library of Congress Catalog Card Number: 88-600578

$\square$ Document describes a computer program; SF-185, FIPS Software Summary, is attached.

11. ABSTRACT (A 200-word or less factual summory of most significant informotion. If document includes a significant bibliography or literoture survey, mention it here)

This study focuses on a novel means of lubrication for ceramics and metals at high temperatures; called vapor phase lubrication. The deposition rate and mechanisms of tributyl phosphate ester and tricresyl phosphate ester have been explored. A Thermalgravimetric Analyzer (TGA) was modified to measure the rate of surface film formation of vapor phase deposition of lubricants on metal surfaces at elevated temperatures. Results from TGA studies showed that the vapor deposition process was a complex function of substrate, time, and temperature. Tricresyl phosphate ester (TCP) and tributyl phosphate ester (TBP) were observed to produce similar amounts of $\mathrm{film}$ on stainless steel substrates. The observed order of metal activity was copper > stainless steel > nickel > platinum. Film formation on nickel was found to be much more rapid at $600^{\circ} \mathrm{C}$ than $700^{\circ} \mathrm{C}$. Also, the concentration of oxygen present during deposition strongly influenced the amount of film formed. Scanning electron microscopy was conducted on TBP films formed on $\mathrm{Si}_{3} \mathrm{~N}_{4}, \mathrm{Al}_{2} \mathrm{O}_{3}$, and $\alpha-\mathrm{SiC}$. The films produced contained globule and filamentous structures. The films on each ceramic were unique, demonstrating that vapor deposition is surface sensitive on ceramic substrates. High temperature friction testing was conducted on a TCP coated $\mathrm{Al}_{2} \mathrm{O}_{3}$ substrate. The coating reduced the friction level for alumina, thus demonstrating the potential of vapor lubrication for high temperature lubrication of ceramics.

12. KEY WORDS (Six to twelve entries; alphabetical order; capitalize only proper nomes; and separate key words by semicolons)

high temperature lubrication; vapor phase lubrication

\section{AVAILABILITY}

[X] Unlimited

For Official Distribution. Do Not Release to NTIS

[X] Order From Superintendent of Documents, U.S. Government Printing Office, Washington, D.C. 20402.

X Order From National Technical Information Service (NTIS), Springfield, VA, 2216I
14. NO. OF

PRINTED PAGES

154

15. Price 




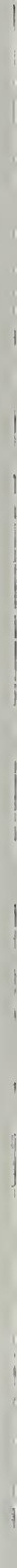




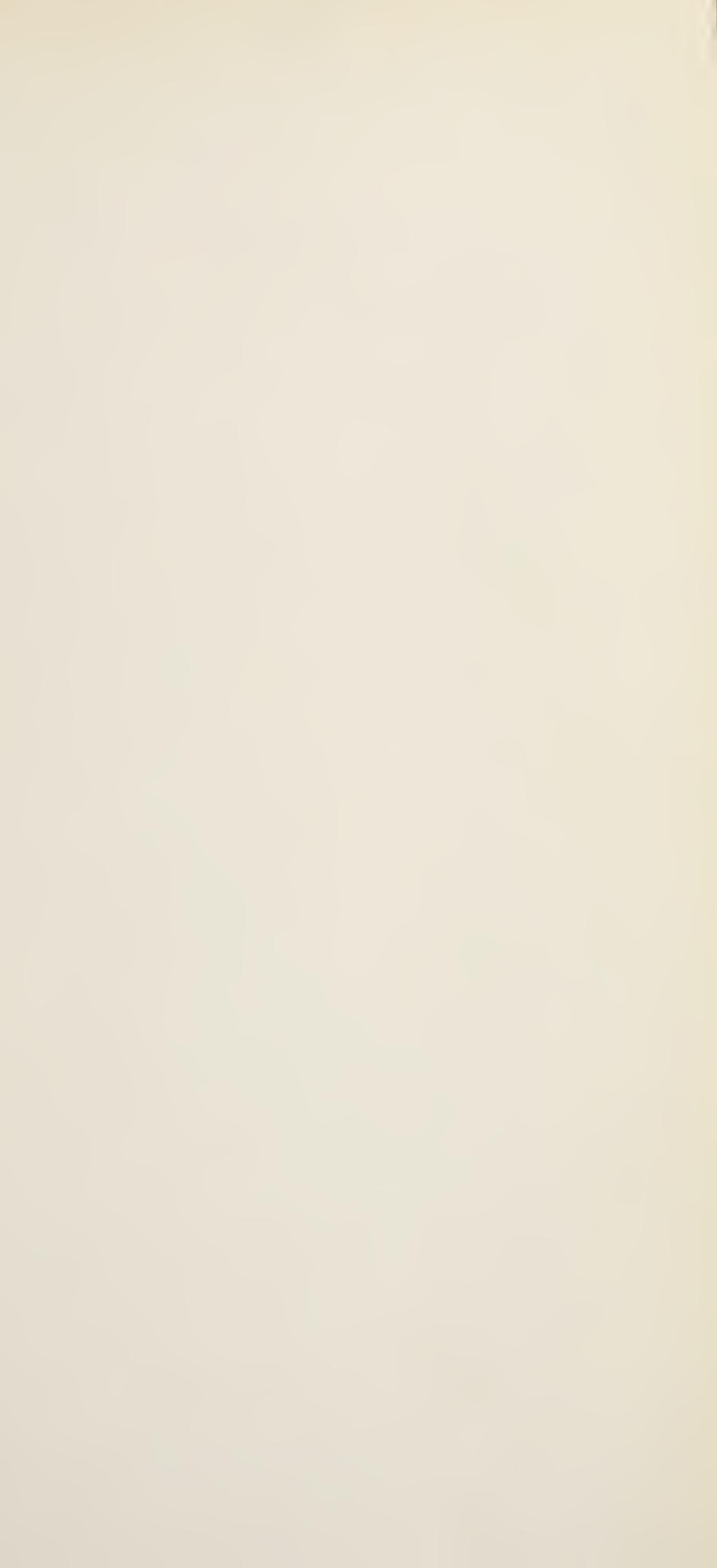


NATIONAL INSTITUTE OF STANDARDS AND TECHNOLOGY

(formerly NATIONAL BUREAU OF STANDARDS)

U.S. DEPARTMENT OF COMMERCE

GATHERSBURG, MD 20899

Official Business

Penalty for Private Use $\$ 300$

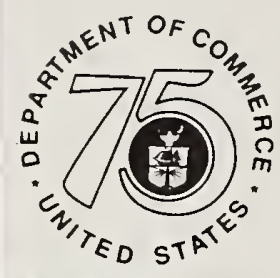

Stimulaling America's Progress 1913.1988 